University of Louisville

ThinkIR: The University of Louisville's Institutional Repository

Electronic Theses and Dissertations

$5-2013$

\title{
The mathematics self-efficacy of rural central Appalachian undergraduate females.
}

Lisa J. Music

University of Louisville

Follow this and additional works at: https://ir.library.louisville.edu/etd

\section{Recommended Citation}

Music, Lisa J., "The mathematics self-efficacy of rural central Appalachian undergraduate females." (2013). Electronic Theses and Dissertations. Paper 1032.

https://doi.org/10.18297/etd/1032

This Doctoral Dissertation is brought to you for free and open access by ThinkIR: The University of Louisville's Institutional Repository. It has been accepted for inclusion in Electronic Theses and Dissertations by an authorized administrator of ThinkIR: The University of Louisville's Institutional Repository. This title appears here courtesy of the author, who has retained all other copyrights. For more information, please contact thinkir@louisville.edu. 
THE MATHEMATICS SELF-EFFICACY OF RURAL CENTRAL APPALACHIAN UNDERGRADUATE FEMALES

\author{
By \\ Lisa J. Music \\ B.S. Morehead State University, 1994 \\ M.A. Morehead State University, 2003

\begin{abstract}
A Dissertation
Submitted to the Faculty of the

for the Degree of

Doctor of Philosophy

Department of Teaching and Learning

University of Louisville

Louisville, Kentucky
\end{abstract} \\ College of Education and Human Development of the University of Louisville \\ in Partial Fulfillment of the Requirements
}

May 2013 

THE MATHEMATICS SELF-EFFICACY OF RURAL CENTRAL APPALACHIAN UNDERGRADUATE FEMALES

\author{
By \\ Lisa J. Music \\ B.S. Morehead State University, 1994 \\ M.A. Morehead State University, 2003 \\ A Dissertation Approved on
}

April 22, 2013

by the following Dissertation Committee

Dr. Karen S. Karp

Dissertation Director

Dr. Elizabeth Todd Brown

Dr. William S. Bush

Dr. Craig B. Howley

Dr. Robert N. Ronau 


\section{ACKNOWLEDGMENTS}

There are many people who have shown support for my educational journey. It would be too difficult to name them all individually but I would like for them to know that I appreciate each and every one. I would like to acknowledge the contributions of the Appalachian Collaborative Center for Learning, Assessment, and Instruction in Mathematics (ACCLAIM) program to my education. Without this program I would not have been about to accomplish my dream of obtaining a doctoral degree.

I would like to thank my coworkers for their support and words of encouragement during course taking and research. I would like to thank my committee for the valuable input they have provided. I would like to extend a special thank you to Dr. Karen Karp for her guidance and numerous edits.

Last, but certainly not least, I would like thank my family for their support during this adventure. I would like to thank my parents for providing a supportive home environment during my developmental years which has contributed to my lifelong love of learning. Also, my wonderful husband, Ricky, has been there to encourage me when things were difficult. Additionally, I would like to thank my beautiful children, Joshua, Stephanie, and Kimberley, for understanding when I needed quiet time to work. I appreciate and love you all. 


\title{
ABSTRACT \\ THE MATHEMATICS SELF-EFFICACY OF RURAL CENTRAL APPALACHIAN UNDERGRADUATE FEMALES
}

\author{
Lisa Jane Music
}

May 10, 2013

This dissertation study was a two-part investigation with a sample of undergraduate students from three community and technical colleges and one university in the state of Kentucky. The purpose of this study was to investigate the factors that contribute to the mathematics self-efficacy of rural Central Appalachian undergraduate females. Two subscales of the Fennema-Sherman Mathematics Attitude Scale, the Confidence in Learning Mathematics and the Effectance Motivation Scale in Mathematics, were used to identify potential interview subjects. The 596 subjects, including 360 females and 236 males, also completed a questionnaire designed to determine their classification as being from rural Central Appalachia, other Appalachia, or non-Appalachia.

Female students from rural Central Appalachia were divided into two categories: negative mathematic attitude and positive mathematics attitude. Thirty-seven interviews were conducted resulting in 15 interviews from students in the negative mathematics attitude category and 22 interviews from students in the positive mathematics attitude category. Interviews were coded according to the four contributors to self-efficacy as 
defined by Bandura (1997). The contributors are enactive mastery experiences, vicarious experiences, social/verbal persuasions, and physiological and affective states.

Results indicate that students in the negative mathematics attitude category did not receive regular feedback for their efforts to learn mathematics. They also identified with peers that were struggling. Students in the positive mathematics attitude category received regular positive feedback to reinforce their self-efficacy. The students in the positive category also wanted not only to increase their mathematics abilities but to help other students understand mathematics. 


\section{TABLE OF CONTENTS}

\section{PAGE}

ACKNOWLEDGMENTS................................................. ii

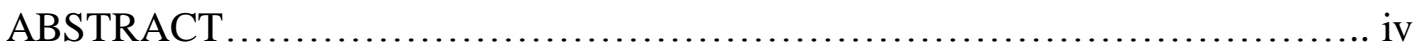

LIST OF TABLES.....................................................

\section{CHAPTER}

I. INTRODUCTION ........................................... 1

Number of Earned Degrees............................2

Degrees awarded to foreign students.............. 3

Future Need............................................4

Future Degree/Career Plans............................. 4

Gender Difference.....................................5

Gender equality................................6

Confidence...........................................

Judgment of competence..........................8

Gifted....................................... 8

Believing in success............................ 10

Questioning ability............................10

Female Need for Relationships........................11

Sources of Self-efficacy............................ 12

Primary sources of self-efficacy................ 12 
Achievement.

Career.

Rural Students' Beliefs about Mathematics. 15

Lack of guidance. 16

Mixed messages

Purpose and Research Question. .18

Need For Further Research. 19

II. THEORETICAL FRAMEWORK............................20

Career Choices.......................................... 21

Self-Efficacy Sources..............................22

Enactive Mastery Experience......................... 23

Effort.....................................23

Activities......................................24

Grades/test scores............................. 25

Vicarious Experiences.............................. 26

Role models.................................... 26

Parents.................................27

Peers.....................................27

Social/Verbal Persuasion................................. 28

Support.................................... 29

Perceived by others......................29

Encouragement.......................... 30

Stereotypes.................................. 30 


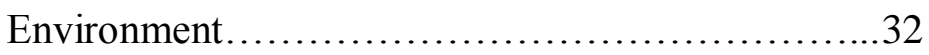

School................................ 32

Home................................... 33

Physiological and Affective States..................... 34

Avoidance....................................... 34

Influence of teacher anxiety..................... 35

Physical....................................... 36

Rural Students........................................ 36

III. METHODOLOGY .......................................... 39

Sample......................................... 40

Appalachia................................... 40

Rural............................................ 41

Community/technical colleges and universities....... 42

Data Collection Instruments........................... 43

Survey instrument........................... 44

STEBI-A and STEBI-B..................... 44

Mathematics Attitude Inventory............ 45

Fennema-Sherman Mathematics Attitude Scale................................ 45

Demographic questionnaire......................48

Interview protocol............................. 49

Human Subjects Procedures.............................. 51 
University of Louisville.

Kentucky Community and Technical College

System.................................52

Morehead State University...................... 52

Data Collection..................................... 52

Demographic questionnaire and survey..............53

Interviews......................................54

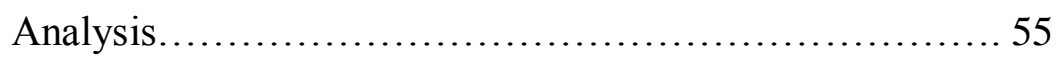

Survey and demographic questionnaire............55

Interviews.................................. 57

IV. $\quad$ RESULTS............................................. 61

Sample..........................................61

Survey Analysis...................................6 63

Interviews........................................ 65

Mathematics Self Efficacy Findings.....................66

Enactive Mastery Experiences...................6 67

Effort....................................67

Activities and struggles..................69

Performance................................. 71

Grades and testing...................... 75

Mathematics outside of school...............76

Vicarious Experiences........................... 79

Role models............................. 79

Parents.............................. 80 
Social/Verbal Persuasions........................ 85

Ability beliefs........................ 85

Support............................... 87

Peers.................................... 90

School environment......................91

Home environment...................................93

Physiological and Affective States................. 95

Avoidance................................. 95

Physical.................................96

Careers/Majors Findings............................. 100

Mathematics Opportunities in Rural Areas Findings........ 103

Summary....................................... 106

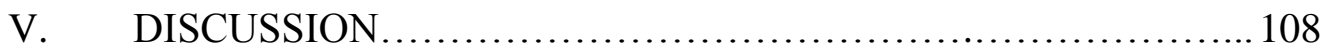

Enactive Mastery Experiences.......................... 109

Vicarious Experiences................................114

Social/Verbal Persuasions............................117

Physiological and Affective States............................ 119

Career/Majors.................................... 121

Mathematics Opportunities in Rural Areas................123

Limitations........................................ 124

Future Research.................................. 126

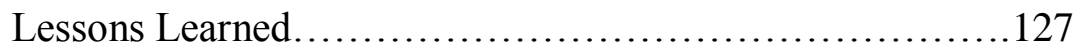




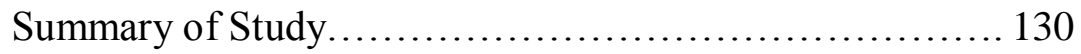

REFERENCES..................................................... 133

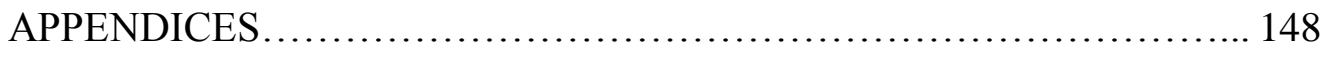

CURRICULUM VITAE................................................. 163 


\section{LIST OF TABLES}

TABLE $\quad$ PAGE

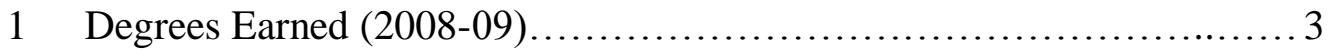

2 Number of Subjects Classified by Location............................ 63

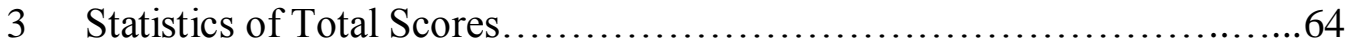

4 Percent of Subjects Classified by Anticipated Occupation................... 102

5 Percent of References to Family Role Models by Each Attitude Group... 116 


\section{CHAPTER I}

\section{INTRODUCTION}

Currently more females than males attend college and complete degrees at a ratio of 1.3 to 1 (Snyder \& Dillow, 2011). This ratio is noticeably different from 65 years ago. From 1900 to 1930 the ratio of undergraduate female to male students was about equivalent; however, by 1947 men outnumbered women at a ratio of 2.3 to 1 (Goldin, Katz, \& Kuziemko, 2006). Nevertheless, female enrollment has progressively increased with the number of women in college now outnumbering men (Snyder, Dillow, \& Hoffman, 2009). Fall 2009 enrollment data reveal that females outnumbered males attending degree-granting institutions whether enrolled (a) full-time or part-time, (b) at a four-year or two-year institution, or (c) at a public or private institution (Snyder \& Dillow, 2011). Examination of data collected on 2008-09 degrees shows that females outnumbered males overall in receiving bachelor's degrees, master's degrees, and doctoral degrees (Chen, 2009; Snyder \& Dillow, 2011).

While the number of females attending college is greater than the number of males, it is not the case in all majors. The National Science Board (2008) reported that the number of bachelor's degrees and master's degrees earned by females in the past two decades has increased in almost all major science and engineering fields with the exception of computer sciences. Unfortunately, females still earn fewer degrees in these

fields than males (Chen, 2009; Snyder \& Dillow, 2011). For example, males still greatly outnumber females in fields such as engineering (Hill, Corbett, \& St. Rose, 2010). In 
2008, only 13.1 percent of chemical engineers, 10.4 percent of civil engineers, 10.3 percent of aerospace engineers, 7.7 percent of electrical and electronics engineers, and 6.7 percent of mechanical engineers were female (Hill et al., 2010).

\section{Number of Earned Degrees}

Although a gap in the number of degrees earned by males and females in areas of engineering, computer and information sciences, and mathematics and statistics remains, the raw numbers tell a more compelling story. In 2008-09 the engineering discipline had 56,716 males compared to 12,417 females earning bachelor's degrees (a ratio of approximately 4.6 to 1$) ; 26,970$ males compared to 7,780 females earned master's degrees ( 3.5 to 1 ); and 6,212 males compared to 1,719 females earned engineering doctoral degrees (3.6 to 1) (Snyder \& Dillow, 2011). In computer and information sciences, 31,215 males earned bachelor's degrees compared to 6,779 females (4.6 to 1); 13,063 males earned master's degrees compared to 4,844 females ( 4 to 1 ); and 1,226 males earned doctoral degrees compared to 354 females (3.5 to 1) (Snyder \& Dillow, 2011). In the combined discipline of mathematics and statistics, males earned 8,793 bachelor's degrees while 6,703 females earned bachelor's degrees (1.3 to 1); 3,064 males earned master's degrees while 2,147 females earned this degree (1.4 to 1); and 1,059 males earn doctoral degrees while only 476 females received this degree (2.2 to 1 ) (Snyder \& Dillow, 2011). Table 1 shows a summary of the degrees earned. 
Table 1

Degrees Earned (2008-09)

\begin{tabular}{|c|c|c|c|c|c|c|}
\hline & \multicolumn{2}{|c|}{ Bachelor's } & \multicolumn{2}{|c|}{ Master's } & \multicolumn{2}{|c|}{ Doctoral } \\
\hline & Male & Female & Male & Female & Male & Female \\
\hline Engineering & 56,716 & 12,417 & 26,970 & 7,780 & 6,212 & 1,719 \\
\hline $\begin{array}{l}\text { Computer and } \\
\text { Information } \\
\text { Sciences }\end{array}$ & 31,215 & 6,779 & 13,063 & 4,844 & 1,226 & 354 \\
\hline $\begin{array}{l}\text { Mathematics } \\
\text { and Statistics }\end{array}$ & 8,793 & 6,703 & 3,064 & 2,147 & 1,059 & 476 \\
\hline
\end{tabular}

Degrees awarded to foreign students. The lack of females from the United

States in these areas becomes more noticeable when considering the number of degrees awarded to foreign students. Of the 12,417 bachelor's degrees awarded to females in engineering, 844 (or approximately 6.8 percent) were awarded to nonresident aliens. Out of 7,780 master's degrees in engineering, nearly half $(3,469$, or approximately 45 percent) were awarded to female nonresident aliens. Also, 864 of the 1,719 engineering doctoral degrees awarded to females, slightly over 50 percent, were earned by nonresident aliens. In the area of computer and information sciences 401 bachelor's degrees were earned by nonresident aliens out of the 6,779 total earned by females $(5.9$ percent); 2,422 master's degrees out of 4,844 were awarded to nonresident aliens (50 percent); and 189 out of the 354 females earning doctoral degrees were nonresident aliens (53 percent). In the area of mathematics and statistics 289 nonresident alien females earned bachelor's degree out of 6,703 total females (4.3 percent); out of the 2,147 
master's degrees earned by females, 862 were nonresident aliens (40 percent); and 241 out of 476 doctoral degrees were awarded to nonresident aliens (50.6 percent) (Snyder \& Dillow, 2011).

\section{Future Need}

Female contributions are needed as the mathematics-related job market grows. The 2018 workforce projections by the U.S. Department of Labor show that considerable mathematical or scientific training will be required for nine out of the ten fastest growing professions (Hill et al., 2010). The Occupational Outlook Handbook reported that the need for mathematicians will increase by 22 percent from 2008 to 2018; engineering needs will increase by 11 percent overall; and the need for computer network, systems, and database administrators is expected to increase by 30 percent (Bureau of Labor Statistics, 2011). When females decide to avoid pursuing careers in physical sciences, engineering, and computer science, they eliminate themselves from a growing job market and keep needed mathematicians and scientists from contributing to society (Huebner, 2009). More females are needed in science, technology, engineering, and mathematics (STEM) careers for society to take full advantage of the imaginativeness and inventiveness of a diverse workforce (Hill et al., 2010). Hill and colleagues (2010) noted that with a lack of females in science and engineering fields, products designed for our daily use sometimes are built from only male perspectives. This situation could, in turn, have devastating long-term results for women and children.

\section{Future Degree/Career Plans}

Females with high mathematics abilities often choose to pursue non-mathematics careers at a disproportional rate to males with similar abilities (Ceci, Williams, \& Barnett, 
2009). Females with higher mathematics skills may also have higher verbal skills increasing their career possibilities (Ceci et al., 2009). Additionally, females with family obligations may dedicate more time to family and less time to their careers (Ceci et al., 2009). Females are more likely to leave the academic workplace earlier in their careers when dissatisfied (Hill et al., 2010). Lack of encouragement, scarcity of female role models, and lack of confidence are contributing factors to females not pursuing long-term academic careers in STEM areas (Handelsman et al., 2005). Importantly, on average, females perform as well as males in mathematics (Hyde, Lindberg, Linn, Ellis, \& Williams, 2008), yet they often do not plan to use their skills to pursue mathematicsrelated careers as often as males. The American Association of University Women reported that female first-year college students were less likely than males to declare that they intended to study in a STEM field (Hill et al., 2010). In 2006, only 15 percent of female freshmen planned to study in a STEM field, while 29 percent of male freshmen declared a STEM field as a major (Hill et al., 2010). Simpkins and Davis-Kean (2005) found that males were more likely than females to report that they planned to pursue mathematics or science careers, and females were more likely to report that they planned to pursue a career in a health-related occupation.

\section{Gender Difference}

Development of complex problem-solving skills is important in order to be successful in STEM careers (Hyde \& Mertz, 2009). In the 1990s, Hyde and Mertz (2009) found no gender differences in computation or deeper understanding of mathematics concepts in high school; however, they found a gender difference favoring males in complex problem solving at the high school level. The researchers indicated that this 
gender difference could be caused by course taking because females were less likely to take such high school courses as advanced mathematics, chemistry, and physics, which often focus on complex problem solving and applications. More recently, however, females seem to be taking calculus in high school at the same rate as males and are performing as well as males in complex problem-solving skills (Hyde \& Mertz, 2009).

Gender equality. Hyde and Mertz (2009) also suggested that gender inequality contributed to fewer females excelling in mathematics than males in other countries. Guiso, Monte, Sapienza, and Zingales (2008) studied cultural and gender influences on mathematics scores in various countries and concluded that the mathematics gender gap disappeared in societies that were "gender-equal" such as Sweden and Norway. Societies with low gender-equalities such as Turkey's show a gender gap in mathematics. They suggest that these findings may provide insight about the mathematics gender gap in the United States decreasing over time. Additionally, they suggest that the improvement of the role of females in society will, in turn, contribute to the advancement of mathematics scores. They also assert that the Gender inequality may be attributed to other factors such as: teachers giving males more attention; inappropriate advising of females by guidance counselors; lack of recognition of females who are gifted in mathematics; feelings by females that they do not belong in mathematics intensive fields because of a lack of role models in these fields; employers using unfair hiring processes with unconscious prejudice against females; and females working in environments that are hostile (Hyde \& Mertz, 2009). Beede and colleagues (2011) also suggested that the lack of female role models in STEM prohibited females from pursuing these fields. They also suggested the passageway to STEM careers was as accepting to someone, likely females, who had to 
move in and out of the labor force due to family obligations. Additionally, they found a lack of encouragement and support for females in STEM fields. According to Steele, Levin, Blecksmith, and Shahverdian (2008), if female students experience a supportive mathematics learning environment that is relaxed and, without the constraints of gender roles, they will begin to realize how valuable mathematics is to their lives, be more likely to take higher level mathematics courses, and seek majors and careers that involve mathematics.

\section{Confidence}

A key factor for the shortage of women in mathematics is a lack of selfconfidence. Hackett and Betz (1989) suggested that a student's assessment of her ability is important when it comes to mathematics career choice. Researchers found that although females perform as well as or better than males in mathematics, they tend to be less confident in their abilities (Betz \& Hackett, 1981; Carmichael \& Taylor, 2005; Lloyd, Walsh, \& Yailagh, 2005). Even though females may have the same mathematics grades and test scores as their male counterparts, males are more likely to view themselves as more mathematically capable (Correll, 2001). Lloyd, Walsh, and Yailagh (2005) studied fourth and seventh graders in Canadian public schools and found that females were less confident in their achievement even though the mathematics achievement of females met or surpassed that of males. In analyzing data from the 2003 Trends in International Mathematics and Science Study (TIMSS) and the 2003 cycle of the Programme for International Student Assessment (PISA), Else-Quest, Hyde, and Linn (2010) found that although males and females performed similarly in mathematics, males had more positive attitudes toward mathematics. In another study involving adult 
students in an Australian tertiary preparatory course conducted by Carmichael and Taylor (2005) found that female academic performance was not significantly different from male students' performance even though females reported lower levels of confidence. Additionally, Pallier (2003) found that adult males were generally more self-assured than adult females in the correctness of their work even though there was no noteworthy gender difference in cognitive ability. He also found that the confidence of males and females varied over a wide age range and that males had more confidence in the accuracy of their work than females.

Judgment of competence. Students who rated their mathematical competence high were more likely to continue on a path to a career in a quantitative profession (Correll, 2001). Having a lower judgment of one's own ability has been found to contribute to inferior performance and less positive self-concept in female students (Pajares \& Miller, 1994). Students with high mathematics self-concepts are more likely than others to enroll in advanced level mathematics courses (Simpkins \& David-Kean, 2005). Furthermore, students with higher self-concepts in mathematics or science are more likely to enroll in mathematics and science courses in high school and to believe that they will pursue careers in mathematics or science. Additionally, students have been found to be more precise in their assessment of mathematics confidence when the material on which they base their judgment is familiar (Carmichael \& Taylor, 2005).

Gifted. Hong and Aqui (2004) found that youth who were gifted or talented in mathematics reported having higher self-efficacy than non-gifted students. They also found that both male and female students who were classified as gifted in mathematics viewed their mathematics classes as valuable, thought of themselves as highly able, and 
had confidence in mathematics. O'Shea, Heilbronner, and Reis (2010) found that high school females academically gifted in mathematics viewed mathematics as useful in their lives, were confident in their abilities in mathematics, and were persistent in mathematics. However, when studying mathematical problem solving of middle school students, Pajares (1996a) found that gifted females were biased toward not having enough confidence even though most students were usually overconfident. He also found that gifted females' self-efficacy did not differ from males' self-efficacy even when females performed better. While studying college and career aspirations of both male and female valedictorians from central North Carolina, York (2008) found that both genders were equally likely to major in a science field, but females were less likely to plan to study mathematics, computer science, or engineering. York (2008) suggested the need for specific career counseling for gifted students in order to help them think beyond the traditional career choices. Females were more interested than males in the humanities or social sciences; while males were more interested than females in mathematics, computer sciences, and engineering majors (York, 2008). York also found that females intended to attend colleges that were less selective even though their SAT scores predicted a more selective college. Finally, York found that females were focused on participating in lower paying careers. Rudasill and Callahan (2010) found that, even though no difference in academically advanced fifth- to eleventh-grade students' selfperceptions of ability was found, males intended to take more mathematics courses than females. The academically advanced males not only projected they would enroll in more mathematics courses, but they also ranked mathematics as having more value for their success while females ranked humanities highest in value (Rudasill \& Callahan, 2010). 
Believing in success. Correll (2001) suggested that those who believed they will be successful in a mathematical career are more likely to pursue such a path. Males tended to pursue mathematical activities more often than females because they believed they were good at mathematics, but not necessarily because they excelled at mathematics (Correll, 2001). The confidence to learn mathematics was usually greater in males than in females (Karp \& Shakeshaft, 1997). A negative mindset about mathematics can (1) keep females from performing at their best, (2) prevent them from taking many mathematics courses, and (3) prevent them from considering mathematics-related careers (Gunderson, Ramirez, Levine, and Beilock, 2012). Herbert and Stipek (2005) found that females rated their mathematics competencies lower than males beginning in third grade even when teachers' evaluations of their mathematics ability was the same and their mathematics achievement was the same. They also found that, in both third and fifth grades, males were rated higher than females in mathematics competencies by their parents. Furthermore, parents' opinions were found to be a strong predictor of the students’ own opinions of their mathematics ability (Herbert \& Stipek, 2005).

Questioning ability. Dweck (2006) found little difference in ability between the male and female students. She did find, however, differences in how students reacted to having their abilities questioned. She found that, while working with young intelligent fifth-grade students, females did not cope well when faced with confusion. The students were given a non-mathematics task that was confusing at the beginning. The females with a higher IQ did not learn the material after having experienced the confusion. In contrast, the higher IQ males learned the material (Dweck, 2006). Additionally, many females did not perform well when put in situations of competing against other students 
or when being timed (Karp \& Shakeshaft, 1997). The researchers suggested that confidence levels predict whether students will enroll in elective mathematics courses in high school. This lack of confidence can cause some females to choose to avoid advanced mathematics courses.

\section{Female Need for Relationships}

Herzig (2004) found that female college students cited negative relationships with faculty members, which caused them to feel ignored and sense a lack of moral support. These students, some of whom left the program without completing the degree, mentioned lack of guidance, advising, and mentoring. Camp, Gilleland, Pearson, and Putten (2009) found that adult females who completed degrees in physical science, mathematics, computer science, and engineering fields had more frequent contact with faculty and study groups than did females who studied in social, psychological, and life sciences.

The findings of Zeldin and colleagues (2008) revealed that the self-efficacy beliefs of males and females in STEM areas were developed from different levels of support from important people in their lives. Zeldin and Pajares (2000) found that adult females needed the influence of others in order to choose and pursue a STEM career. Interestingly, males viewed this influence as strengthening but not essential to their confidence; whereas females viewed it and the accompanying support as critical (Zeldin et al., 2008). Zeldin and Pajares (2000) found that many adult females in their study identified a family member who demonstrated strong mathematics skills regularly, and all females in the study reported that their confidence and competence was influenced by a teacher at some level. Peers were also mentioned as influential but in a more supportive 
role after the choice was made to pursue a mathematics-related career (Zeldin \& Pajares, 2000). Zeldin and Pajares (2000) also found that the women in the study not only needed to believe in themselves, but also needed to have others believe in them and openly support them.

\section{Sources of Self-efficacy}

Self-efficacy is the innermost construct in social cognitive theory (Bandura, 1997). It is the belief about the skills one has to achieve accomplishments. Self-efficacy is a contributing factor in how a person will perform a given task. If a person has high self-efficacy with regard to a task that she values, then she will more likely perform well. Low performance in a task subsequently leads to anticipating low self-efficacy. A person's self-efficacy beliefs determine how he or she will react in a situation, how much effort he or she will put forth, and how long he or she will persevere. When someone is successful at a task, then his or her efficacy generally is increased. Alternatively, when one fails, his or her efficacy generally is damaged (Bandura, 1997). Repeated success in a task can build confidence and lead to further perseverance in that task (Bandura, 1977a; Bandura, 1997).

Primary sources of self-efficacy. Self-efficacy beliefs are constructed from mastery experiences, vicarious experiences, verbal persuasion, and physiological and affective states (Bandura, 1997). Bandura suggested that mastery experience was the most significant source of self-efficacy. In studying the self-efficacy of 13- to 15-yearold students, Pietsch, Walker, and Chapman (2003) found that enactive mastery experiences formed efficacy beliefs in mathematics. Zeldin and others (2008) found that the primary source of self-efficacy beliefs for males in STEM fields was mastery 
experience. They examined the narratives from 10 male subjects and found that they identified mastery experiences as having the highest impact on their self-efficacy. This finding was consistent with Bandura (1997) who classified the mastery experience as the "most influential source of efficacy" (p. 80).

Earlier findings by Zeldin and Pajares (2000) revealed that social persuasions and vicarious experiences are the primary sources of self-efficacy beliefs for females in STEM fields. Zeldin and Pajares (2000) studied responses from 15 adult females in mathematics-related careers and found that the females identified examples of vicarious experiences and verbal persuasions as essential not only to building self-efficacy but also for maintaining self-efficacy beliefs as well. The importance of verbal persuasions and vicarious experiences on self-efficacy beliefs may have a stronger impact on females who are in traditionally male careers (Zeldin \& Pajares, 2000). Hutchison, Follman, Sumpter, and Bodner (2006) found in their study of first-year engineering students that although the largest number of factors influencing the students' self-efficacy beliefs was mastery experiences, females reported being influenced by vicarious experiences more often than males. Zeldin and Pajares (2000) found that females who chose and did well in mathematics areas had the necessary self-efficacy perceptions to persevere over educational and occupational barriers. The females viewed obstacles encountered in the pursuit of a mathematics-related career as dangers while the males in Zeldin, Britner, and Pajares (2008) viewed the obstacles as challenges. The males tended not to doubt their success in a mathematics- or science-related field, perceived many career opportunities available to them, and did not question whether they belonged there but rather if they wanted to be there. 
Achievement. Usher's (2009) results revealed high levels of achievement from students reporting high levels of mathematics self-efficacy and low performance from students with low self-efficacy. Also, a study of ninth- and tenth-grade students showed that self-efficacy was a factor in predicting mathematics performance and that student motivation and beliefs contributed to mathematics achievement (Stevens, Olivarez, Lan, \& Tallent-Runnels, 2004). Additionally, Cavallo, Potter, and Rozman (2004) studied students in a year-long college physics course. They found that male students had higher self-efficacy than female students, and this difference continued through the course.

Low self-efficacy in mathematics can lead to a lack of participation in higher level mathematics courses (Zeldin \& Pajares, 2000). Low self-efficacy and negative beliefs toward mathematics-related fields were cited also as possible causes for the underrepresentation of women in such fields as engineering (Plant, Baylor, Doerr, \& Rosenberg-Kima, 2009). Pajares (1996b) suggested that students who are not confident in their skills are not likely to participate in tasks where those skills are required and may give up quicker when they encounter difficulty. A student must not only have high efficacy in mathematics but must also believe that mathematics is important. Pajares (1996b) stated, "A high sense of efficacy may not result in behavior consistent with that belief if an individual also believes that the outcome of engaging in that behavior will have undesired effects" (p. 558).

Career. The findings of Zeldin and others (2008) suggested that self-efficacy beliefs were influential in a student's choice to pursue a mathematics-related career. Females who lacked self-efficacy in mathematics chose not to pursue a mathematicsrelated major in college or a mathematics-related career (Zeldin \& Pajares, 2000). 
Females seemed not to pursue mathematics related fields due to a lack of self-efficacy, rather than the lack of ability (Hackett \& Betz, 1989). Betz and Hackett (1981) also found that adult males reported high self-efficacy in both the traditional male careers and traditional female careers while females reported having high self-efficacy in only traditional female careers. They found that traditional classification of a career as a male domain or a female domain was a more important factor for female self-efficacy expectations than for male expectations.

\section{Rural Students' Beliefs about Mathematics}

Students in rural areas were likely to be unaware of the need for advanced mathematics courses or the careers that require them (Anderson, 2006). Students in rural areas were unlikely to know anyone, other than their mathematics teacher, who studied mathematics as a major in college (Anderson, 2006). Furthermore, often in rural areas, teaching high school mathematics is the only job for a person with a background in postsecondary mathematics (Anderson \& Chang, 2011). Rural students often related advanced mathematics studies with education or careers that they would have to leave the community in order to pursue (Anderson \& Chang, 2011). Anderson (2006) also found that rural high school students were unaware of the use of mathematics in the work environment. They also did not make connections with the mathematics in school and future career goals. Lucas (2005) and his team conducted a study in a rural Appalachian community in which females in the study outnumbered males three to two. They found that all age groups (ages 10 and up) believed mathematics should be taught at all levels of school and that learning mathematics was important for the future. They also found that students in all age groups believed that advanced mathematics skills were not important 
for local jobs. Cogan, Schmidt, and Wiley (2001) reviewed data from the 1995 Third International Mathematics and Science Study (TIMSS). They found differences in the availability of mathematics courses to eighth-grade students. They also discovered that there was discrepancy in the topics covered in the courses and the textbooks used. They revealed that advanced and enriched mathematics courses were more likely to be offered in rural schools if the eighth-grade class had higher enrollment. Anderson and Chang (2011) examined the 2005 National Assessment of Education Progress (NAEP) High School Transcript Study data and found that close to 50 percent of urban fringe high school students completed Advanced Mathematics or Calculus while less than 40 percent of rural high school students completed these courses. They also found that rural high school graduates did not have equal access to advanced placement classes in mathematics. Even though rural students took required mathematics courses, they lagged behind in the pursuit of mathematics at the same level as non-rural students. They also found that rural high school students were more likely to end their mathematics coursetaking early and that one-third of students completed their last high school mathematics course prior to their senior year.

Lack of guidance. Rural students were also not likely to seek guidance for career planning. Ali and Saunders (2006) speculated that the cultural seclusion and selfsufficiency of rural Appalachian youth influenced students not to seek help from teachers and counselors about career planning. They tended to rely more on family members for guidance because of their strong family relationships. Ali and Saunders (2006) also found that support from parents played key roles in rural Appalachian high school 
students' expectations to attend college. This support was more important in the students' decision-making than the occupation or education of their parents.

Mixed messages. Females from rural areas often receive mixed messages from influential adults. In a qualitative study of middle school females in a rural area, Seaton (2007) found that the females received mixed messages from teachers about appropriate classroom behavior. In addition, the status of the females' families in the community seemed to influence how they were treated by authority figures. Even though the rural females perceived their teachers as an important source of support, they had difficulty connecting emotionally with them (Seaton, 2007). She found that the females in the study wanted to know their teachers cared about them. One student expressed how it bothered her that her teachers seemed to have gendered expectations. The student had observed and been involved in what she perceived as unfair treatment, ranging from a female student being sent out of class for wearing sunglasses to a male student not being punished for rude and foul language toward a female student.

A powerful message is sent to students about their worth when a teacher, for whatever reason, fails to act in students' best interest. In addition, when students have parents who resist education and are distrustful of the educational system, these students do not find support from teachers. This action reinforces the message that they are not suited for education (Seaton, 2007). Mireles-Rios and Romo (2010) found that females had better grades in mathematics when they believed that their teachers cared about their education. Through interviews with females from an agricultural community, MirelesRios and Romo (2010) found that even though the students liked mathematics, they did not receive adequate input from teachers concerning college. Mireles-Rios and Romo 
(2010) suggested that students may perceive a lack of input from teachers about collegegoing as a comment on their college readiness and/or the importance of college to their future.

\section{Purpose and Research Question}

Even though the predicted job outlook shows an increased need for individuals in mathematics-related careers (Bureau of Labor Statistics, 2011), females are not pursuing STEM careers as often as males (Chen, 2009; Snyder \& Dillow, 2011). Students who rate their mathematics skills higher and believe that they will be successful are more likely to pursue quantitative careers (Correll, 2001). However, when females perform as well as or better than males in mathematics, they show less confidence in their work (Carmichael \& Taylor, 2005; Betz \& Hackett, 1981; Lloyd et al., 2005). Students with higher self-efficacy tend to have higher levels of achievement (Usher, 2009) and selfefficacy is a factor in predicting mathematics performance (Stevens et al., 2004). Overall, students from rural areas are less likely to have equal access to advanced mathematics courses in high school (Anderson \& Chang, 2011), in which skills necessary for success in STEM fields are taught (Hyde \& Mertz, 2009). Furthermore, female students have been found less likely than male students to take high school courses that focus complex problem solving skills (Hyde \& Mertz, 2009).

In order for high school guidance counselors and college admission committees to best serve female students in rural areas, it is important for them to know whether they are interested in pursuing careers in mathematics-related areas. This study will seek to find those factors that influence college major selection and career choices (both selection and avoidance) of rural females. The results of the study have the potential to lead to the 
development of strategies to improve the education and future success of female students from rural areas.

Therefore, I propose the following research question: What factors contributing to self-efficacy do rural Central Appalachian undergraduate females believe influence their decisions to pursue or not pursue majors and careers in mathematics-related fields?

\section{Need For Further Research}

Self-efficacy beliefs have important influences on the choices females make with regard to mathematics-related careers. Guidance counselors and teachers could benefit from understanding the development of self-efficacy beliefs (Zeldin \& Pajares, 2000). Pajares (1996b) suggested that additional studies need to explore the influences that peers have on students' self-efficacy beliefs because students often base judgments of their ability by comparing their performance to the performance of others. Rudasill and Callahan (2010) called for additional studies to investigate why mathematics and science seem to be less interesting to females even though females may report the same levels of self-perceptions of their ability as males. Gunderson and others (2012) suggested that the development of mathematics attitudes needs to be understood in order to understand rationales for better mathematics choices in college and careers. Additionally, Bush (2005) asserted that the research for both mathematics learning and mathematics teaching in rural areas is lacking. Pajares (1996b) recommended that researchers conduct

qualitative studies to explore the development of efficacy beliefs, students' perceptions of the influences of these beliefs on their own academic achievement and educational paths, and ways students' beliefs influence their choices, effort, and determination. 


\section{CHAPTER II}

\section{THEORETICAL FRAMEWORK}

Theories about behavior have enhanced knowledge about understanding the contribution of experience and learning on the modification of behavior (Bandura, 1977). Social learning theory has considered the consequences of reinforcement on behaviors (Rotter \& Mulry, 1965; Rotter, 1966). If individuals believe that external influences control the outcome of an event, they are less likely to place emphasis on skill improvement (Rotter \& Mulry, 1965; Rotter, 1966). The theoretical framework for this study is based on the construct of self-efficacy defined in Albert Bandura's social cognitive theory. This theory focuses on causes and influences that interact at different strengths at different times in one's life (Bandura, 1989). Individuals contribute to their own development, motivation, and behavior (Bandura, 1989), and efficacy beliefs influence performance (Bandura, 1997). Even if persons have developed the skills needed to achieve a task, their perceived self-efficacy will have a greater effect on their accomplishments (Bandura, 1997) because their beliefs will influence their actual behavior (Pajares, 1996b). If they have little confidence in their ability to perform an activity, they will avoid or put forth little effort. If they are confident of success, they will put forth more effort and perceive it as a challenge (Bandura, 1997). Their selfefficacy will likely influence their choice of activities, the amount of effort that they put forth in the activity, and the length of their persistence with the activity when they are faced with difficulty (Bandura, 1977a; Bandura, 1997). Individuals with low self- 
efficacy can weaken their potential for accomplishments by doubting and belittling themselves (Bandura, 1977b). Even when capable of being successful at an activity, they will not pursue the activity because they are not motivated to do so (Bandura, 1977a). If persons do not believe that their actions will produce the results that they want, then they are unlikely to act due to lack of motivation (Bandura, 1997). Additionally, when people do not have guidelines defined for appropriate behavior, they gather the information needed from what they have observed or experienced (Bandura, 1977b). The selfregulation of motivation is continuously influenced by efficacy beliefs (Bandura, 1997).

\section{Career Choices}

Career choices are influenced by efficacy beliefs (Bandura, 1997). Bandura noted that individual efficacy beliefs are formed by their experiences and these beliefs serve to direct their academic and career paths. Socioeconomic status influences parents' beliefs about how they can support their child academically. Student's efficacy beliefs about their future career are influenced by their educational accomplishments, which are indirectly influenced by the support of their parents. Bandura goes on to state that if students perceived efficacy is high, they will prepare for a future career; however, students with lower perceived efficacy will not value putting forth the effort to work hard.

Additionally, a lack of mathematical efficacy can create a stopping block for students pursuing careers that require quantitative abilities (Bandura, 1997). Although some studies show that females find careers in STEM fields satisfying, other studies reveal that at a young age, females are discouraged from pursuing these careers due to lack of role models, guidance, and positive stereotypes (McCarthy, 2009). Factors at 
school and home can influence their level of career choices (O'Shea et al., 2010). A student's choice to pursue a mathematics-related career can also be influenced by how he or she perceives his or her abilities (Dweck, 2006) and by their level of confidence (Gunderson et al., 2012).

\section{Self-Efficacy Sources}

Bandura (1997) identified four main sources that contribute to the construction of self-efficacy beliefs: (1) enactive mastery experience; (2) vicarious experiences; (3) verbal persuasion; and (4) physiological and affective states. Evidence reveals that women in traditionally male domains may be influenced differently by particular selfefficacy sources (Zeldin \& Pajares, 2000). Zeldin and Pajares (2000) found that women relied on both males and females as sources of social persuasions and vicarious experiences. When people see someone similar to themselves being successful at an activity, they tend to believe that they, too, have the ability to be successful with a similar activity (Bandura, 1977a; Bandura, 1997; Zeldin et al., 2008). Zeldin and others (2008) also found that males in their study identified performance achievements as critical in the development of their confidence to pursue a STEM career. Cordero, Porter, Israel, and Brown (2010) implemented a 15-minute mathematics self-efficacy intervention with first-year college students at a public university. They found that the intervention resulted in increased mathematics self-efficacy maintained for six weeks for the male participants; however, no significant increase in mathematics self-efficacy for the female participants was found (Cordero et al., 2010). 


\section{Enactive Mastery Experience}

Bandura (1997) labeled mastery experiences the most powerful influences on selfefficacy because they provide the most genuine confirmation that a person has what it takes to be successful. Repeated successes generally raise mastery expectations and repeated failures lower them (Bandura, 1977a). Once persons have established that they can be successful with an activity, they persist when faced with difficulties and bounce back quickly after failures (Bandura, 1997). However, if they experience easy successes, they come to expect easy success and a failure easily discourages them (Bandura, 1997).

Effort. Bandura (1997) asserted that efficacy determines how much effort persons apply, as well as how long that they persist, when they encounter difficulties. Zimmerman and Martinez-Pons (1990) studied fifth-, eighth-, and eleventh-grade students and found that as students advanced in school, their use of self-regulated learning strategies increased. Additionally, use of learning strategies was linked with student perception of mathematical and verbal efficacy. Females used goal-setting, planning, record keeping and monitoring more than males did. Vogt, Hocevar, and Hagedorn (2007) found female engineering students put forth more effort than their male peers and cited this effort as a possible explanation as to why females who chose to continue in the engineering field do well academically.

Students' level of effort seems to be connected to their self-efficacy. Usher (2009) conducted a qualitative study involving middle school students who were classified as either low self-efficacy or high self-efficacy. One female student indicated that her high scores in mathematics class contributed greatly to her confidence. On the other hand, two male students indicated that their performance was a result of 
mathematics having always been easy for them. Another female student indicated that she had previously felt bored in non-advanced mathematics classes. Although understanding the mathematics came easy to her, she did not brag but revealed pride in her methods and hard work. Two students' academic records revealed that they were equally capable in mathematics; however, the female student attributed her success and confidence to effort and hard work while the male student indicated that his talent was a factor for success. Usher (2009) found that middle school students with low self-efficacy were not as likely to seek help from teachers, and they were more likely to struggle in managing their mathematics work. Perceived weakness of the low mathematics selfefficacy students was revealed by rigorous coursework. The students perceived the effort they had to put forth as a sign of lack of efficacy. One student remained in a mathematics course that was too difficult, and this decision resulted in a lowered sense of self-efficacy (Usher, 2009).

Activities. Exposure to mathematics-related activities may influence the pursuit of a STEM career. While studying the experiences of students in STEM fields who transferred from community colleges, Jackson (2010) found that female students had been exposed early in their development to STEM-related activities and areas. Correll (2001) asserted that males are more likely to overrate their mathematical abilities than females and, as a result, are more likely to look for activities that would lead them to a mathematics-related career. Usher (2009) found that two of the males interviewed in her study indicated that mathematics had always been easy for them and early success had contributed to their confidence. 
Grades/test scores. Correll (2001) found that mathematics grades earned by females had a larger effect on their self-assessment than the males' grades. She found that, in mathematics, males tended to believe they were more competent than females even though tests scores and mathematics grades were similar. She speculated that females believed they needed grades as evidence to combat the lower expectations of female mathematical abilities by society. The mathematics test performance of females is affected by gender stereotypes, and female interest in STEM careers can be adversely affected by these negative stereotypes (Hill et al., 2010). Leaper, Farkas, and Brown (2012) found that females' mathematics and science motivation was positively linked to grades. Students who were in the higher mathematics self-efficacy category reported high achievement on standardized tests such as the Iowa Test of Basic Skills and the Scholastic Aptitude Test (Usher, 2009). Students with high self-efficacy received messages that were synonymous with being successful in school while the students with low self-efficacy received messages that had little positive feedback about their capabilities. Two students in the high self-efficacy category indicated that they had always received a high grade average in mathematics and had scored higher than others on standardized tests. The students in the low mathematics self-efficacy category reported struggling with mathematics, receiving low grades, and viewing mathematics as difficult. These beliefs resulted in lower capability beliefs. One of the females in the low self-efficacy group indicated that improvement in her mathematics grades was a result of taking her time and learning steps, and one of the male students indicated that he stopped believing in himself when he received his first failing grade on a report card. Another 
female student in the study felt her high scores contributed to her confidence. Usher (2009) found that confidence was influenced by strong performance academically.

\section{Vicarious Experiences}

Self-efficacy can be influenced by vicarious experiences. Modeling contributes to efficacy beliefs (Bandura, 1997). Observing someone being successful in a challenging activity can lead people to believe that they, too, can accomplish such a task if they are persistent (Bandura, 1977a; Bandura, 1997). The more observers see themselves as being similar to the model, the more influence the model's behavior has on the observer (Bandura, 1997). This relationship is true for both successes and failures.

Vicarious experiences can have greater influence on an observer's efficacy if the observer has had little experience with the activity as a basis for judging his own capability. Even if people have had many past experiences, they may have had a combination of successes and failures leaving them uncertain and self-doubting, opening them to the need for a model for comparison. Models can also provide observers with new, better ways to do something and contribute to an increase in efficacy (Bandura, 1997).

Role models. Females often choose not to pursue careers in STEM fields because these fields have fewer female role models (Beede et al., 2011; Handelsman et al., 2005; Hyde \& Mertz, 2009). Interactions with strong female role models can: (1) serve to weaken negative gender stereotypes and reduce stereotype threat; (2) serve as guides to possible achievement for other females; and (3) demonstrate to other females that elevated levels of success can be accomplished (Lockwood, 2006). Stereotype threat is a situational and psychological threat that occurs when a negative stereotype exists about a 
group (Steele, 1997). When a negative stereotype exists about a group, the group members can experience the fear of being reduced to that stereotype. Furthermore, if a person is a member of the group negatively stereotyped and he or she identifies with the area for which the stereotype exists, then self-threatening can hinder achievement (Steele, 1997). It is important for females to have role models who have been successful in nontraditional fields and who have overcome gender stereotypes (Lockwood, 2006). Lockwood found that female role models had a positive effect on adult females more so than male role models, and adult females also identified more with female role models. Also, females working in nontraditional careers may have improved performance if they have strong female role models.

Parents. Usher (2009) found that vicarious learning opportunities can be provided by models. Most of the middle school students interviewed from the high selfefficacy category indicated that their parents were good mathematics role models. These students' parents encouraged them in mathematics as well as showed an interest in mathematics themselves. The students interviewed from the low self-efficacy category indicated that their mothers and some their fathers did not do well in mathematics and that they received little support in mathematics at home (Usher, 2009).

Peers. The behavior and success of peers can influence how students see themselves. Some of the middle school students interviewed by Usher (2009) reported being asked for help by their peers, which increased their self-efficacy. One of the female students indicated feeling humiliated when her classmates would understand concepts before she did, and another student seemed to judge her mathematics competence by the standards set by her peers' experiences. One of the male students 
seemed to compare his achievements with those of his peers and saw mathematics accomplishments as competitive. Some of the students in the high mathematics selfefficacy category reported self-talk and internal values as aiding them in being successful. On the other hand, one of the students in the low self-efficacy category confessed that seeing other students succeed made her feel disgraced. She felt as if she should understand because her peers seemed to understand. Another student measured her mathematics competence by comparing herself to her former classmates who were in a higher level class. She felt that if they were having difficulties then she would not be able to be successful at that level (Usher, 2009).

\section{Social/Verbal Persuasion}

Another contributor to self-efficacy beliefs, even if only in a reassuring manner, is social persuasion. This strategy is another way of reassuring a person's belief that he or she can accomplish what they set out to do (Bandura, 1997). When encouraged with verbal persuasions, people are more likely to put forth greater effort and sustain that effort when difficulties arise rather than to consider uncertainties and personal imperfections. People are likely to put forth greater effort and maintain that effort if given verbal persuasions ensuring them that they have what it takes to persevere. If students receive feedback stressing their abilities or praising their accomplishments, then their efficacy beliefs can be strengthened. Persuasions of efficacy beliefs can also arise in an indirect form. Unfortunately, messages can be sent to persons indirectly that not much is expected from them. They may not be challenged or may not receive praise for accomplishments (Bandura, 1997). 
Support. Jackson (2010) found that even though females may enter STEM majors academically prepared in science and mathematics, they may still need advisors and faculty members to support them. The level of respect perceived from their professors predicts the level of self-confidence in female students (Huang \& Brainard, 2001). Faculty members can have an effect on a student's perceptions of self, which, in turn, has an effect on achievement (Vogt et al., 2007). Zeldin and others (2008) found that males viewed members of their family, instructors, and peers as self-efficacy reinforcements and models for information. However, the males did not view these individuals as directly building their self-efficacy. In contrast, females indicated support from others as directly related to their pursuit of a career in a mathematics-related area. Vogt and others (2007) found that females preferred to ask questions outside of class, and they would ask peers first before asking the instructor. Also, females were more likely to look for help, and a stronger relationship existed for females than for males between selfefficacy and the willingness to look for help (Vogt et al., 2007).

Perceived by others. Self-confidence in female students is influenced by their belief of how they are perceived by significant others (Huang \& Brainard, 2001). Zeldin and Pajares (2000) found that the opinions of individuals whom are deemed important influenced adult females' self-efficacy beliefs. The most important influence on selfefficacy for females was that significant others not only have confidence in the females but that they also directly express this confidence to them. The influence of the expression of confidence by significant others was critical regardless of whether the confidence was displayed by a male or a female (Zeldin \& Pajares, 2000). Additionally, 
Huang and Brainard (2001) found that female engineering majors were more dependent on the influence of others than females in general.

Encouragement. Finley (2002) found that females with doctorates in mathematics credit different individuals with encouraging them to enroll and excel in mathematics courses. One freshman student intending to be an architect was encouraged by a mathematics professor to take his calculus course, leading her to find it was something that she enjoyed (Finley, 2002). Finley also reported that another student noted that she decided to major in mathematics when she was in eighth grade and received encouragement from a particular geometry teacher. The same student stated that when courses became particularly difficult for her, she had strong support from family and friends. A third student in the study indicated that she was encouraged to participate in mathematics courses and enjoyed mathematics, but she did not intend to major in mathematics until professors encouraged her to take advanced mathematics courses. A fourth female mathematics Ph.D. graduate credited her mother's consistent encouragement as motivation to pursue her degree in mathematics.

Stereotypes. The lack of alignment among academic efficacy beliefs and ability may be due to efficacy beliefs connecting to stereotypes (Rudasill \& Callahan, 2010). Females sometimes may choose not to pursue careers in STEM fields because of gender stereotypes (Beede et al., 2011; Hill et al., 2010). Such stereotypes in mathematics may cause both teachers and parents to act differently toward males and females and have different expectations of them (Gunderson et al., 2012). Shapiro and Williams (2012), through examination of the literature, found that gender stereotypes can have a negative influence on females even if the females had positive attitudes towards mathematics. 
Ramsey and Sekaquaptewa (2011) found that an increase in stereotyping of females resulted in decreased in mathematics performance. Performance in courses and career aspirations of females can be negatively influenced by gender stereotypes (Shapiro \& Williams, 2012). Leaper and others (2012) found that females who accepted gender equality were more apt to have stronger motivation in mathematics and science. Likewise, Turner and others (2004) found that middle school students who believed that mathematics was a suitable pursuit for someone of his or her gender had higher mathematics efficacy.

Mathematics as a male domain. Cheryan (2012) suggested that although females score just as well as males on standardized tests and often receive better grades in mathematics courses, they tend to choose not to pursue mathematics-related careers because these jobs are often viewed as masculine. One of the males in a study conducted by Zeldin and colleagues (2008) observed that females were routinely discouraged from studying mathematics by teachers from elementary school through college; another male found it surprising and strange when he encountered an attractive female who was knowledgeable in the subject of mathematics. Vogt and others (2007) found that females reported more discrimination than males reported and that females reported not feeling respected by their male classmates.

Female beliefs. Although females' beliefs about mathematics gender stereotypes may change over time (Ramsey \& Sekaquaptewa, 2011), negative mathematics stereotypes are less threatening to females if they believe that mathematics ability is gained through effort rather than innate ability (Dweck, 2006). When female students believe that abilities are a gift, they are more vulnerable to stereotypes, which may result 
in the loss of desire to continue in that area when faced with a setting where these stereotypes are manifested. Dweck (2006) discovered that females who believed that intellectual abilities were developed did better in mathematics than those who believed that these abilities were a gift. In fact, she found the gap almost disappeared when looking at students who believed that intellectual skills can be increased. In other words, students who believe intellectual abilities are nurtured are less likely to subscribe to gender stereotypes.

Environment. Zeldin and Pajares (2000) speculated that childhood experiences may be different for males and females, resulting in adult females having limited exposure to key components required to build self-efficacy in male-dominated areas. Home and classroom environments where the significance and worth of mathematical skills were stressed lead to higher mathematics self-efficacy in females (Zeldin \& Pajares, 2000). O’Shea and others (2010) noted that female high school students identified as gifted were influenced by teachers and encouraged mathematically at both home and school. These female high school students identified a home atmosphere that encouraged educational pursuits including mathematical accomplishments. Usher (2009) interviewed middle school students and revealed that some of the students reported using self-regulatory skills. These students were able to make it through difficulties by coaching themselves.

School. School and classroom environments can influence student efficacy. Some of the students interviewed by Usher (2009) reported being teased by classmates about being smart; however, these students used their personal goals and accomplishments to protect themselves from being upset. One of the students 
interviewed contributed her mathematics confidence to the responses that she received from her work. On the other hand, students can be influenced by a teacher's lack of confidence. One of the female middle school students interviewed by Usher (2009) was given reassurance that she was capable when she was promoted to a higher mathematics course during the school year while another female student's lack of efficacy was reinforced when she did not move to a previous mathematics course even though her teacher requested that she do so. She indicated that the feeling that the teacher believed she should be in a lower level mathematics course stayed with her and was internalized. Another student interviewed by Usher (2009) indicated that his teacher's lack of patience with his questions made him feel that he was not as capable even though she did not overtly discourage him.

Home. A supportive home environment can contribute to higher mathematics self-efficacy. One of the females classified in the high self-efficacy category interviewed by Usher (2009) indicated that her father would quiz her in mathematics. Jackson (2010) found that many of the females interviewed credited parental influence as having an impact on their overall perception and experiences in STEM areas. Turner, Steward, and Lapan (2004) found that support of both mother and father affected the mathematics selfefficacy of middle school students. Also, the support of mothers and fathers was significant in building the belief that mathematics was suitable for them (Turner et al., 2004). Leaper and others (2012) studied motivation of 13- to 18-year-old females and found that the females' perceived support of parents and peers was positively related to the females' mathematics and science motivation. The mothers' support and beliefs in 
the females' mathematics ability influenced motivation more than the fathers' support and beliefs.

Lack of a supportive home environment also contributes to lower self-efficacy. The mothers and some fathers of the students in the low self-efficacy category interviewed by Usher (2009) indicated their belief that their child was lacking in mathematics skills. One of the male students felt burdened by his parents' expectations, and their lack of encouragement contributed to his low expectations of his mathematics success (Usher, 2009). Another reported discouragement from family resulting in the student's lowered self-efficacy. The student felt that there was no purpose in having confidence in himself when no one else did.

\section{Physiological and Affective States}

Persons' fearful thoughts about their perceived lack of ability can cause their anxiety to rise above what the fear of being in the actual situation would produce (Bandura, 1977a). Sometimes fears and insufficiencies are mutually supporting; avoiding activities that are stressful can cause coping skills not to develop. The shortage of ability resulting from the avoidance creates a real basis for fear (Bandura, 1977a). Bandura (1997) also noted that the way the emotional and physical reactions are perceived is more important than the strength of the reaction. He stated that someone may perceive his or her arousal as being from lack of ability, therefore lowering his or her self-efficacy, as opposed to a common reaction that someone competent in an area may experience.

Avoidance. Low performance may disclose low ability and result in some students withdrawing effort in an attempt to avoid damage to their self-worth (Thompson \& Dinnel, 2007). These researchers studied adult females in high and low self-worth 
protection categories and found with a quantitative reasoning test that females in the high self-worth protection category and females in the low self-worth protection category performed the same under success conditions. However, under failure conditions, females in the low self-worth protection category showed more success than females in the high self-worth protection category. Thompson and Dinnel (2007) recommended that attention be given to promoting ability and skill.

Influence of teacher anxiety. The negative stereotype of females being mathematically incapable is also reinforced by a female teacher's mathematics anxiety (Beilock, Gunderson, Ramirez, \& Levine, 2010). If teachers have mathematics anxiety, they can unknowingly pass it on to their students (Geist, 2010; Karp, 1988). Beilock and others (2010) found that if female teachers had mathematics anxiety, it can influence the attitudes of their female students. They established that a female teacher's mathematics anxiety may not have an influence on her female students at the beginning of the school year; however, by the end of the school year, it was more likely that her female students would demonstrate lower mathematics achievement. Karp (1988) found that when students were taught by a teacher with a positive attitude toward mathematics, students not only believed that the teacher liked mathematics, but they also liked mathematics as well. Karp (1988) also concluded that students taught by a teacher who had a negative attitude toward mathematics still believed that the teacher liked mathematics; however, the students did not like mathematics. Additionally, previous experiences, such as the use of high stress methods as opposed to interactive and developmental approaches to learning, can increase mathematics anxiety (Geist, 2010). 
Physical. Students may experience physical reactions that can lead to lower mathematics self-efficacy. One of the students interviewed by Usher (2009) reported feelings of confusion and tension when beginning a new topic in mathematics. The student also reported experiencing physical factors such as sweating and hives. Another student reported becoming frustrated quickly when he did not understand what was being presented, why something was marked incorrectly, or when his questions were not answered immediately. Nervous feelings before taking tests were experienced by another student, especially in situations when she knew the results were important. When studying sources of self-efficacy in middle school students, Usher also found that students with low mathematics self-efficacy experienced feelings of distress. They also exhibited feelings of anger, impatience, and stress. Other students in the low selfefficacy category reported hating mathematics, believing that it was boring, feeling pressured when taking standardized tests, and finding it difficult to focus. One of the students reported having mixed feelings, sometimes believing he could do it while other times being sure he could not. His teacher reported him exhibiting fatigue when presented with confusing material. Additionally, a male engineering student interviewed by Hutchinson and others (2006) indicated his doubts and frustrations, stating that if he had difficulties at the beginning he would worry that he would not be able to make it through the course.

\section{Rural Students}

Hardre, Sullivan, and Crowson (2009) conducted a study with rural high school students and found that school achievement was influenced greatly by students' perceived competence of themselves. They also found that, compared to other subject 
areas, the rural students reported that their effort was less, their competence was lower, and their anticipated accomplishments were lower in mathematics. However, Howley and Gunn (2003) found, through investigation of the literature that there was not an achievement gap in mathematics for rural versus non-rural students. Hardre and others (2009) found that effort and interest were influenced by the worth that the students saw in what they were learning and the contributions toward their goal achievements. Burnell (2003) interviewed 26 college-able rural students from 11 high schools. The students identified themselves as work bound rather than college bound. Some factors these students identified as influencing their decision to pursue work instead of college included: (a) having vocational/technical training that prepared them for work; (b) having enthusiasm for the vocational field for which they had trained in high school; (c) wanting an immediate way of making money to prepare for college; (d) supporting the goal of getting married and beginning a family; (e) exploring options available to them, (f) wanting a break from school; and (g) not being able to identify what college held for them (Burnell, 2003). Corbett (2007) conducted interviews of people from a rural coastal area and found that the local business opportunities and attitudes of the local people greatly influenced students' decisions about college. The immediate rewards of local jobs would provide a means of making a living with the hope of earning more than the local standard. Families expected students to be involved in the local business. Pursuing higher education would mean that the student would have to leave the community. Rural students felt a sense of shame or lack of loyalty to family when their education level surpassed that of their parents' (Seaton, 2007). 
Howley, Gholson, and Pendarvis (2006) interviewed talented rural students and found that they viewed mathematics as memorization and application of rules as well as following procedures. Their parents also viewed mathematics this way as well. Few of these students reported having activities outside of the classroom that they recognized as having to do with mathematics. Most reported that the only mathematics experiences that they had at home were related to their class work and homework. The students received support at home from their parents and other family members for learning school mathematics (Howley et al., 2006). Rural females tended not to ask for help because of the community-instilled sense of needing to be self-reliant. Seaton (2007) interviewed groups of rural middle school girls and found that many felt disconnected from their teachers although they valued their teachers as important sources of information. The female middle school students interviewed by Seaton (2007) revealed feelings that teachers did not treat them the same as the males. They believed that the teachers favored the male students and had different expectations of them. Teachers' preconceived notions about a student can serve to restrict her ability to develop her own identity. These notions can lead her to believe that opportunities are not available to her and can restrict her self-efficacy (Seaton, 2007). Hardre and others (2009) found that support of the teacher was an important environmental impact on motivation and rural students' interest was influenced by teacher support. However the support from peers was not as important an influence. 


\section{CHAPTER III}

\section{METHODOLOGY}

A two-part study was conducted to answer the following research question:

What factors contributing to self-efficacy do rural Central Appalachian

undergraduate females believe influence their decisions to pursue or not pursue majors and careers in mathematics-related fields?

To answer this question, a demographic questionnaire and survey were

administered. The questionnaire determined those in the study who were categorized as rural Central Appalachian females. Also, a survey determined which females were categorized under the classifications of positive mathematics attitude and negative mathematics attitude using two subscales of the Fennema-Sherman Mathematics Attitude Scales: (1) the Confidence in Learning Mathematics Scale and (2) the Effectance Motivation Scale in Mathematics (Fennema-Sherman, 1976a). Next, selected females falling in each of the categories positive mathematics attitude and negative mathematics attitude were interviewed regarding what factors influenced their decision to pursue, or not pursue, majors or careers in mathematics-related fields. The interviews were coded using Bandura's (1997) four themes related to mathematics self-efficacy: (1) enactive mastery experience; (2) vicarious experience; (3) verbal/social persuasions; and (4) physiological and affective states.

This chapter describes the research methods employed in the study. First, the sample selection process for Appalachian females from six geographic region 
(Appalachia, Central Appalachia, rural Appalachia, rural Central Appalachia, other Appalachia, and non-Appalachia as determined by information from the Appalachian Regional Commission and the Economic Research Service of the United States

Department of Agriculture) is described. Second, data were collected from undergraduate college students attending educational institutions in Kentucky. The institutions are described with justification for the selection of the institutions. Third, the instruments used for data collection including the survey, demographic questionnaire, and interview protocol are described and justification of the selections given. Fourth, the procedures used to collect the data using the demographic questionnaire, survey, and interviews are detailed. Fifth, the analysis of the data is described.

\section{Sample}

The primary goal of the study was to investigate factors that influence rural central Appalachian adult females to pursue mathematics-related majors and careers. The population for this study included undergraduate adult female college students attending general classes at a community/technical college or university in central Appalachia. The study focused specifically on undergraduate college students attending classes in the state of Kentucky and from rural Central Appalachian areas. The Central Appalachian region encompasses parts of several states and contains both rural and nonrural areas. The community/technical colleges and universities included in the study are also discussed.

Appalachia. The Appalachian Regional Commission (ARC) describes the region of Appalachia as following along the Appalachian Mountains and containing counties in Alabama, Georgia, Kentucky, Maryland, Mississippi, New York, North Carolina, Ohio, 
Pennsylvania, South Carolina, Tennessee, Virginia, and West Virginia (Appalachian Regional Commission, 2012). Appalachia for this study is more narrowly defined as the counties listed by ARC. ARC also classifies Appalachia into sub-regions based on characteristics such as topography, demographics, and economics. Central Appalachia is comprised of the Appalachian area of Kentucky and selected counties in West Virginia, Virginia, and Tennessee. Although ARC classifies 42 percent of Appalachia as rural, the focus of ARC tends to be on poverty levels rather than rurality of the counties. Additional classification of rurality is necessary.

Rural. In 2010, the U.S. Census Bureau defined populations of 50,000 or more as urbanized areas and an urban cluster as having at least 2,500 people in the territory, with at least 1,500 of these people living outside of institutional group housing (Bureau of the Census, 2011). "Rural" is defined as "all population, housing, and territory not included within an urban area" (Bureau of the Census, 2011, p.53039). The Economic Research Service (ERS) of the United States Department of Agriculture (USDA) further classifies the urban and rural areas by level of rurality and relation to metropolitan areas (United States Department of Agriculture [USDA], 2010). The 2003 Rural-Urban Continuum Codes contains nine classifications including three for metropolitan (metro) counties and six for non-metropolitan (non-metro) counties (USDA, 2010). This coding allows researchers to further breakdown data for analysis when counties are classified into levels other than just metro and non-metro. The counties are first grouped by the Office of Management and Budget 2003 classification using population, the size of the county's urban population is used to classify non-metro counties as well as the county's adjacency to metro areas. Of the non-metro codes four are the most rural, with the 
restriction on the population of at most 19,999. The four codes are as follows: (1) completely rural or less that 2,500 urban population, not adjacent to a metro area (code 9); (2) completely rural or less that 2,500 urban population, adjacent to a metro area (code 8); (3) urban population of 2,500 to 19,999 , not adjacent to a metro area (code 7); and (4) urban population of 2,500 to 19,999 , adjacent to a metro area (code 6). For the purposes of this study, a rural area included counties classified by code 9, 8, 7, and 6 . Furthermore, counties classified as part of Appalachia by the ARC and classified as rural by the ERS codes 9, 8, 7, or 6 are considered rural Appalachia (see Appendix A). Counties classified as part of Central Appalachia and are classified by the ERS as codes 9, 8, 7, or 6 are considered rural Central Appalachia. Counties classified by the ARC as part of Central Appalachia that do not fall under the classification of codes 9, 8, 7, or 6 by the ERS and other parts of Appalachia are considered "Other Appalachia" for the purposes of this study. All other counties are classified as non-Appalachia.

Community/technical colleges and universities. The sample for the study was undergraduate students $(n=648)$ attending general education classes at community/technical colleges or universities in Appalachian Kentucky. The focus of data collection was undergraduate students who lived in Central Appalachia. The educational institutions were chosen because they are located in central Appalachia, and the majority of the areas served are classified as rural. Data were collected from students at Big Sandy Community and Technical College (BSCTC); Hazard Community and Technical College (HCTC); Southeast Kentucky Community and Technical College (SKCTC); and Morehead State University (MSU). Thirty-two instructors from BSCTC were asked to administer the survey and demographic questionnaire to students in their 
classes. Twelve instructors agreed to allot time in their classes for administration of the survey. Out of 17 instructors at HCTC, five allotted class time for the survey. Nineteen instructors at SKCTC were contacted with a request to administer the survey, and two instructors allotted time in their classes. Fifteen instructors at MSU were contacted and asked to administer the survey, and three agreed.

BSCTC serves students in five eastern Kentucky counties (Big Sandy, 2012). All counties are classified by the ARC as part of Central Appalachia and all counties are also classified by ERS as codes 7, 8, or 9. HCTC has campus locations in four Central Appalachian counties in Kentucky (Hazard, 2012). These counties are classified by ERS as either code 7 or code 9. SKCTC serves students from four Appalachian counties in Kentucky, one Appalachian county in Tennessee, and one Appalachian county in Virginia (Southeast, 2012). All of these counties are classified by ERS as codes 6, 7, 8, or 9. MSU serves 22 Kentucky counties (Morehead, 2012b). Twenty-one counties from the list are classified by the ARC as part of Central Appalachia. Additionally, 19 of the 21 counties are classified by ERS as codes 6, 7, 8, or 9. A listing of rural Central Appalachian counties served by these educational institutions can be found in Appendix B. These institutions provided an adequate number of participants for the current study $(n=648)$.

\section{Data Collection Instruments}

A demographic questionnaire and survey were used to identify potential candidates for interviewing. The demographic questionnaire and survey were labeled using a four-digit code. To protect the identity of the students in the study, the demographic questionnaire was stored separately from the survey. The survey instrument included two adapted 
subscales of the Fennema-Sherman Mathematics Attitude Scales (1976a). The revised subscale items, and their negative and positive weights, can be found in Appendix C. The demographic questionnaire and survey can be found in Appendix D. The interview protocol was adapted from Usher (2009) and can be found in Appendix E. This section will discuss the survey instruments considered for data collection, the demographic questionnaire, and the interview protocol.

Survey instrument. The purpose of the survey instrument was to determine which students had a positive or negative attitude in mathematics. Three attitude inventories were reviewed: the Science Teacher Efficacy Belief Instrument form A (STEBI-A) (Riggs \& Enochs, 1990) and form B (STEBI-B) (Enochs \& Riggs, 1990); the Mathematics Attitude Inventory (MAI); and two subscales of the Fennema-Sherman Mathematics Attitude Scales. The latter were chosen as the survey instrument. A discussion of the instrumentation follows.

STEBI-A and STEBI-B. STEBI-A was created as an instrument for inservice teachers (Riggs \& Enochs, 1990) while STEBI-B was created for preservice teachers (Enochs \& Riggs, 1990). Both instruments use a 5-point Likert-type response scale. The STEBI-A and STEBI-B are composed of two scales: (a) the Personal Science Teaching Efficacy Belief scale and (b) the Science Teaching Outcome Expectancy scale (Enoch \& Riggs, 1990). The STEBI-B contains items that have been reworded from the STEBI-A in future tense (Enochs \& Riggs, 1990). While these scales are based on self-efficacy, they are also designed for use in education. Although the students in this study were all adults, they will not all be studying in the field of education. Therefore this instrument was excluded for consideration. Additionally, the questions focused on science rather 
than mathematics. Therefore other instruments were better aligned with the goals of this study.

Mathematics Attitude Inventory. Sandman (1980) designed the Mathematics Attitude Inventory (MAI) to measure attitudes of secondary students towards mathematics (Sandman, 1980). The MAI is divided into six scales, each measuring a mathematics attitude construct: (a) Perception of the Mathematics Teacher; (b) Anxiety toward Mathematics; (c) Value of Mathematics in Society; (d) Self-Concept in Mathematics; (e) Enjoyment of Mathematics; and (f) Motivation in Mathematics. The response scale is a 4-point Likert scale with choices that include: strongly agree, agree, disagree, or strongly disagree. Because Sandman did not indicate whether the scales could be used independently and the response scale did not provide an option for undecided, this scale was eliminated from consideration.

Fennema-Sherman Mathematics Attitude Scale. Fennema and Sherman (1976a) designed instruments to measure attitudes toward success in mathematics. In their research, they found that many females were prevented from participating in careers that were rewarding economically and psychologically because of their lack of mathematical knowledge (Fennema \& Sherman, 1976b). The Fennema-Sherman Mathematics Attitude Scales includes nine Likert-type subscales: (a) Attitude toward Success in Mathematics; (b) Mathematics as a Male Domain; (c) Mother scale; (d) Father scale; (e) Teacher scale; (f) Confidence in Learning Mathematics; (g) Mathematics Anxiety; (h) The Effectance Motivation Scale in Mathematics; and (i) Mathematics Usefulness (Fennema \& Sherman, 1976a). Each scale consists of 12 items with six worded positively, six worded negatively, and five response choices of strongly agree, agree, undecided, disagree, and 
strongly disagree. The Fennema-Sherman Mathematics Attitude Scales can be used individually, as a whole, or in any combination (Fennema \& Sherman, 1976a). The Mathematics Anxiety Scale is highly correlated with the Confidence in Learning Mathematics Scale, but it was included as a scale due to the recognized interest by researchers (Fennema \& Sherman, 1976b). When constructing the instrument, the authors sought content validity by defining a dimension for each scale, writing items independently for the dimension, and judging the other author's items for validity. The items were agreed upon by both authors to measure the chosen dimension. The initial instrument was administered to 367 high school students consisting of 180 males and 187 females. The students included both mathematics and non-mathematics students. Items for the final scale versions were chosen using the following criteria: items with the highest correlation with the total score for each gender; the higher standard deviation for each gender; items consistent with the theoretical construct; and items that made a distinction between the mathematics students and the non-mathematics students. Splithalf reliabilities were calculated on the scale after the final selection of items. Each subscale followed by the reported reliability in parentheses is listed: Attitude towards Success in Mathematics (.87); Mathematics as a Male Domain (.87); Mother scale (.86); Father scale (.91); Teacher scale (.88); Confidence in Learning Mathematics (.93); Mathematics Anxiety (.89); The Effectance Motivation Scale in Mathematics (.87); and Mathematics Usefulness (.88). The Fennema-Sherman Mathematics Attitude Scales have been widely used for investigating attitudes toward the study of mathematics (Mulhern \& Rae, 1998). Melancon, Thompson, and Becnel (1994) investigated the validity of the 
Fennema-Sherman scales using a sample of 174 teachers from elementary schools. They concluded that the Fennema-Sherman scales had reasonable validity.

The purpose of the survey instrument is to identify subjects that have either a positive or negative attitude toward mathematics. Having a negative mindset can hinder females' mathematics performance and prevent them from pursuing mathematics courses and careers (Gunderson et al., 2012). Additionally, a person's confidence will influence their effort (Bandura, 1997). The survey had to be easy to administer, require a short completion time, and still allow enough information to be gathered. Two dimensions of the Fennema-Sherman Mathematics Attitude Scales were chosen to serve as the instrument: The Confidence in Learning Mathematics Scale and the Effectance Motivation Scale in Mathematics. These instruments included 24 items; 12 positively worded and 12 negatively worded. The Confidence in Learning Mathematics Scale was designed to measure whether students are sure of their ability to learn mathematics and to handle task in mathematics. The Effectance Motivation Scale in Mathematics seeks to determine how much involvement students invest in mathematics.

The author of the Fennema-Sherman Mathematics Attitude Scales was contacted for permission to use the instrument. E. Fennema (personal communication, March 3, 2012) granted permission to the researcher for use of the instrument but cautioned about using an instrument that is more than 30 years old. In order to ensure that instrument wording is up-to-date, the item statements were presented to more than 20 college students with the purpose of determining if any statements seemed strange, used familiar language, or were confusing. Feedback from the college students resulted in the need to reword two items. The statement "I'm no good in math" has been rewritten as "I'm not 
good in math." Additionally, the statement "Most subjects I can handle O.K., but I have a knack for flubbing up math" has been rewritten as "Most subjects I can handle O.K., but I tend to mess up in math." The instructions for the instrument were altered to reflect the need to circle the choices of strongly agree, agree, undecided, disagree, and strongly disagree rather than to mark the letter that represents the choice. The revised items, and their negative and positive weights, can be found in Appendix C. The survey can be found in Appendix D.

Demographic questionnaire. The purpose of the demographic questionnaire was to determine whether students met the criterion of being an undergraduate female from a rural Central Appalachian area and to provide contact information in the event that the student may be selected for an interview. The demographic questionnaire was attached to the survey when administered to students but stored separately. The information requested from the student on the demographic questionnaire included name, home address, home and cell phone number, year in college, gender, age, high school attended, and location of high school. The student's name and home and cell phone number was requested in order to contact the student if she was selected for participation in an interview. The student's year in college served to verify that the student is an undergraduate. The student's home address, high school attended, and location of high school provided information to determine if the student was from the Central Appalachian area. The student's gender and age verified that only adult female students are selected for interviews. The demographic questionnaire was stored separately from the survey; however, information about gender, age, and rural area was associated with the survey information after coding. Additionally, the classification of the student as 
having positive attitudes in mathematics or negative attitudes in mathematics was connected with the interview information after the interviews were conducted; however, interview files did not contain names and were identified by coded numbers.

Interview protocol. Patton (2002) identified three types of sources for collecting qualitative data: interviews; observations; and documents. Interviews use questions that are often open-ended to gather information about a person's thinking, views, ideas, and understanding. Observations require notes taken in the field describing what is seen. Documents include writings, photos, publications, lesson plans, homework, and other written evidence (Patton, 2002). The narratives provided the opportunity for richer descriptions than possible with quantitative methods (Zeldin \& Pajares, 2000). The current study focused on influences on rural Central Appalachian females' decisions to pursue or not pursue mathematics degrees. The data was best gathered through interviews because observations and documents did not allow for participants to express and expand on their experiences, thinking, and views.

Interviews using open-ended questions allowed the researcher to gain insight into the interviewee's opinions, views, perceptions, and experiences (Patton, 2002). Patton (2002) listed four main reasons to use a standardized open-ended interview: (1) the standardized open-ended interview allows the instrument questions to be available for inspection by concerned parties before the actual interviews; (2) in the event that multiple interviewers are used, this type of interview minimizes variation; (3) it allows for the efficient use of time by focusing the interview; and (4) analysis is aided and eased by allowing responses to be easy to locate and evaluate. In a standardized open-ended interview, the wording and order of the questions were determined ahead of time (Patton, 
2002). The standardized open-ended interview format made comparisons easier because every interviewee was asked the same set of questions in the same arrangement (Patton, 2002). Also, data were collected from every interviewee for each topic covered in the interview (Patton, 2002). This type of interview had the advantage of reducing interviewer bias and effect when using more than one interviewer (Patton, 2002). However, this type of interview had the disadvantage of limiting the naturalness of the interview by restricting the questions (Patton, 2002). It also limited the significance of the questions and responses (Patton, 2002).

The interview questions allowed the students to expand on their experiences and beliefs in mathematics. Vicarious experiences and verbal persuasions originate from others (Bandura, 1997) so the questions allowed the student to expand on relationships and interactions with others (Patton, 2002). Usher (2009) conducted a study of selfefficacy beliefs of middle school students. She found that interview questions allowing the students to tell about the type of mathematics student that they were or to talk about themselves as a mathematics student allowed information about mastery experience to emerge. She modeled the interview protocol after that of Zeldin and Pajares (2000). Additionally, interviewees were given the opportunity to clarify or modify their responses after the interviews were completed. Usher (personal communication, April 18, 2012) granted permission to adapt the interview protocol for use in the current research project.

The interviews for the current research were conducted with adult undergraduate students as opposed to the middle school students who were interviewed by Usher (2006). The interview protocol was adapted to adjust for the age difference and difference in schooling patterns. The protocol followed by Usher referred to state 
mathematics testing which is common in public schools. Questioning about current mathematics classes was also used; however, some students interviewed for the current study were not enrolled in a mathematics course at the time of the interview. Additionally, a question was added to obtain information about mathematics opportunities for people in rural areas. The interview protocol for the current study contained 14 prompts. The adapted interview protocol can be found in Appendix E.

\section{Human Subjects Procedures}

All research involving human subjects was reviewed and approved by the Institutional Review Board (IRB) for the involved institutions. Approval was applied for and obtained from the University of Louisville (UL), Kentucky Community and Technical College System (KCTCS), and Morehead State University (MSU). The policies and procedures for the institutions were followed to ensure the protection of the subjects involved in the study. The policy for each institution was followed to acquire approval to conduct the research study. Both UL and MSU required the researcher to complete the Collaborative IRB Training Initiative (CITI) human subjects training which was completed in March and April 2012. Refresher courses were completed in April 2013.

University of Louisville. According to the University of Louisville's (2012) Human Services Protection Program website, the institution is fully accredited by the Association for the Accreditation of Human Research Protection Programs, Inc.

(AAHRPP). The procedures were followed for an expedited review and submitted using the Biomedical Research and Assurance Network (BRAAN2) electronic system. 
Approval was received from the University of Louisville to proceed with data collection September 7, 2012.

Kentucky Community and Technical College System. BSCTC, HCTC, and SKCTC are part of the Kentucky Community and Technical College System (KCTCS). Approval for research was obtained from the KCTCS Human Subjects Review Board (HSRB). Expedited review was requested as the protocol involves a normal population of subjects that will be exposed to no more than minimal risk (Kentucky Community and Technical College System, 2006). The procedures outlined by KCTCS policy were followed: the non-exempt application form (Request for Expedited or Full Review) was completed; the approval signatures of each college Chief Executive Officer (CEO) were obtained; and the application form was submitted to the System Chancellor as required in policy (Kentucky Community and Technical College System, 2006). The approval from the IRB at UL was submitted with the application. Approval to proceed with data collection was received from the System Chancellor's office October 1, 2012.

Morehead State University. According to Morehead State University (2012a) article 3.5 “Accepting Review of another IRB” of MSU's Index of Standard Operating Procedures (SOP), MSU will accept another institution's IRB review. The approving institution must be HRPP accredited and the approval must be submitted with the MSU IRB Application. The application and approval from the IRB at UL was submitted to MSU's IRB. Approval was received from MSU to proceed with data collection October $22,2012$.

\section{Data Collection}

Candidates for the study were selected using a demographic questionnaire and 
survey. Students attending general education classes at BSCTC, HCTC, SKCTC, and MSU were administered a demographic questionnaire attached to a survey containing the selected Fennema-Sherman attitude scales. The demographic questionnaire and survey took eight to ten minutes for students to complete. The consent statement was attached to the demographic questionnaire and survey. These were read aloud each time it was distributed to students. The researcher reviewed demographic information request and read the instructions for the survey. The questionnaire collected demographic information to determine gender and whether the undergraduate student was from a rural Central Appalachian area. The researcher coded the survey using the guidelines specified in the analysis section. The researcher also chose female students from rural Central Appalachian areas as determined by the previously given guidelines and who scored either high or low on the chosen dimensions for a follow up interview. Scoring higher indicated a more positive attitude (Fennema \& Sherman, 1976b). Attempts to interview the 20 highest scoring students and 20 lowest scoring students first with the goal of interviewing at least 15 in each group were made. The researcher attempted interviews with additional students as needed until at least 15 positive mathematics attitude students and 15 negative mathematics attitude students were interviewed. Interview candidates came from a pool of subjects who were more than one standard deviation away from the mean. The interviews provided opportunities for a description of the influences on the females' decisions to pursue or not pursue a mathematics-related degree.

Demographic questionnaire and survey. In order to maintain confidentiality and avoid bias, the researcher marked all pages of the demographic questionnaire and survey instrument with a four-digit code. The first page of the instrument contained 
identifiable information including name, home address, home telephone number, cell number, year in college, gender, age, high school attended, and location of high school including county and state. The first sheet was separated from the rest of the survey upon the student's completion of the instrument. The first sheet with the identifiable information was placed in an envelope that was then sealed and stored separately from the rest of the instrument. The sheets with identifiable information were given to an outside reviewer for storage until needed. The demographic questionnaire and survey can be found in Appendix D.

Information from the survey instrument was entered into a Microsoft Excel spreadsheet and a total score for each survey was calculated. (See the Analysis section for more detail of the scoring process.) Survey results were ranked from lowest to highest and identified by the four-digit code preprinted on the survey instrument. The ranked list was given to the outside reviewer who cross referenced the codes with the identifiable demographic information. Since the research question focuses on rural Central Appalachian females, the reviewer provided contact information of females who only lived in or graduated from high schools located in rural Central Appalachian areas. To avoid identifying students who had positive or negative attitudes in mathematics, the outside reviewer released the contact information in a random order for the rural central Appalachian females ranking as the highest 20 and lowest 20 with the goal of securing an interview with at least 15 from each category.

Interviews. The 40 females were contacted by telephone. They had the opportunity to decline an interview or stop the interview at any time. The interviews occurred via telephone. Individuals who could not be contacted or interviewed were 
reported to the outside reviewer and contact information for another student was released as a replacement. The interviewer was employed at one of the educational institutions involved in the study. In order to avoid bias, current students attending on-campus classes taught by the interviewer were not invited to participate. The outside reviewer released contact information for additional students as needed without revealing their ranking. Thirty-seven students were interviewed. Interviews lasted between 4.5 and 12.5 minutes and were audio recorded with permission from the interviewee. After the interviews were conducted, the reviewer verified that at least fifteen students from each category (positive or negative) were interviewed. To reduce bias while collecting and analyzing the data, the researcher did not know the ranking of any individual interviewed at the time of the interview, as well as during the coding process of the interview transcripts.

\section{Analysis}

This study attempted to address the research question: What factors, contributing to self-efficacy, do rural central Appalachian undergraduate females believe influence their decisions to pursue or not pursue majors and careers in mathematics-related fields? A demographic questionnaire, survey, and interviews were used to investigate the factors that undergraduate females from rural central Appalachian areas believe influence their decisions. The analysis of the survey data and interview data are discussed in this section. An a priori list of master codes and subcodes used for interview coding can be found in Appendix F.

Survey and demographic questionnaire. The survey incorporated the Confidence in Learning Mathematics Scale and the Effectance Motivation Scale in 
Mathematics of the Fennema-Sherman Mathematics Attitude Scales. These scales were used to rank the females responding to the survey from lowest to highest in mathematics attitude. Each scale had 6 positively worded items and 6 negatively worded items (Fennema \& Sherman, 1976b). Each item on the scales included choices strongly agree, agree, undecided, disagree, and strongly disagree. For coding, each positively worded item was assigned a point scale as follows: strongly agree $=5$; agree $=4$; undecided $=3$; disagree $=2$; and strongly disagree $=1$. Negatively worded items were reverse coded and therefore assigned a point scale as follows: strongly agree $=1$; agree $=2$; undecided $=3$; disagree $=4$; and strongly disagree $=5$. The total for each of the respondents was calculated and ranked. A more positive attitude reflected a higher score (Fennema \& Sherman, 1976b).

The surveys were analyzed using a Microsoft Office Excel spreadsheet. Headings included Four-Digit Code Identifier, Gender, Age, County, Rural, S1, S2, S3,...S22, S23, S24, and Total. The information from the questionnaire and each survey was entered in the spreadsheet. The totals were calculated using the spreadsheet, and surveys were then ranked from lowest to highest.

The information from the demographic questionnaire allowed the external reviewer to identify the four-digit codes of students who were female and from rural Central Appalachian areas. The contact information for the rural Central Appalachian female students who achieved the twenty highest scores (indicating a positive attitude toward mathematics) and those with the lowest twenty scores (indicating a negative attitude toward mathematics) were released by the outside reviewer to the researcher in a 
random order with the goal of securing an interview with fifteen females from each ranking.

Interviews. Interviews were transcribed, reviewed by the researcher, and coded. Patton (2002) suggested that verbatim transcripts provide raw data that will be essential for a qualitative analysis. He also suggested that the researcher both analyze the data and transcribe the interviews, or at least review the transcripts by listening to the recordings while reading. Although Miles and Huberman (1984) indicate that codes can be created at different times during analysis, they recommend creating a list of codes before beginning fieldwork. Following their recommendation, a set of master codes were derived from the four contributors to self-efficacy prior to the study. The master codes were: mastery experience (ME); vicarious experience (VE); social/verbal persuasions (VP); and physiological and affective states (PS). Subcodes under each of these master codes were also listed. Miles and Huberman (1984) indicated that codes can change or develop as the fieldwork progresses. Keeping this in mind, I added a small number of subcodes for this study as the analysis progressed. For a complete listing of a priori codes see Appendix F.

Enactive mastery experience includes the interviewees' actual successes or failures with mathematics-related tasks. Success included accomplishing a task, solving a mathematics problem, achieving a passing grade, scoring well on a test, completing a classroom activity, and other similar tasks. Failures included not accomplishing a task or solving a mathematics problem, receiving low grades or scoring low on a test, and not completing a classroom activity. With this in mind, I used the following categories to be 
subcodes under enactive mastery experiences: effort, management, struggles, successful activities, failed activities, high grades, low grades, high test scores, and low test scores. Vicarious experiences included the mathematical successes or failures of the interviewees' role models and peers. Observations of someone else doing well on a task were included in this category. The following were used as subcodes under vicarious experiences: male role models, female role models, male peers, female peers, peer success, peer failure, female relative (which includes mother, sister, aunt, grandmother, etc.), and male relative (which includes father, brother, uncle, grandfather, etc.).

Verbal persuasions included encouraging and discouraging remarks of others, such as teacher feedback and parental encouragement. Verbal persuasions could be negative as well. This category also included social influences such as stereotypes. The following were used as subcodes under the category of verbal persuasions: male relative support (including father, brother, uncle, grandfather, etc.), female relative support (including mother, sister, aunt, grandmother, etc.), male teacher support, female teacher support, ability beliefs, positive mathematics childhood experiences, negative mathematics childhood experiences, positive mathematics home environment, negative mathematics home environment, positive mathematics classroom environment, and negative mathematics classroom environment.

Physiological and affective states include the interviewees' physical and emotional reactions, such as anxiety or lack of anxiety, that result when encountering mathematics-related tasks. Physical reactions such as sweating and rapid heartbeat may be including in this category. The following were used as subcodes under the category of physiological and affective states: avoidance, self-worth protection, anxiety, stress, 
nervous, distress, and other physical reactions related to mathematics instructional situations.

The interviews were coded by hand using the margins for marking codes and remarks as suggested by Miles and Huberman (1984). They suggested that doublecoding be used to increase reliability. Even using double-coding for the same transcript for a single researcher can be useful. With this in mind, three transcripts were doublecoded to increase reliability. Once the interviews were coded, they were dissected, placed in a matrix for the appropriate negative attitude or positive attitude category, and reviewed for themes and patterns. The findings are reported under the overarching headings of enactive mastery experience, vicarious experiences, social/verbal persuasions, and physiological and affective states. Additionally, the careers and majors of interviewees, as well as findings for mathematics opportunities in rural areas, were reported.

As suggested by Miles and Huberman (1984), a display was used to assist in organizing data for analyses. Direct quotations were entered into the matrix cells. The matrix contained column headings of enactive mastery experience, vicarious experience, social/verbal persuasions, physiological and affective states, rural, and career and/or major. The information falling under each column heading was subdivided as needed to reflect subcode categories. For example, the enactive mastery experience column contained a separate section for effort, as well as a section for grades. Clustering under subcodes was necessary for analysis. The columns were examined for patterns, and occurrences were counted. 
Using the information gathered in the matrix, the researcher summarized findings under enactive mastery experience, vicarious experiences, social/verbal persuasions, physiological and affective states, rural, and career/major. She developed a narrative from the information gathered describing the findings of the study and presented in the following chapter. Patterns and occurrences are discussed along with the factors that the rural central Appalachian undergraduate females identify as influencing their decisions toward mathematics. 


\section{CHAPTER IV}

\section{RESULTS}

This chapter presents the findings of the study. First, the sample that resulted from data collection at three community and technical colleges and one university is described. Second, the data that resulted from the surveys are discussed. Third, the interviews are described. Finally, findings identified as a result of the analysis are presented.

\section{Sample}

Survey and demographic questionnaire data were collected during the fall semester months of October and November 2012 at three two-year community and technical colleges and at one four-year university in Kentucky. Undergraduate students completed the survey in one of their general education classes. The study included 648

undergraduate students from the following education institutions: Big Sandy Community and Technical College, $n=428$; Hazard Community and Technical College, $n=70$; Southeast Kentucky Community and Technical College, $n=20$; and Morehead State University, $n=130$. Students completed a demographic questionnaire and two subscales of the Fennema-Sherman Mathematics Attitude Scales: the Confidence in Learning Mathematics Scale and the Effectance Motivation Scale. Subjects were eliminated from the study if a survey response item was left blank; $n=40$. Additionally, because dual credit enrollment is allowed at some institutions, subjects were eliminated if their age 
could not be verified as being at least 18 years of age; $n=12$. A sample size of 596 subjects that included 360 females and 236 males comprised the sample. The subjects' ages ranged from 18 to 65 with a mean age of 21.6 .

Information from the demographic questionnaire, along the classification of Appalachia by the ARC and level of rural as classified by the ERS, was used to determine the locale and rurality for each subject. Counties located in Central Appalachia and classified as codes 9, 8, 7, or 6 by the ERS are classified as rural Central Appalachia. Other counties classified as part of Appalachia by the ARC and Central Appalachian counties that do not fall under the codes of 9, 8, 7, or 6 by the ERS are considered Other Appalachia. All other counties are considered as non-Appalachia. Subjects reported location of high school attended, including county and state, on the demographic questionnaire. The county and state were cross-referenced with the listing for rural Central Appalachia and Appalachia. The classifications rural Central Appalachia, other Appalachia, and non-Appalachia, along with gender, were entered into a Microsoft Office Excel spreadsheet for each subject. The number of subjects in each category is shown in Table 2. Rural Central Appalachia male ages ranged from 18 to 44 with a mean age of 20.4. Rural Central Appalachia female ages ranged from 18 to 65 with a mean age of 22.6. 
Table 2

Number of Subjects Classified by Location

$\begin{array}{lll}\text { Location } & \text { Males } & \text { Females }\end{array}$

199

295

Other Appalachia

10

14

Non-Appalachia

27

51

\section{Survey Analysis}

The survey included of two Fennema-Sherman Mathematics Attitude Scales: the Confidence in Learning Mathematics and the Effectance Motivation Scale in Mathematics. Each scale had of six positively worded and six negatively worded items that were randomly located in the survey instrument. Subjects marked the Likert-type scale according to their level or agreement or disagreement with each item statement. The survey items were coded following directions provided by the authors of the scale. Each positively worded item was awarded a point scale as follows: strongly agree $=5$, agree $=4$, undecided $=3$, disagree $=2$, and strongly disagree $=1$. Negatively worded items were reverse coded and awarded a point scale as follows: strongly agree $=1$, agree $=2$, undecided $=3$, disagree $=4$, and strongly disagree $=5$. Ten surveys were scored a second time to verify accuracy. Responses for each item were recorded in the Excel spreadsheet. Entries in the spreadsheet of 10 additional surveys were verified for accuracy. An overall Cronbach's alpha of .9195 was found on the two combined subscales of the Fennema-Sherman instrument. A value of .876 was found for the 
Confidence in Learning Mathematics Scale and a value of .834 was found for the Effectance Motivation Scale in Mathematics.

Subjects' total scores were calculated and ranked (see Table 3). A higher score indicates a more positive attitude (Fennema \& Sherman, 1976b). Scores for all male and female subjects together ranged from 31 to 120 (120 being the highest possible score) with a mean score of 75.5 and a standard deviation of 20.6. Scores for rural Central Appalachian males ranged from 32 to 120 with a mean of 76.9 and a standard deviation of 20.9. Scores for rural Central Appalachian females ranged from 31 to 120 with a mean of 73.4 and a standard deviation of 20.4. Cohen's d was calculated for the rural Central Appalachian males and rural Central Appalachian females. An effect size of 0.17 was found indicating a small effect.

Table 3

Statistics of Total Scores

\begin{tabular}{llll}
\hline & Range & Mean & $\begin{array}{l}\text { Standard } \\
\text { Deviation }\end{array}$ \\
\hline All Subjects & 31 to 120 & 75.5 & 20.6 \\
Rural Central Appalachian Males & 32 to 120 & 76.9 & 20.9 \\
Rural Central Appalachian Females & 31 to 120 & 73.4 & 20.4 \\
\hline
\end{tabular}

The four-digit identification codes for the 20 rural Central Appalachian females scoring the highest (indicating a positive attitude toward mathematics) and the 20 scoring the lowest (indicating a negative attitude toward mathematics) were released to the outside reviewer. The outside reviewer released the name and contact information in a random 
order. Subjects were replaced as necessary. The pool of scores for students interviewed in the negative mathematics attitude category ranged from 31 to 47 , which fell more than one standard deviation from the mean. The pool of scores for the positive mathematics attitude category ranged from 98 to 120 which fell more than one standard deviation from the mean.

\section{Interviews}

Interviews were conducted during January and February of 2013. Subjects from whom an interview was requested were contacted by telephone. The researcher reported to the outside reviewer if the phone number provided was not working or the subject did not want to be interviewed. The researcher also reported to the outside reviewer if, after several attempts, the subject could not be contacted using the number provided. Additionally, some subjects did not provide telephone contact information on the questionnaire. Additional names and contact information were released in a random order as necessary. A total of 32 names were released for the subjects scoring in the negative attitude category and 35 names for the subjects scoring in the positive attitude category. A total of 37 subjects were interviewed with 15 falling in the negative category and 22 falling in the positive category. The ages of the students interviewed ranged from 18 to 43 with the negative attitude category having a mean age of 25.6 years and the positive attitude category having a mean age of 25.3 years.

Interviews were conducted by telephone. Students were interviewed when initial contact was made with the student. This may have contributed to some restrictions on the interviewees responses to questions. Interviews lasted between 4.5 and 12.5 minutes with a mean interview time of approximately 7.5 minutes. Interviews with students in the 
negative attitude category had a mean interview time of approximately 6.5 minutes while interviews with the subjects in the positive attitude category had a mean interview time of approximately 8 minutes.

Thirty-six interviews were recorded. An error with the recorder prevented one interview from being recorded in its entirety. Subject responses to the interview questions were transcribed verbatim and coded by hand using the master codes derived from the four self-efficacy contributors of mastery experience, vicarious experience, social/verbal persuasions, and physiological and affective states as described by Bandura (1997). Subcodes for each master code were also used. Three transcripts were coded an additional time with accuracy of 80 percent, 89 percent, and 90 percent. After all coding was completed; the researcher then sorted the interviews by category of negative attitude and positive attitude as released by the outside reviewer. Each interview in the negative attitude category was analyzed, without reference to the hand coded documents, and placed in a matrix with headings of Mastery Experience, Vicarious Experience, Social/Verbal persuasions, Physiological and Affective States, Rural, and Career/Major. Direct quotes were placed in subheadings as needed. Interviews in the positive attitude category were placed in a matrix in a similar manner. For ease of comparison, all interviews were color coded before placing the direct quotes into the matrix. All hand coded interviews were then compared with the matrix to ensure that quotes were placed under the appropriate headings and subheadings.

\section{Mathematics Self-Efficacy Findings}

A person's efficacy will determine if she pursues an activity, the strength of her determination, and if she continues when faced with difficulty (Bandura, 1997). Four 
contributors of self-efficacy will be discussed in this section. Enactive mastery experiences, including effort, activities, and grades will also be discussed. Findings from the interviews related to vicarious experiences will then be presented. Next social/verbal persuasions that include ability beliefs, support, and environment will be discussed. Finally, physiological and affective states, including avoidance and physical reactions, will be discussed.

Enactive mastery experiences. According to Bandura (1997), enactive mastery experiences are very influential on self-efficacy because these experiences provide proof that a person can be successful. Five subcategories of enactive mastery experiences will be detailed. They include effort, activities and struggles, performance, grades and testing, and mathematics outside of school.

Effort. Eleven of the 15 students in the negative attitude category stated that they put forth much effort to learn mathematics. Six students indicated that they took copious notes in mathematics class. One student said, "I try to write down, you know, everything I can, whatever the teacher, instructor would say." Another said, "I do take a lot of notes." She went on to say, "[I] write down a lot of examples just because that seems to help me a little bit if I can see a similar problem to it." When asked about her grades in mathematics, one student said, "no matter how much I study or try, it seems like just a C is the best that I can get." Another student felt that she had to spend more time with mathematics than any other subject. A third student spoke of struggling with mathematics by stating 'I'm not saying that I didn't work on it and eventually get there with it and did fine, but it's not my strong point." A fourth student said she tries, "but I usually don't understand it [mathematics]." Four students admitted to doing only the 
basic amount homework or enough practice to make it through the course with a passing grade. One student, speaking of homework assignments, said, "I'm bad to put it off, wait till the last minute, $[\mathrm{I}]$ don't really like to, you know, spend a lot of time on it." When asked about tests, one student said she expected to fail but admitted, "I don't really study much for them either so that could be part of the reason."

Six of the 22 students in the positive attitude category stated that they did not have to study in their mathematics courses or for mathematics tests. However, these students talked about listening in class, taking notes, reading the textbook and working problems. One student said that she does not "really have to study" but went on to say that she would "be the one paying attention" in class. When asked about homework assignments, she said, "It's the first thing I do. I come straight home and do it." Another student said, "Math is something that I don't usually have to study for." When addressing the issue of homework assignments, she said, "The more the merrier, great, homework. I like to do math." Sixteen of the 22 students in this group were aware of their efforts to learn mathematics. Note-taking was mentioned 11 times while working practice problems and example problems was mentioned 21 times. One student said, "I always take notes, whatever the teacher writes on the board I always write down. If they say anything very important, I will always highlight it.” Another student mentioned keeping her mathematics work from all of her classes together to keep organized. Three students talked about working to make sure they understood formulas. One said, "I like to make little note cards with the formulas and things like that." Another student said that she tries to keep information "fresh." She said, "I go back over and check it, you know, check to see if I still remember formulas and stuff like that." Five students said 
they put forth effort to listen and pay attention in class. A student said, "I follow him, you know, listen to what he says, work problems in class, try to get them done before he, you know, shows how they're done on the board." Two students mentioned that, if they felt they needed it, they would ask for help. Only one student in this group stated that, if she had to work by herself and did not understand, she would quit working on it. She said, "I like to go and work with my classmates or the teachers over these problems. That way, I can get it right.”

Activities and struggles. The 15 students in the negative attitude category mentioned participating in positive and negative activities related to mathematics. Excluding the discussion of grades, these 15 students mentioned positive experiences with mathematics at least 25 times while they spoke of negative experiences at least 28 times. Thirteen of the 15 students mentioned successes with activities. Three spoke of handling money. One student said, "I like to count money and shop and budget things, save money." Three students spoke of working with measurements. A student said, "We do a lot of work on our own, have to remodel and build stuff." Another student employed in health care said she likes to "figure out what dose a child will get of medication." She also spoke of calculating "the antibiotic that they'll get in an injection." Five students had a successful experience with a geometry class. One student said, "I did really good in geometry" while another believed that "it was really easy." While speaking of her geometry class, a student said, "It dealt with a lot of shapes and stuff like that. It seems like I could do that better." Algebra held positive experiences for three students. One student spoke of her high school algebra class. She said, "The teacher made it interesting, and it actually helped me a lot. And I actually understood it." The 
developmental mathematics classes offered by the college helped three students' understanding. One student spoke highly of the developmental sequence of classes at the college level, "I learned a lot more in her class than I did in high school."

The 15 students in the negative category also talked about negative activities and struggles. A student talked about failing algebra twice in college and deciding to start at the beginning of the college's developmental sequence of mathematics classes. One student's negative experiences in mathematics learning came in elementary school when she struggled. She said, "She knew that I was struggling really hard with it, and she just told me to stop trying so hard and just start using a calculator." She started relying heavily on a calculator after that experience. When this same student was taking an algebra class in high school for the second time her teacher told her he was giving her a D-. She said, "[He] told me that the only reason that he was passing me was just so I could be out of his class." Six other students talked about struggling to understand the mathematics. One student said she has "a hard time comprehending" while another said "it took me a while...I'd have to do a few problems before I could really show that I understood the concept." A third student stated "math's a really hard subject for me."

The 22 students in the positive attitude category mentioned positive experiences at least 36 times while negative experiences were mentioned four times. One student spoke of participating in mathematics competitions as part of a team. She said, "I was a member of the Math Bowl and we traveled from, you know, from school to school competing." She also spoke of her teacher, who also worked with the team, always having activities for the class to complete to increase learning. She said, "She made things fun. She helped them make sense with her method of teaching, you know, with 
hands-on stuff." Another student spoke of learning things in a college developmental algebra class that she had not seen before in her high school mathematics classes. She said, "It was pretty neat." Another student spoke about how easy success in mathematics came to her. She said, "I’ve always enjoyed mathematics. It just makes sense to me I guess. I never really had to study much. It's just math is something that comes quick with my brain. I usually just look at the material once, maybe twice, and I can apply it and remember it."

Three of the 22 students in the positive mathematics attitude category mentioned negative experiences a total of four times. One student spoke of feeling confident in her mathematics skills when she began college only to realize that she did not know as much as she felt she should have. She also mentioned that she should have tested higher in mathematics on her college entrance exam because she had received good mathematics grades in school. Another student mentioned that, although she was a good mathematics student, she had "a hard time with trig." A third student talked about being "a little iffy" when it came to "reading problems."

Performance. Students were asked under what conditions that they performed well in mathematics. Six of the 15 students in the negative attitude category indicated they performed better if they received one-on-one assistance. One said, "they have to show me that it's right, and if it's not right, they have to point out what I did wrong and what steps I took wrong and where I went wrong from there.” Another student based good performance on "coming to class every day, with good attendance, and with a helping teacher." Another student indicated that she needed situations without distractions. She said, "I perform well when there's no loud thing, no loud people in the 
class and its quiet, and no distractions." Another student said in order to perform well, "I probably need to be put more in the front of the room so I can pay more attention during math class." One student indicated that she would learn better by herself working on a computer. She said, "I'm the type of person that would like to be to myself and kind of learn from the computer. And, I had computer math last semester, and it felt like I could learn better with that than having class discussion about it."

Three students in the negative mathematics attitude group indicated that they did not perform well under any conditions. A student said, "I try to avoid it as much as I can." When one student was asked to describe conditions where she performs well, her response was simply, "None at all." When asked for conditions she performs less well, she responded, "Everything. I'm just not good with math period." Three students indicated that they perform less well if they are in situations that require discussion or other students viewing their work such as group activities or public board work. When asked for conditions in which she would perform less well, one student said, "If I'm in a bigger crowd, especially whenever it comes to tests in math and things like that. I don't feel like I can do my work, especially like, if we are having class discussions and you have to go up to the board and answer things. I'm so like totally not comfortable with that." Another said, "Actually having to go up on the board in front of the class and trying to work out something." Four students indicated that they would not do well in timed situations such as testing. When asked for a situation she would perform less well, a student said, "On a test, whenever it's pressured." In response to the same question, another said, "Timed math problems." One student listed an internet class as a situation 
where she would perform less well. She indicated she would not perform well in a distance learning class because "there's no teacher to help me."

When asked under what circumstances they would perform well, seven students in the positive attitude category indicated that they could learn well under any conditions. When asked for conditions she would perform well, one student replied, "Any conditions, it doesn't really matter. If I'm stressed or if I'm aggravated or under pressure I still do good." Another student replied, “Any condition really. I don’t really have a problem with it. There's no pressure as far as tests and things like that. If you're ready, you're ready." One student stated she would perform well under any condition and said, "Let's say you have to go up and perform a homework problem in front of the class. I'm fine with that because I'm very confident of my skills in math." She went on to say, "If it's math, I feel like I can perform any task under any situation very well."

Three students expressed the need to be able to ask questions and three students wanted detailed examples given. One student, when asked for a situation when she would perform well, said, "When examples are given on the board and everything is gone through and I understand everything and we can come back in and ask questions about problems we had on the homework." Another student responded that she would be able to understand the mathematics "pretty good" if she had someone to "go through it in detail at least once or twice."

Five students indicated they would prefer a relaxed environment without pressure or time constraints. When asked for a situation when she would perform well, one student said, "Not under pressure or time [constraints]." She went on to say, "I go blank. If they're going to put a time frame on me I go completely blank. I need for it to be more 
of a relaxed setting." An additional student talked about needing to be required to work quickly to perform well. She has discovered if she has time to think too long about how to solve mathematics problems, she will change her answers from correct to incorrect. She said, "I can think of other ways to do it and usually it's the wrong way to do it." Seven students in the positive attitude category indicated that stressful situations would cause a lower performance. A student said, "I do better if I'm not stressed out over thinking about other things that I have to do or need to get done." When asked for a situation when she would perform less well on mathematics, one student said, "Probably stressful, if I had a real short time frame to do something." Another student said, "I do well on tests, [I do] well on tests that are not timed. I do very bad on timed tests because I feel a lot of pressure, but as long as I have as much time as I need, I'm really fine with tests."

Five students mentioned distractions such as talking and noise would lower performance. One student said, "It has to be quiet where I can be able to focus and be able to concentrate." Another student said, "I guess if it's really quiet in the room and I can just really focus on the material and listen to everything and concentrate." One student spoke of a noisy classroom being distracting. She said, 'It's hard for me to grasp what they are trying to teach because I feel like there is too much going on around me in the classroom." One student indicated lack of study time as a situation when lower performance would be expected. She said she does not do as well, "when I don't have a lot of time to study with work and school going on at the same time." She also said that, when the teacher explains poorly, "I'm kind of left wondering what I should do." One student indicated that working alone would be difficult for her. She said, "My worst is 
actually having to go off by myself and try to work through math problems." When asked for a situation in which she performs less well, one student said, "If it was any subject other than math, I could answer it."

Grades and testing. Only three of the 15 students in the negative mathematics attitude category mentioned getting a grade of $\mathrm{A}$ in mathematics classes. One student said, "As of right now I have an A [in my developmental mathematics course], but I'm not taking any college math." Two were in the A and B range, but one student admitted that her grades "started going downhill" when she began college mathematics classes. Another student said, 'I've always done good just because I've tried hard. Like I've always got A's in high school and grade school, then I got a B in College Algebra." One student reported receiving $\mathrm{B}$ grades while four said they were in the $\mathrm{B}$ to $\mathrm{C}$ range. $\mathrm{A}$ student said, "In math, usually I'm about a B minus/C plus student." Three students were in the $\mathrm{C}$ grade range, but one mentioned having failed mathematics classes. One student said, "I've not taken a math class in college yet, but in high school, I got like Cs except for in geometry." Another student said she usually gets $\mathrm{C}$ grades in mathematics. She said, "I can't pull anything stronger. No matter how much I study or try, it seems like just a $\mathrm{C}$ is the best that I can get [in mathematics classes]." Two reported being in the C to $\mathrm{D}$ grade range in their mathematics classes. One student said her mathematics grades were 'bad ones, like C's and D's or like incompletes in college because I have not finished my math course." Another student felt she did well in high school, but when she started college mathematics classes, she "didn't do too well." A different student only rated her grades as "good." 
Twelve out of the 22 students in the positive attitude category indicated they received grades of A in mathematics classes. One student said, "I always got straight A's in math, and I'm doing really good still." Another student said, "Every math class I took in high school was an A, and I've taken Calculus so far in college. That was an A too." Eight received both A and B grades. Two had only received one B grade, and the rest of their mathematics grades were A. One student said, 'I've got A's and B's in the classes I took in college." Another student said, "Usually I get A's, but usually A's or B's in math. But I generally do pretty good, unless I get an online course.” One student said, "I'm a B student." She went on to say, "Math's not very hard for me. I mean, it's fairly easy." Another student indicated that she had gotten an A+ in her math class at the college the previous semester, but she rated herself as a "B average" all through school. One student, when asked about her grades, said she had received "A's throughout grade school and B's and C's throughout high school." She went on to say, "I had two premath classes in college, and I made a B in one, a C in one, and then I made an A in the college algebra and that was my last course." Interestingly, four students in the positive attitude category reported having to take one or two mathematics classes to prepare for a college algebra course. One student expressed dissatisfaction of her mathematics education prior to entering college by saying, "I felt pretty confident, you know, in my math skills, but when I started college, I realized that there are a lot of things that I should have known that I didn't." This student also pointed out that, with the grades that she received through school, she should have tested higher on her college entrance exam.

Mathematics outside of school. Students from the negative mathematics attitude category had difficulty remembering where they had applied mathematics to real-world 
situations. Seven out of the 15 students interviewed indicated that they did not do anything related to mathematics outside of school or could not think of anything. One student said, "That's tough, not too sure, not much." Another student said, "I don't really. I try to avoid math as much as I can." A third student said, "Nothing really." Three students recognized that they use mathematics when working with money. One works as a teller at a bank and said that "math skills come in handy there." Another student enjoys counting money and tries to "budget things" and "save money." Another student indicated that she likes music. She said, "Music involves math if you think about it, you know. You have to count the beats and everything." Three students indicated that they use measurements. Two of the three described the use of measurements for projects dealing with home improvements such as remodeling, building, measuring rooms, and drawing plans. When asked about things she does related to mathematics outside of school, one student said, "Do-it-yourself stuff at home." A third student spoke about calculating the amount of a dose of medicine for a child.

Only one student in the positive attitude category indicated that she was unaware of activities outside of school dealing with mathematics. She said, "Probably nothing to be quite honest, other than homework." She went on to say, "That's my time away from it." Using mathematics in everyday life was mentioned by several students. One student said, "I actually enjoy the times when I run into it in everyday life. It makes it kind of cool that I can remember how to do it and I see where math from the classroom comes in with math in real life." Five students indicated that they used mathematics in their workplace. One said, "I work in a doctor's office so, I like to learn a lot about, like, dosage calculations." Another student said, "Every once in a while I will just actually 
practice my math skills while I'm at work 'cause I'm a cashier. Or, if I see a similar problem that I had during my math class, I'll actually do it, you know, 'cause I understand it a lot better now." Two students mentioned game activities such as "math game apps" and "Sudoku." One said, "I play cool math games on the internet." Another student said, 'I've gotten on websites when I'm bored and I've taken a couple of quizzes just because I'm bored." A different student said, "I get on the internet sometimes and just find math sheets or, you know, algebra problems or whatever and work them." She also mentioned, "I like to help my girls with their homework."

Five students talked about teaching their children or helping them with mathematics homework. One said, "I love helping my kids with math because it is just so interesting to me." Another student talked about helping her daughters, "I'm teaching my girls to do math. They're two and three and they're actually starting to add numbers now." One student spoke of teaching her two-year-old son to count, and she also said her fiancé "is in the lower math class at the college and I help him out, too." Four students talked about helping adults with mathematics homework. One student said, "I'm tutoring several students right now that are disabled, with math. I enjoy trying to explain it cause I like doing math, and I try to help others who don't love math as much as me. I try to get them to understand why we have to do certain equations and how it works so hopefully they can understand and like math more themselves." One student likes sewing and quilting, recognizing the need for mathematics in her activities. She said, "you have to know a lot of different math to get the dimensions right." Two students mentioned shopping and using mathematics to determine a good purchase. One said, "I total up the prices and see about getting bargain sales.” 
Vicarious experiences. Self-efficacy beliefs can be influenced by the experiences of others (Bandura, 1997). If someone is not sure of her own capabilities to perform a task, she may rely on the experiences of models (Bandura, 1997). Models provide a standard to compare, and people actively look for models that have the qualities they desire (Bandura, 1997). Vicarious experiences, including role models, parents, and peers, will be discussed in this section.

Role models. Relatives other than parents were mentioned by five students in the negative mathematics attitude category as doing something that involves mathematics. One student said, "My aunt is a tax preparer. I don't know if that counts or not." Another listed one of her aunts as a teacher and another as an accountant. Another student mentioned a brother-in-law as having a job that uses mathematics. She said, "The only thing that I can think of would be that my brother-in-law used to scale land and stuff." One student said, "My grandmother is a loan officer right now, so I can remember times when she would help me with math. My parents aren't very good at math so they don't have much to do with it." Another student said, "My grandparents are both really good at math, pretty much everybody in my family is." However, she was not able to identify their occupations as ones that used mathematics.

Eleven students in the positive mathematics attitude category spoke of others in their lives, besides their parents, that used mathematics. One student spoke of a special teacher. She said, "She was actually the one that, I think, inspired me as far as math goes." Five students spoke of their siblings. One student said, "My brother works at Lowe's. I'm not sure; he probably has to have some mathematics knowledge to help people build things." Another said, "Let's see the only thing that pops up is my brother, 
that's current though. He, well, he lives away from home. He's got a good job that pertains to a lot of math, mathematics and stuff." An additional student said, "My sister's a doctor, so that, I would imagine, that would include a lot of math." Another said, "My sister's not very good in math at all, but my brother... he is like a math genius. He is better than I am at math." One student spoke of her spouse saying, "My husband used to be a welder. I know there's a lot of math with that." Two students spoke of their aunts. One said, "My aunt is an RN. She went on to say, "I know the RNs use math for the dosages and all that." Another said, "I have an aunt and a cousin that work at the bank." Two students spoke of their grandfathers. One said, "He does, like the reading of the maps and finding out how far things are, and he'll go and do the deed work, and he has to find out how many years in between stuff. He's constantly using math and geometry. And he also is a carpenter, so he's always using the geometry aspect of that to be able to cut like the perfect shape. So honestly my grandpa is pretty much the one that has based me around math."

Parents. Three students in the negative attitude category listed their mother's occupation as dealing with money. One student said that her mother worked in the "billing department" at her work. Another said, "My mom ran a cash register." A third student said, "My mom sells Avon, and that would involve money, and money involves math." Two students said their mothers were teachers. One said, "My mom was a K-8 teacher." The other said, "My mom's a teacher. She teaches elementary. She used to teach math." One student talked about her mother helping her learn to count money as a child, but that was the only mathematical interaction with her parent. Another student said, "My mom's good at math and can do just about anything." 
Three students in the negative mathematics attitude category mentioned their father's occupation. One student said, "My dad taught science in high school." Another said, "My dad works on vehicles so, I mean, he uses I'm sure some kind of math." The third student said, "My dad's an electrician. I don't know if math had anything to do with that."

Students in the positive attitude category spoke of their parents using mathematics in their occupations. Ten students were able to identify with their mothers using mathematics. Many had mothers that worked as nurses. One student said, "My mom was a nurse so she's done dosage and that kind of stuff." Another student said, "My mom's job--she's a nurse in the ER. She sometimes has to do the dividing and all the problems that go into that so that she can actually give the right dosage to patients." A third student said, "My mom's been a nurse for about fifteen years now." She went on to say, "She's always constantly doing the equations that she needs to get medicine right." One said, "My mom, she works in pharmacy, so she would definitely have to know milligrams and prescriptions and how much of everything that someone needs to make sure they don't get overdoses." A student spoke of her mother having calculated "her mileage and stuff like that." One student said, "My mom works at the social security office so she, you know, has to deal with numbers and figuring stuff out and everything like that too." Another said, "My mom, she works at the food stamp office so she's always having to calculate like different types of income and, you know, medical stuff." An additional student spoke of her mother working for a tax preparation company. She said, "She has a lot of involvement with math there; she was always doing taxes." 
Another student said, "My mother is a cosmetology instructor, so there's a lot of, you know, chemicals and things like that."

Twelve students in the positive attitude category spoke of their fathers using mathematics. One said, "My dad works for the state doing construction, and so he has to have all kinds of formulas and know how to do things to build things." A student said, "My stepdad, he's a high school science teacher, but he also does agriculture, so he helps students like rebuild lawn mowers and stuff like that." She went on to say, "[He uses] measurements and that sort. He also, he like builds bird houses so he always has to do calculations and measurements as far as building those." Another student said, "My dad, he works with math, and he has with his dad, my grandfather, since I was little." She went on to say that they use measurements when they perform "carpentry work and build things." A student said, "My dad works with like a lot of equipment and stuff, and he has to use like measurements and know different quantities and all that." Another spoke of her father using measurements, "My dad is a section foreman so he has to take measurements and stuff all the time. He's a section foreman, like in the mines. He has to take measurements all the time." One student said, "My father owns a plumbing company so there's a lot of mathematics there. A lot of blueprints, drawings, stuff like that." A student spoke of her parent's encouragement to learn math. She went on to say "My dad was a DJ at a radio station, a local radio station. He also did sales, so definitely with him, he had to make sure that all of his, quotes and stuff for prices and advertising were correct." Another said, "My father's a salesman so that includes a lot of it [mathematics]." A student identified both her father and stepfather as using mathematics in their jobs as an electrician and a supervisor in coal mines, respectively. An additional 
student spoke of her stepfather. She said, "My stepfather was an accountant." She went on to say, "He always had to use a lot of formulas and stuff like that."

Peers. Three of the 15 students in the negative mathematics attitude category identified with peers that did not excel in mathematics. One student said, "Most of my classmates were similar to me, they were very weak in math." Another student said there could have been students in her mathematics classes that understood the material "but on average, everybody was probably like me and had trouble." A third student said, "You always have your smarter classmates that go above and beyond the understanding. You also have the ones that don't understand. Those are the kind of people that I kind of grouped with that didn't really understand."

One student in the negative mathematics attitude category said she and her peers "all pretty much had the same attitude--get the work done so we wouldn't have anything to worry about when we went home." Two students spoke of peers helping them. Both mentioned copying from someone else. One student said, "They'd help me with stuff but sometimes they wouldn't know stuff either." She went on to say, "In high school sometimes we'd copy off each other."

Three students in the negative attitude category believed they were behind their peers mathematically. She said, "It seemed like everybody caught on to it and succeeded when I didn't." Another student said, “Some of them caught on when I didn't." She went on to say, "Some of them were faster than I was." An additional student said, "It didn’t seem like anyone struggled as hard as I did." Still another student said, "Some were better at it than others, and some just caught on easier." 
Four students in the positive mathematics attitude category talked about being on the same level with peers. Two of the four spoke of being in honors level mathematics classes with peers that were on the same level as they were. One student said, "I was with the honors students, and they were pretty determined as well as I was." Another said, "I usually took honors classes. I always had a lot of people in the class that were just like me, like were strong in math that actually enjoyed it." An additional student said, "In high school, I was in the top ten in my math class but we were all pretty much on the same level."

Seven students in the positive mathematics attitude category talked about peers wanting to learn and working together. One student said, "They were all good. They were all really smart. They never...I never had a math class to where people actually didn't want to try or learn. Like I always had the same mindset people like me in my classes, tried, always tried and wanted to actually figure the problems out." Another said, "We kind of worked together." A student said, "Mostly everyone in my classes wanted to learn. Everybody paid attention pretty good. There were a couple of people that goofed off a little bit, but mostly everyone wanted to get a good grade so everybody paid attention." Another student said that her mathematics classmates "seemed to do very well with it, they understood." Recalling her classmates, one student said, "They were always normally paying attention and taking notes with me." Still another student said, "They've been eager to learn and friendly." One student recalled that she and her classmates would "get into groups." She went on to say, "From whenever I even started learning math to even up till now, everybody was just trying to help each other out as classmates so we could all get the work done and understand it a lot better." Another 
student said, "We all worked to figure things out." A student said, "There was some that did not like math, and then there were others like myself that loved it." She went on to say that she would work with one of her classmates in particular. She said, "We would work together, work the problems out, share our notes." She continued to explain, "If she didn't know something, I'd share what I knew with her. She'd share what she knew with me."

One student in the positive attitude category recalled classmates in her college mathematics course "asking a lot of questions [during class]." Another student talked of her peers coming in to a certain mathematics class with problems and "ended up actually being better at it once the class was over." A student talked about her classmates in college being younger than she was and said, 'Generally, people don't like math anymore." She went on to say, "They don't like math at all, so a lot of times they are like, they want help or they want to copy or something like that." Another student talked about classmates asking for help. She said, "I was always the one to help them."

Social/verbal persuasions. Self-efficacy can be influenced by social and verbal persuasions (Bandura, 1997). The perception of self-efficacy can be influential on accomplishments. When positive verbal persuasions are genuine, an increase in efficacy beliefs can occur. Persuasions may also be indirect and still influence efficacy beliefs (Bandura, 1997). This section will discuss social/verbal persuasions including ability beliefs, support, peers, school environment, and home environment.

Ability beliefs. Twelve of the 15 students in the negative mathematics attitude category indicated they believed that they were not good with mathematics or could not learn mathematics. One student said, "I am no good with math. I can't take it worth 
anything." She also said, "I'm just not good with math period." Another student said, "I'm not very good at math at all, at all. I hate it." Five mentioned struggling with mathematics. One student said, 'I'm not the greatest. I've always struggled, and it's always been my worst subject.” Another said, "I wouldn't say my skills are very good. I've struggled with it my whole school career." One student admitted that she feels "very intimidated by math." She said, "Math is definitely my weakest link, that's for sure. I just feel very intimidated by math. It's never the teachers that intimidate me; it's just always the math itself. I'm pretty weak in math." Another student said that she is a hard worker, and she sometimes feels mathematics is difficult for her. "I believe that I have a really good, hard-working personality to do math but sometimes it's hard for me to understand particular equations and things."

All students interviewed from the positive attitude category indicated that they do well in mathematics. One student said, 'I've always liked math. I excelled at it when I was in middle school and high school and, when I decided to go back to school after my children were raised, it just seemed like a natural fit." Another student said, "Math is my best subject. I'm actually studying to be a math teacher." A third student said, "Unlike a lot of people, math is probably one of my favorite subjects." Another said, "Math was always one of my stronger subjects. I always enjoyed it. Like I always liked math much better than English or anything like that." Four students stated that they "love math." One said, 'I've always loved math. Math is probably one of my favorite subjects. I've always been pretty good at it." Another student said, "I've always loved math. I always got straight A's in math and I'm doing really good still." One student talked about being "average" in math in the past, but after taking a class with a particular instructor, she said, 
"My math skills have actually gotten better." Another student said, "As far as math is concerned, I am fairly ok with math. It's just that I don't understand as soon as I see it. I normally pick up on it." This same student, when asked about mathematics assignments said, "Honestly, I'm a little bit of a nerd. I like math assignments. So I enjoy doing them."

Support. Some students in the negative mathematics attitude category felt that they received support from teachers, but others did not. Eight of the 15 students made both negative and positive references to teachers. Out of 31 references to teachers, a specific teacher was mentioned 10 times and 21 references were made about teachers in general. Four female teachers and two male teachers were described as being helpful, supportive, or well liked. During the course of the interviews this group mentioned that teachers helped them learn mathematics 15 times. They described teachers who were available to help and made class interesting. One student said, "The only good math teacher that I had was in sixth grade, and she really took her time, I guess, to work with me one-on-one with it. She really pushed it rather than just ignoring the problem." Another student said, "He made it easy to understand." A different student, referring to her high school mathematics teacher said, "You could tell that she really understands what she's teaching, and she has a good habit of a way to teach." Another student said, "Whenever I went to high school, I finally had teachers who would help me [with mathematics] and would stay after school with me and tutor me until I understood it." Another student indicated that her high school algebra teacher was supportive. She said, "She was just so good about helping and tutoring and all that." One student had a good with a high school geometry teacher saying, "He made it easy to understand." Another 
student spoke of taking developmental mathematics courses in college. She spoke fondly of her instructor saying, "She taught me a lot. She was a really good teacher. I learned a lot more in her class than I did in high school."

Students in the negative mathematics attitude category averaged two references about teachers: one reference about supportive teachers and one reference about teachers who were not deemed as supportive. Negative references suggested a lack of support about male teachers twice and about female teachers twice. Other references were made about mathematics teachers in general. One student said, "I've not had a lot of good [mathematics] teachers." One student mentioned not feeling that she had learned much in her high school classes, "I know that through high school I didn't like any of them [mathematics teachers] really because I didn’t feel like I learned anything." Students mentioned that teachers that would assign "busy work" to keep them occupied and that they did not explain the material in a way that was interesting or understandable. One student said, "She only had one way of teaching, and it was difficult for some people." Another student said, "I never met a math teacher that would make it fun or exciting enough for me to be able to concentrate just on math." One student spoke of a teacher that would get upset if he was asked a question about the material. She said, "You could ask him something and he'd get mad. He'd be like, 'Don't you know? I've done this a hundred times' and stuff like that." Another student spoke about a lack of concern for her learning expressed by her teachers. She said, "[They] just tried to get me by." She spoke of struggling, and one mathematics teacher told her to "stop trying so hard."

Students mentioned helpful and supportive teachers in the positive attitude category more than three and a half times as often as teachers who were not supportive. 
Out of 50 references, 39 focused on helpful and supportive teachers, only 11 references focused on teachers who were not supportive. On average, this tally represents 2.3 references per student: 1.8 references about supportive teachers per student and 0.5 references about teachers who were not helpful or supportive per student. Specific teachers were mentioned 27 times, and 23 references were made about teachers in general. Thirteen male teachers and eight female teachers received favorable comments, and three male teachers and three female teachers received unfavorable comments. The students making favorable comments remembered teachers making class enjoyable as well as presenting the material in an understanding manner. One student said, "He had logic explanations for everything." Another student said, "He was a really good teacher. He talked out every little thing." They appreciated teachers explaining problems step-bystep, using hands-on methods, and presenting real-life applications. One student said, “[He] broke down every problem step-by-step to where I could understand each step and why I was doing it." Another student said, "She did hands-on stuff and it made it more fun." A third student said, "We would work out the problems for real-life situations, and that's what I remember most because we could actually relate it to something that we could actually do outside of school." One student spoke of her teachers being proud of her. Many students remembered teachers who were helpful and wanted the students to learn. One said, "He was determined to make sure that everybody understood it before we moved on." Another student fondly spoke of one teacher saying, "He was more patient [than other mathematics teachers]."

Eight of the 22 students in the positive mathematics attitude category remembered teachers who were also negative or did not provide productive learning environments. 
One student mentioned a teacher who had retired but had returned to the high school to teach a geometry class. She said, "They brought her out of retirement, and she didn't really want to do it so she would assign us a chapter of homework to do, but never teach us how to do it." Another student spoke of a teacher of her college mathematics course. The teacher told the class that he did not care if they learned or not. She was upset that he had told the class, 'If you get it, you get it. If you don't, you don't. I'm not taking time to slow down and show you how to do it." She said, "He is very fast paced. That doesn't bother me. I can go at it at a fast pace, but he flat out told us that he didn't care." Another student spoke of her college mathematics teacher by saying, "He went through the things that we needed to know, but he didn't really explain it well." She went on to say, "We really had to just teach ourselves with the math lab that we had online."

Peers. Only two students in the negative attitude category mentioned peers helping them. One said, “They'd help me with stuff, but sometimes they wouldn't know stuff either." Two students mentioned copying other students' work. One said, "I copied off of them just so I could, you know, get by." Four students felt that they were behind classmates while six students talked about peers being on the same level as they were. One student said, "It seemed like everybody caught on to it and succeeded in it when I didn't." Another student said, "There might have been a couple [of peers] in class that really grasped what was going on and could do it with no problem but, on average, everybody was probably like me and had trouble." None talked about being the one to help peers with mathematics; however, two students mentioned helping their children.

Nine students in the positive attitude category had classmates that liked mathematics. Four students said they performed on the same level as their peers. One 
student said, "I always took honors classes. I always had a lot of people in the class that were just like me, like were strong in math that actually enjoyed it.” Another student said, "They're all pretty much the same, you know. In high school I was in the top ten in my math class but we were all pretty much on the same level." Two students noted that they performed better than their peers. One said, "I was always smarter than everybody else in math." Four students talked about working together with their peers to learn mathematics material, and two students mentioned being asked for help by peers. One student stated, "We all worked to figure things out." Another student said, "If one person had problems, then everybody just kind of stopped and said ok, let's see how we can get you to understand it." When one student was asked what she remembered about her mathematics classmates, she said, "Asking me for help. I was always the one to help them." Three talked about peers struggling with mathematics. One student said, "A lot of my classmates had, had trouble with math." One student spoke of peers trying to complete college mathematics requirements so they would have it finished. She said, “They don't like math at all, so a lot of times they are like, they want help or they want to copy or something like that."

School environment. Twelve students in the negative mathematics attitude category spoke of helpful teachers. One student said, "Whenever I went to high school, I finally had teachers who would help me and would stay after school with me and tutor me until I understood it." Another student spoke well of her developmental math class indicating that it was the teacher that made it a good class. She said, "The way that she taught and how she was so available to help [made it her favorite class]." Another 
student spoke of liking her algebra class in high school. It was an "all-girl class," and the student was fond of the teacher.

Eleven students in the negative attitude category talked about classes they did not feel were productive. They talked about the lack of explanations and effort put forth by teachers in their mathematics classes. One student said, "Most high school teachers don't really give [or] put any effort toward teaching math as far as I could ever recall." Another student said, "The biggest problem I had in high school was she really didn't understand, well not understand, but explain it in a way that everybody understood it." A third student spoke of her mathematics experiences in middle and elementary school saying, "I didn't really have any good math teachers who were willing to explain and try to teach me in a way that I could understand it." One student said, "I've had some [high school mathematics teachers] that were just there to give busy work." One student indicated that none of her mathematics teachers had ever made class exciting. Another student spoke of being in a class with peers who were not able to support her. She said, "Most of my classmates were similar to me; they were very weak in math or they just didn't, didn't like math." She went on to say, “That didn't help when I didn't have anyone in there to, to kind of push me to the limit that I needed to be pushed to." Another student said, "You always have your smarter classmates that go above and beyond the understanding. You also have the ones that don't understand. Those are the kind of people that I kind of grouped with, that didn't really understand.”

All students in the positive mathematics attitude category spoke of having been in classes that were productive learning environments. Some students spoke of favorable classroom environments in which teachers would explain the material, breaking it down 
step-by-step. One student remembered experiences in two of her college mathematics classes and credited the instructors for the productive learning environment by saying, "They didn't teach at you. They tried to explain everything. They were very good at that." Another student pointed out that the class seemed to do well if the teacher cared about students' learning. She said, "I think overall the class does really well as long as the teacher actually cares about how the students do, but if the teacher is not really into it, then it's hard for the students to get into it." One student spoke of one of her mathematics classes having a "family atmosphere" because of the small number of students in the class. Another student said, "I never had a math class to where people actually didn't want to try or learn. Like I always had the same mindset people, like me, in my classes that always tried and wanted to actually figure the problems out."

Eight students in the positive attitude category indicated that they had been in classes where they believed they did not learn as well. One student mentioned a lack of effort by the teachers at the high school level to ensure that the necessary information was taught. She said, "I think, like there's a little, you know, left to be desired as far as education in math. I feel like a lot of fundamental things were kind of rushed over." Another student spoke of a college mathematics environment that had an excessively fast pace. She said, "Not taking the time to slow down and show you how to do it, well, you can't be like that, not with math. It's not something that if you don't get it, you're not going to be able to pick it up late." She also said, "I mean, you are there to learn. If you knew it you wouldn't be in his class."

Home environment. Six students in the negative attitude category talked about seeing mathematics at home. When one student in the negative attitude category was 
asked about what members of her family do with mathematics, she said, "My mom ran a cash register. That was about it. And my dad, he was a mechanic. So if he had any math, he kept it there at work. I've never seen it at home." One student talked about her mother helping her learn to handle money when she was a child. She said, "When I was a kid, learning how to handle money [is] probably the only thing I remember." She went on to say that her mother helped her learn to "count money, correct change, things of that nature." Three students in this category received help from parents with homework assignments. One student spoke of receiving mathematics help at school and at home as well. She said, "I studied in class, like, with the teacher, and out of class sometimes, the teacher would help me study, and then I would go home and my parents would help me study too." She went on to say that her mother would help her but "my dad was the better one at it so he would always interfere and help me." Another student indicated that she did not see her family doing any mathematics at home "unless they were just helping me with homework."

Sixteen students in the positive attitude category spoke about seeing mathematics used at home or being encouraged by family to learn mathematics. One student talked about seeing mathematics used while she was growing up. She said, "My father owns a plumbing company, so there's a lot of mathematics there. A lot of blueprints, drawings, stuff like that. My mother was, is a cosmetology instructor. So there's a lot of, you know, chemicals and things like that. It's been a constant growing up." Another student spoke of her parents, especially her father, helping her with homework in elementary and middle school. She went on to say, "By high school, I didn't really need that much help. And then, once I got to Algebra 2, Pre-calculus, and Calculus, they couldn't really help 
me. They hadn't taken those classes." She also spoke fondly of her brother saying, "He is like a math genius. He is better than I am at math." One student spoke about her parents saying, “They've always encouraged me make sure that I can understand math to the best of my abilities." She went on to say, "They don't necessarily understand [the mathematics that she is learning], but they've always encouraged me to learn. And if I can't understand something, to get tutored so that I can master it as much as possible." Another student spoke of her grandfather using mathematics for his job. She credits him as "pretty much the one that has based me around math." Six others in the positive mathematics attitude group did not talk about seeing mathematics used at home while they were growing up.

Physiological and Affective States. Efficacy beliefs can be influenced by physiological and affective states (Bandura, 1997). A person may view a physical reaction as meaning that she is not capable of performing a task instead of believing the reaction would be common for anyone (Bandura, 1997). Physiological and affective states will be discussed in this section under the subcategories of avoidance and physical.

Avoidance. Only four students in the negative attitude category indicated that they tried to avoid mathematics or purposely avoid using mathematics. One student, when asked what she does related to mathematics outside of school, said, "Nothing. I try to stay away from it." Another student said, "I try to avoid it as much as I can. If I can add, subtract, multiply, and divide and know how to measure and stuff like that, I really don't try to go on and learn more." Two students actually said that they "hate" mathematics. One of these students indicated that she couldn't see the benefit of mathematics. She said, "I hate it. I hate math. I don’t find it useful." 
No students in the positive attitude category indicated that they tried to avoid mathematics, and only one student reported that she did nothing outside of school involving mathematics. She said, "That's my time away from it." Only one student in this category mentioned that, if she was working by herself, she would quit on her mathematics work if she didn't understand. She said, "My worst is actually having to go off by myself and try to work through math problems because I tend to be that person, if I don't get it I just quit. I don't even want to look at it." She went on to say that she would prefer to work with her teacher or peers. Most students in this category sought opportunities to use mathematics whether it would be to help others, use it at work, apply it to real life situations, or use it for playing games. One student said, "Oh, goodness! I do math in my head constantly." Another student talked about having mathematics on her mind all the time. She said, "I drive myself crazy. I see road signs, and I'm trying to square them or break them down. Angles on the road signs, I mean I drive myself crazy sometimes doing stuff like that."

Physical. Students were asked about their feelings when they had to complete a mathematics test or assignment. Twelve out of the 15 students in the negative attitude category said feelings of nervousness or anxiety were experienced when taking a mathematics test. When asked about how it makes her feel when she is given a mathematics test, she said, "I feel very anxious, nervous. The thought instantly enters my mind that I'm going to fail. I already know that I'm going to fail." Another student responded, "Really horrible. Really bad, anxious like." A third student responded, "Very anxious, very, so apprehensive. I mean, it takes a lot for me to do a math test. I always second guess myself. I'm always erasing, yea, I don't do well at all at math tests. I'd 
rather take an anatomy test any day." Another student said, "I have test anxiety, so I always freak out on math, whenever I take a math test or something, because I always feel like I'm not doing it right when really I am. And I always change my questions and end up getting them wrong because I think that I got it wrong." Only one student in this group said that taking a mathematics test did not bother her. When asked how it makes her feel when she is given a mathematics test, she said, "Feels ok, don't bother me." When asked about her feelings when given a mathematics assignment, she said, "If I need help, I ask." Another student said that a mathematics assignment "is just like any other assignment, you know. There's a deadline. [I've] got to get it done." Four students felt better about assignments because they would have more time to complete it than they would a test. One said, "The assignment I feel better about because I have all the time I need. I could look up stuff in the book or ask for help. So it's better." Another said, "If it's something I can take home and work on it at my own pace and in my own ways, I feel more confident about it." Three students spoke of being reluctant to begin mathematics assignments. One said, "I dread it. I put it off until I have to do it." Another student said, "I feel intimated, but I want to feel accomplished by completing that assignment and to be able to get the correct answers." A third student said, "It depends on, like, what kind of assignment it is, and if I'm good at it or not. If I'm pretty familiar with the content, then I'm like confident in my abilities. But if it's a new thing, then I probably think I'm going to do bad at it anyway."

Many students in the positive attitude category had feelings of anxiety and nervousness when it came to taking a test however, many indicated that they were excited also. Nine students reported that they felt some nervousness, anxiety, or stress when it 
came to taking a mathematics test. One student said, "At first, before I look at the exam, of course I'm...I get very anxious and nervous, but I've noticed that as I look through the test and realize that what's on it is what I can do I get really relaxed and I can, I just go through and do it." Another student said, "I panic a little bit, but then I'm okay once I get the test." When asked for conditions she would perform less well in mathematics, one student said, "Any test that is timed because I get stressed about how much time I have left, and I lose time to the stress because I make careless mistakes.” Two students reported worrying about whether they had studied the material sufficiently or had prepared well enough. One said, "I get anxious, you know. 'Do I know the material? Have I studied well enough?' And then I go back after I've taken the test, you know, once I've got some time, then I'm trying to redo everything second guessing myself." Four students indicated that it was not at all bothersome to them to take a mathematics test, with one student saying, "I don't get anxious, it doesn't really bother me." Seven students indicated that taking a test was exciting. One student said, "I love it. I get excited." Another student said, "I'm actually excited to, you know, solve the problem. It's a sense of accomplishment." A third student said, "Really, it excites me because I want to see how well I did, or I want to see if I can actually do it without looking at an example, or you know, having to figure it out that way. I want to see if I actually learned how to do it instead of being able to look back and say ok, yea, I did do that right." Two students viewed taking a test as an opportunity to show what they had learned. One said, "I get to show that I've actually been doing my homework and prove to the teacher he's teaching me something that I have actually learned from him." 
When it came to mathematics assignments, six students in the positive attitude category indicated being ready to get started with all assignments right away. One said, "I love it. It's the first thing I do. I come straight home and do it." Another said, "I can't wait to get started on it." When asked about how she feels when given a mathematics assignment, a third student said, “Good. I mean, it's usually, if I have more than one assignment, it's usually the first one I do." Another said, "I get busy and try my best on it, but I feel fine though. I don't freak out or nothing." Five students indicated they like having mathematics assignments. One said, "Kindly, to be honest, excited, 'cause, like I said, I enjoy math very much." Another student said, "The more the merrier, great, homework. I like to do math." Three students said that the assignments were good practice and helped to prepare for tests. One said, "I like math assignments because that is what I take home and work with problems on my own so I can do well on my test." Another said, "I would rather have that so that I can have extra practice and stuff with whatever we're working on." Five students indicated no pressure was felt when given a mathematics assignment. They were fine with completing the assignments. One said, "I feel fine with that because I can go home and open my book and my notes and rework the problems and look at the problems I worked in class and be able to get the problem right." Another said, "It doesn’t bother me. I usually get it done really fast." Two students believed that mathematics assignments were sometimes a waste of time for them, with one of them saying, "Sometimes I feel like it is a waste of time but sometimes I feel like if I don't really know something then it is good practice." She went on to say, "For me, sometimes I feel like it is a waste of time, and I don’t feel like doing it because I already know that, you know, that type of math that's being taught. And other times if I 
don't know something that well, it is good practice and it helps me prepare for tests." Another student said, "It depends on the math assignment. If it's a very lengthy assignment with a lot of questions, I feel easily aggravated because usually I don't need

to do as much work as other people." She continued with, "If it's an assignment that has a lot of different examples on it, like a large variety, then I feel enjoyment because I enjoy doing math and I know that it's actually helping me."

\section{Careers/Majors Findings}

The Occupational Outlook Handbook, 2012-13 Edition lists actuaries, mathematicians, operations research analysts, and statisticians as occupations in mathematics (Bureau, 2013). In addition, the following are listed as occupations that are similar to that of mathematicians: computer programmers, computer systems analysts, database administrators, financial analysts, market research analysts, nuclear engineers, physicists and astronomers, postsecondary teachers, and survey researchers (Bureau, 2013). Although there are many occupations from which to choose, Torpey (2012) highlights three jobs that use mathematics: cryptologists, health data analysts, and mathematics teachers. Chen (2009) lists STEM fields to include mathematics, natural sciences, physical sciences, biological and agricultural sciences, engineering and engineering technologies, as well as computer and information sciences. For the purposes of this study, all of the careers listed in these references will be considered mathematics-related careers. The Occupational Outlook Handbook lists dental hygienists, licensed practical and licensed vocational nurses, medical records and health information technicians, pharmacists, pharmacy technicians, registered nurses, respiratory therapists, and speech-language pathologists under healthcare occupations (Bureau, 2013). Social 
and human services assistants, social workers are listed as community and social service occupations. High school teachers, kindergarten and elementary school teachers, and middle school teachers are listed as education, training, and library occupations. Chemical technicians, chemists and materials scientists, physicists and astronomers, and psychologists are listed as life, physical, and social science occupations. Physical science occupations such as chemists and physicists are listed under this category but are considered as mathematics-related occupations. Protective service occupations include correctional officers, police and detectives, private detectives and investigators, and security guards. Criminal justice will be included in this category (Bureau, 2013). A summary of the percent of students from the study for each of these occupation categories is listed in Table 4.

Healthcare occupations were the top choice for the students who placed in the negative attitude category with four students pursuing a degree in nursing. Additionally, one student was seeking a degree in respiratory therapy and another in speech pathology. Three students interested in a protective service occupation were pursuing degrees in criminal justice. One student expressed interest in a life, physical, and social science occupation with a major in psychology. Two students were interested in human services, which fall under the category of community and social service occupations. One student was seeking an education occupation and plans to teach high school English. Two students were undecided but were working on an Associate in Arts (AA) degree, which requires fewer mathematics and science requirements than an Associate in Science degree (AS). 
Table 4

Percent of Subjects Classified by Anticipated Occupation

\begin{tabular}{lcc}
\hline & Mathematics Attitude Group \\
\cline { 2 - 3 } Occupation Group & Negative & Positive \\
\hline Mathematics Related (excluding healthcare) & $0 \%$ & $18.2 \%$ \\
Healthcare Related & $40.0 \%$ & $59.1 \%$ \\
Education Related (non-mathematics) & $6.7 \%$ & $4.5 \%$ \\
Community and Social Service & $13.3 \%$ & $4.5 \%$ \\
Undecided or AA/AS degree & $13.3 \%$ & $13.6 \%$ \\
Life and Social Science & $6.7 \%$ & $0 \%$ \\
Protective Service & $20.0 \%$ & $0 \%$ \\
\hline
\end{tabular}

Similar to the negative attitude group, the positive mathematics attitude group also had healthcare occupations as the top choice with nine students pursuing nursing degrees; two students pursing degrees as dental hygienist; one student interested in pharmacy; and one in medical information technology. Another student pursing a degree in social work, a community and social service occupation, was considering changing her degree plan to teach high school or middle school mathematics. Two students planned to pursue mathematics-related occupations in education. One was pursuing a degree to teach middle school mathematics and science but indicated that she really only wanted to teach mathematics. She was also preparing to teach science so that she would have job security. One student was set on teaching mathematics but was not sure if she would 
prefer to teach in middle school or high school. One student wanted to teach in a primary classroom and is pursuing a $\mathrm{K}$ through 5 degree. One student, pursuing a mathematicsrelated physical science occupation with a chemistry degree, was considering pharmacy. She really wanted to train in chiropractic but would have to travel too far from home to complete the degree. One student was studying the mathematics-related occupation of physics with a concentration in astrophysics but was not sure if she wants to teach or pursue research opportunities. One student had considered nursing but decided to pursue both an Associate in Science and an Associate in Arts degree. Two students were undecided on their career plans, one intended to complete an Associate in Arts degree and then transfer to a four year institution.

\section{Mathematics Opportunities in Rural Areas Findings}

When the students in the negative attitude category were asked about people from rural areas opportunities in mathematics, four were not sure of such opportunities, and six did not believe many opportunities were available. Even when indicating the possibility of a job needing mathematics skills, some students did not believe that opportunities were available. One student mentioned pharmacy saying, "I don't think there is really much opportunity as far as careers go for people who want to do anything with math, unless they're like a pharmacist or something. And I don't know if they need high skills in math or not." Three students mentioned the need for mathematics in healthcare occupations. One student said mathematics skills were needed "definitely in the medical workforce." She went on to say, "Our doctors here use a lot of math for dosage and calculations. I know we definitely have a lot of doctors in this area." Three students mentioned teaching mathematics. One said, "I guess you could say you have a lot more math opportunities to 
teach and stuff, to become a math teacher. I don't know." Two students mentioned accounting. One student said, "Accounting, definitely accounting." Another student stated that a basic understanding of mathematics would be needed for any job. One student believed that students struggle with mathematics more than other subjects, but with "help and determination, they could do whatever they wanted with it." Another student indicated that she believed mathematics opportunities were more self-motivated rather than area-related. She believed that a person would have to have a "love" or "passion" for mathematics to pursue a mathematics-related career. Four students felt that the effort was not put into teaching mathematics. They also felt that the importance of mathematics was not stressed in the public schools. One student said, "There's not enough emphasis put on it starting in grade school through high school to college." Another student indicated that she believed that the recognition is not there for people in rural areas and that "we're looked down upon a lot so we don't get the same opportunities as people in other areas." One student talked about her experience when she had moved to another state. She had the opportunity to babysit for elementary students and found that the children were working mathematics problems that she had not been exposed to until middle school. She believed that rural areas "are kind of far behind compared to other places."

Students in the positive attitude category were asked about opportunities for people in rural areas to pursue mathematics-related careers. Eleven students believed that opportunities were not often available. One student said, "I think that they're few and far between." Another said, "There's probably not a lot of them if you think about it." Four students mentioned cashier jobs, and two mentioned jobs in a bank such as a teller. 
Another student said a job dealing with any form of money would require mathematics skills. The medical workforce and accounting were mentioned three times each. A student said, "I'm sure any job in the medical field would involve math." One student said that mathematics skills would be used in construction and another mentioned engineering. Seven students identified teaching as a mathematics-related job available in rural areas. One student said, "In my hometown about the only thing that you could do with higher level math is become a high school teacher or teach at the college. But other than that, there's no other opportunity for someone with a math degree." Another said, "If you want to major in mathematics, the only thing you can really do is be a math teacher that I know of." Four believed that the importance of mathematics and uses of mathematics are not adequately stressed in the public school system. One student said, "We have to use math every day, but they don't make it seem like, you know, you need to know this if you want to do this." Another said, "I don't think people expect as much from a rural person, so maybe sometimes we don't get as high of an education in math as other people do."

Overall, 21 of the 37 students interviewed were not sure of opportunities or did not believe many opportunities existed in mathematics-related careers were available for people from rural areas. Teaching was mentioned most as a job opportunity in mathematics for someone from a rural area. The "medical workforce" and "accounting" was the next highest mentioned overall, tying with teaching for the negative attitude group. Eight students believed that mathematics was not emphasized enough in public schools. 


\section{Summary}

A survey and questionnaire was administered to 648 students attending classes in Central Appalachian institutions of higher education. Follow-up interviews were conducted with a sub-set of 37 female students, who were identified as being from rural Central Appalachia. The interview subjects were from one of two groups: negative mathematics attitude or positive mathematics attitude, as scored from two subscales of the Fennema-Sherman Mathematics Attitude Scale. Transcripts of the interviews were coded and analyzed and the findings reported.

When examining the students in the negative mathematics attitude group, several finding were particularly interesting. Seventy-three percent of students (11 of 15) in the negative mathematics attitude group reported putting forth a great deal of effort in mathematics. Forty-seven percent ( 7 of 15) received grades of $\mathrm{C}$ and below previous to college. Positive experiences in mathematics were mentioned by 87 percent of students (13 out of 15) while 100 percent of students (15 of 15) mentioned negative experiences. Several students did not recognize using mathematics outside of the classroom with 47 percent of students (7 out of 15) reporting not using or rarely using mathematics in reallife activities. Eighty percent of students (12 of 15) reported that they were not good at mathematics while 33 percent (5 of 15) gave examples of struggling with mathematics. When expected to take a mathematics test, 80 percent (12 out of 15) reported feelings of anxiety and nervousness. However, 60 percent (9 of 15) mentioned they did not feel as anxious about mathematics assignments as they did exams.

On the other hand, students in the positive mathematics attitude group revealed other interesting responses. Seventy-three percent of students (16 of 22) in the positive 
mathematics attitude group were aware of their persistent efforts to learn mathematics. Yet, twenty-seven percent of students (6 of 22) did not recognize the efforts they were putting forth to study mathematics even though they reported taking notes and completing homework assignments to aid their learning. Ninety-one percent of students (20 out of 22) indicated they received A and B grades in mathematics. One hundred percent of students (22 out of 22) spoke of positive experiences with mathematics while only 14 percent ( 3 of 22 ) mentioned negative experiences. Ninety-five percent of students (21 of 22) recognized that they used mathematics outside the classroom. One hundred percent of student (22 of 22) reported that they do well in mathematics and gave examples of at least one mathematics class they felt had a productive learning environment. Forty-one percent of students ( 9 out of 22) indicated that they had initial feelings of anxiety, nervousness, or stress when taking a test. Thirty-two percent ( 7 of 22) indicated that they felt excited when they had to take a mathematics test. They were pleased to be given the opportunity to show their teacher what they have learned.

When asked about opportunities for mathematically related occupations in rural areas, 57 percent of the students interviewed ( 21 of 37 ) indicated that they were not sure of any such opportunities or they did not believe there were many opportunities available. Sixty-seven percent of students (10 of 15) in the negative mathematics attitude group felt career opportunities related to mathematics were rare or they could not think of any opportunities. Fifty percent of students (11 of 22) in the positive mathematics attitude group believed that there are not many mathematics-related job opportunities in rural areas as in urban or suburban areas. 


\section{CHAPTER V}

\section{DISCUSSION}

In social cognitive theory behavior, the concepts of cognition and environmental influences work together to influence motivation and self-regulation of one's behavior (Bandura, 1997). Self-efficacy is the key construct in social cognitive theory. Efficacy beliefs, which are formed by experiences, influence effort and persistence and can also influence career choices. Bandura identified four main sources contributing to selfefficacy beliefs: (1) enactive mastery experiences, (2) vicarious experiences, (3) verbal/social persuasions, and (4) physiological and affective states. Mastery experiences are considered the most influential on self-efficacy beliefs because these experiences provide the most authentic evidence that a person has the ability to be successful. Once a person had been successful repeatedly with an activity, mastery expectations will increase and persons will likely persist when they encounter difficulties. Efficacy beliefs are also influenced by vicarious experiences. Persons may form efficacy beliefs by observing others successfully accomplishing a task. The more similar observers believe themselves to be like the role model, the more influential the model's behavior is to the observers. Social and verbal persuasions also influence a person's self-efficacy as they assure individuals that they have the characteristics it takes to achieve the goal they set out to accomplish. When they sense the ability to succeed, greater effort is likely to be put forth and maintained. Indirect persuasions can also influence efficacy beliefs. Last in this model, efficacy beliefs are influenced by physiological and affective states. Individuals 
can believe the reaction they experience such as anxiety or intense nervousness is from lack of ability rather than an ordinary reaction that anyone capable in an area would experience. This perception of reactions, both physical and emotional, can provide more significant influences than the power of the reaction (Bandura, 1997).

This chapter will present the similarities and differences discovered between a positive mathematics attitude group and a negative mathematics attitude group of rural Central Appalachian females. The categories that will be discussed are under the four contributors to self-efficacy: enactive mastery experiences, vicarious experiences, verbal/social persuasions, and physiological and affective states. The career choices of the students interviewed and what the students suggest are mathematics-related career opportunities for rural areas will also be presented. Limitations of the study will be discussed and future research possibilities will be presented. Finally, practical next steps as a result of lessons learned from the study will also be discussed.

\section{Enactive Mastery Experiences}

Repeated successes help build a person's belief in her efficacy, but failures weaken that belief, especially if the failures occur before the belief is firmly in place (Bandura, 1997). Additionally, "to perform poorly without really trying tells little about what one can do." (Bandura, 1997, p. 80). This description matches descriptions given by four out of 15 participants ( 26.7 percent) in the negative mathematics attitude category when they did not find it beneficial to put forth much effort in their mathematics classes. Additionally, when persons experience failures and have put forth effort, efficacy beliefs are lowered (Bandura, 1997). This aligned with approximately 73 percent of the students in the negative mathematics attitude category when they indicated that they were putting 
forth effort, but the grades they reported received did not always reinforce that effort. Usher (2009) found that the effort students with low mathematics efficacy put forth was perceived by these students as an indicator of the lack of efficacy. Additionally, for a person to put forth effort and not succeed can even under the best conditions be perceived as inadequate ability to perform (Bandura, 1997). Also, whether effort indicates a person as having high or low capability will vary among individuals (Bandura, 1997). Although three students (20 percent) in the negative mathematics attitude group received grades of A and B in mathematics courses and one student (6.7 percent) was in the B range, the amount of effort they perceived may have negatively influenced their beliefs about their abilities. Overall, the grades they received did not support their efforts. Correll (2001) found that the self-assessment of female students was influenced by their mathematics grades more so than the self-assessment of male students.

As students progressed through school, Zimmerman and Martinez-Pons (1990) found an increase in self-regulated learning strategies and mathematical efficacy was connected to the use of learning strategies. Sixteen of the 22 students (72.7 percent) in the positive mathematics attitude category reported putting forth effort in their learning experiences in mathematics classes. Along with taking careful notes, one student noted that she kept all of her work from her mathematics classes together for future reference. Another student mentioned using note cards to organize formulas. Six of the 22 students (27.3 percent) discussed in great detail the effort they put forth to learn mathematics. However, they often did not perceive it as effort. Instead, learning mathematics was something they enjoyed, so the effort they exerted was viewed as part of their normal learning routine or strategy to learn and they did not code it as effort. This was even 
though they described similar work styles and habits as those who did code it as effort and persistence. Their efforts were rewarded not only with good grades, but with the belief that, by organizing the information successfully, they understood the mathematics which, in turn, reinforced their efficacy. This finding is consistent with Usher (2009) who described a female student who revealed she contributed her success to working hard rather than to natural talent. Twelve (54.5 percent) of the students in the positive category received A grades, eight (36.4 percent) were in the A to B range, and one (4.5 percent) was a B student. Additionally, only one student (4.5 percent) in this group mentioned ever receiving a $\mathrm{C}$ in mathematics so largely the feedback they were reporting aligned with their success.

The students in the negative attitude category spoke of negative experiences more often than positive experiences. Although thirteen of the 15 students ( 86.7 percent) spoke of positive experiences, all 15 (100 percent) spoke of negative experiences. On the other hand, the 22 students (100 percent) in the positive mathematics attitude category repeatedly spoke of positive experiences. Only in a very few cases were negative experiences mentioned by the positive group. However, once a well-built sense of efficacy is established through successful experiences, failures occurring every once in a while will seldom weaken these beliefs (Bandura, 1997). Three of the 22 positive students (13.6 percent) mentioned negative experiences for a total of four examples. What is exciting is that both groups discussed positive experiences frequently. What may be important is the power of negative experiences to overshadow students' efficacy beliefs in mathematics. Efficacy beliefs are both contributors to and results of experiences (Bandura, 1997). The students in the positive attitude category had 
experienced enough successes that efficacy beliefs were reinforced while the students in the negative attitude category were experiencing both successes and failures.

Many factors influence how a person processes a successful or failed activity as judgment of capability (Bandura, 1997). For the students in the negative mathematics attitude category, three of the 15 (20 percent) believed they would not perform well in mathematics under any conditions. Again, although the students in the negative mathematics attitude category spoke of many positive experiences, overall, they recalled more negative experiences in their learning experiences. How persons alter their efficacy beliefs can be influenced by the level of perceived difficulty of the undertaking, their self-defined preconceived notion of their, the effort amount, and the amount of help they received from others (Bandura, 1997). Six out of the 15 students (40 percent) believed they regularly needed individualized attention in order to understand the mathematics that they encountered in their classes. Successes achieved with assistance from others may not increase efficacy beliefs because they are likely recognized as being from outside support rather than results of personal ability (Bandura, 1997). This is in direct contrast to the positive attitude group where seven of the 22 students ( 31.8 percent) believed they could perform well in mathematics under any conditions. Also, in juxtaposition to the negative attitude group, eight of the 22 students ( 36.4 percent) mentioned using their mathematics knowledge to teach others rather than sensing the need to be supported by others. They spoke of not only helping their own children learn mathematics but their peers as well. This shift from seeking support (negative attitude) to instructing others (positive attitude) is important. In fact it may mean that we need to encourage some 
female learners to actually work with younger children to tutor them in mathematics as a way to gain confidence and self-assurance.

Students in the negative mathematics attitude category did not demonstrate a secure sense of mathematics self-efficacy, so public challenges such as group activities, class discussions, and working mathematics problems in front of others served as further discouragers. Furthermore, if people cling steadfastly to beliefs that they have low capability, they tend to perform lower and in turn lessen their efficacy (Bandura, 1997). This can have implications for teachers in their use of public forums for presenting student work. Instructors should not avoid these instructional approaches, but possibly by providing opportunities for students to work in small groups first - or if they come to the front of the class to present to bring a partner - will enable them to build the courage and skills they need to develop confidence.

Seven of the 15 students (46.7 percent) in the negative attitude category reported they did not use or rarely use mathematics skills outside school. When students talked about using mathematics outside of school, it was limited to working with money, basic counting, or the use of measurements. Also, they did not seek activities outside of the classroom to use and practice their mathematics skills. In comparison, 95.5 percent (21 of 22) in the positive mathematics attitude category provided multiple examples of using mathematics outside of classes. They saw opportunities to use and practice mathematics in real-life activities reinforcing their efficacy. This connection between mathematics and real-world activities (including career-based activities) likely needs to be made for some students by instructors in much more explicit and direct ways. 


\section{Vicarious Experiences}

A person's perceived self-efficacy can be influenced by observing models when she does not have enough experiences to base her efficacy evaluation (Bandura, 1997). The students in the negative mathematics attitude category did not describe role models who they observed who were strong in mathematics. Most students in the negative category struggled to think of relatives who used mathematics. When students did identify relatives that may have used mathematics, they were unsure if mathematics was used in their jobs. Thirty-three percent ( 5 of 15) recalled relatives other than parents as doing something they believed was mathematics-related. Thirty-three percent ( 5 of 15 ) mentioned their mothers using some mathematics and 20 percent ( 3 of 15) spoke of jobs held by their fathers that may require some mathematics. Again, the level of uncertainty may mean that this is not often discussed at home or they are not familiar with the full range of responsibilities in particular jobs. Twenty-seven percent ( 4 of 15) negative attitude students could not list any relatives using mathematics other than their own children using school mathematics. This aligns with the work of Usher (2009) who found that the students she interviewed in the low mathematics self-efficacy group had parents that did not do well in mathematics and they did not receive much support at home.

Students in the negative mathematics attitude category also did not recall significant peers doing well in mathematics. Three of the 15 students (20 percent) believed they were not as advanced as their peers in mathematics. And, three of the 15 students (20 percent) mentioned that their peers were also weak in mathematics and they classified those classmates that struggled as being like themselves. If one bases her self- 
efficacy beliefs on observing others similar to her and who fail, she is more likely to accept her own failures as inadequacies (Bandura, 1997).

Individuals may observe the accomplishments of others similar to themselves and establish the belief that they can successfully accomplish an activity as well (Bandura, 1997). Unlike the students in the negative grouping, students in the positive mathematics attitude category easily identified known others who used mathematics. Table 5 shows a comparison of the references made by the negative and positive mathematics attitude groups. Eleven of the 22 positive attitude students (50 percent) without difficulty identified others in their lives, besides their parents, who used mathematics. One student identified a particular teacher that served as her mathematics role model. Other positive students recalled parents, stepparents, grandparents, and siblings who regularly used mathematics. In the interviews, the students mentioned a variety of jobs held by relatives that used mathematics on a regular basis. Unlike the students in the negative attitude group, they were not challenged by trying to provide examples of how mathematics was used in a relative's job. These students identified both their mothers and their fathers using mathematics. Herbert and Stipek (2005) found that the opinion of parents can predict a students' opinion about their mathematics abilities. Ten out of 22 students (45.5 percent) spoke of their mothers using mathematics and 12 of the 22 students $(54.5$ percent) mentioned their fathers using mathematics. They seemed to have relatives that were mathematically supportive. This is consistent with Usher's (2009) findings that indicated that middle school students with high self-efficacy identified their parents as good mathematical role models. 
This obvious difference between the struggle that the negative group had in identifying role models and the ease that the positive group had points to work that should be done with families and communities to develop a stronger connection to mathematics in the workplace or in the home. By building connections early on, students can begin to see the ubiquity of mathematics in the world, particularly in the workplace.

The students in the positive mathematics attitude group identified peers doing well in mathematics classes. Some students in this category explicitly identified their classmates being similar to themselves. Four of the 22 students ( 18.2 percent) mentioned being on the same level as their peers. Seven of the 22 students (31.8 percent) expressed that their peers were eager to learn mathematics. The more similar an individual is to a model the more influence the model will have on her self-efficacy (Bandura, 1997). These students mentioned working together with their peers to spend time understanding and learning mathematics concepts and skills. Efficacy beliefs can be raised by observing a model being successful at an activity by performing it in a better way (Bandura, 1997).

Table 5

Percent of References to Family Models by Each Attitude Group

\begin{tabular}{lll}
\hline & \multicolumn{2}{c}{ Mathematics Attitude Group } \\
\cline { 2 - 3 } Relationship & Negative & Positive \\
\hline Mother & $33.3 \%$ & $45.5 \%$ \\
Father & $20 \%$ & $54.5 \%$ \\
Other & $33.3 \%$ & $50 \%$ \\
\hline
\end{tabular}


Overall, students in the negative mathematics attitude category seemed to relate to peers and provide examples of peers who also had negative attitudes. Gunderson and her colleagues (2012) suggested that females are kept from performing their best if they have a negative mindset concerning mathematics. Students in the positive mathematics attitude category grouped with and spoke of students that may also have positive attitudes toward mathematics.

\section{Social/Verbal Persuasions}

Students' opinion of their ability in mathematics is a strong predictor of their actual ability with mathematics (Pajares \& Miller, 1994). Twelve out of 15 students (80 percent) in the negative mathematics attitude category indicated they believed that they were not good at mathematics. Five of the 15 students (33.3 percent) specifically mentioned struggling with mathematics.

Students in the negative mathematics attitude category recalled experiences with teachers they believed were not supportive of their learning more often than teachers who were supportive. Eight out of the 15 students (53.3 percent) made both positive and negative references to mathematics teachers. Students recalled taking mathematics classes with teachers that they felt did not make the class interesting or described teachers who did not teach them anything. Teachers who were not open to answering questions or giving support were also described. Huang and Brainard (2001) found that perceived level of respect from instructors influenced the self-confidence level of female students in mathematics classes. Students in this category also made references to peers. Only two of the 15 students (13.3 percent) talked about peers helping them learn mathematics. Unfortunately, two of the 15 students (13.3 percent) mentioned copying another student's 
work. Some believed their peers were also struggling with mathematics, and three of the 15 (20 percent) believed they were not performing as well as their peers academically.

Eight of the 15 students (53.3 percent) in the negative mathematics attitude category spoke of both classroom environments that were conducive to learning as well as environments where mathematics learning was not taking place. Some remembered teachers who were helpful and made mathematics class interesting, as well as easy to understand. Females were found to have higher mathematics efficacy when they had home and classroom environments that stressed the importance of and worth of mathematics (Zeldin \& Pajares, 2000). Six of the 15 students (40 percent) in this category spoke of receiving mathematics support at home, but 9 of the 15 (60 percent) did not mention receiving support at home. Although students did not report that mathematics was used at home on a regular basis some specifically stated that they received assistance with homework from family members. This absence of a strong mathematically supportive environment could result in a lack of motivation to learn mathematics. Leaper and colleagues (2012) found that the perceived support of parents and peers by females was related to the females' motivation.

A way to help reinforce a person's belief that she has what it takes to achieve her goal is social persuasion (Bandura, 1997). All 22 students (100 percent) in the positive mathematics attitude category indicated that they do well in mathematics. Many said mathematics was their favorite subject or they enjoyed mathematics. Four of the 22 students (18.2 percent) actually stated that they "love math." The students in this group made mostly positive references about teachers. They also made references to specific teachers who supported their growth rather than merely mentioning teachers in general. 
Some spoke of teachers who made class interesting, presented detailed and logical explanations, and gave real-life examples. They also spoke of teachers who were helpful and wanted students to learn. Having important people in a person's life express support about one's performance rather than having them express doubt will help maintain efficacy (Bandura, 1997). These students also spoke of peers enjoying mathematics and trying to gain knowledge of mathematics. Nine of the 22 students ( 40.9 percent) spoke of classmates who liked mathematics. Four of the 22students (18.2 percent) talked about working together with their peers to learn mathematics material. Additionally, eight of the 22 students ( 36.4 percent) in this category spoke of helping others learn mathematics by offering assistance on topics that their peers or others did not understand. They wanted to help others enjoy and appreciate mathematics. The students in this category expressed experiencing a positive mathematics classroom learning environment more often than not. All 22 students (100 percent) mentioned at least one class they felt was a productive environment while 8 of these students ( 36.4 percent) also talked about nonproductive environments. Six students (27.3 percent) in this category did not talk about seeing mathematics used at home. Sixteen (72.7 percent) spoke about family members who used mathematics in their jobs; some of which spoke of receiving help and support from their family. Adult females' self-efficacy beliefs were found by Zeldin and Pajares (2000) to be influenced by the opinions of those who are important in their lives.

\section{Physiological and Affective States}

The perception and interpretation of both physical and emotional reactions by an individual is more important than the strength of the reactions (Bandura, 1997). Additionally, efficacy beliefs can be lowered if a person believes that her physical 
response is from lack of capability rather than a response that one would normally have if she is knowledgeable in an area (Bandura, 1997). Four of the 15 students (23.7 percent) in the negative mathematics attitude category indicated they tried to purposely avoid using mathematics. Thompson and Dinnel (2007) found that students may withdraw effort in an attempt to protect their self-worth fearing that low performance may reveal low ability. Two of the 15 students (13.3 percent) said that they "hate" mathematics. Twelve of the 15 students (80 percent) from this category reported feelings of anxiety and nervousness when expected to take a mathematics test. Some students reported second guessing themselves when taking a test. Mathematics assignments from class did not cause 9 out of 15 students (60 percent) to feel as anxious as taking an examination. Four of the 15 students ( 26.7 percent) indicated that they felt better about having time to complete assignments and being able to look up information and ask questions if needed. Only three of the 15 students (20 percent) indicated that they would put off working on assignments and were hesitant to start an assignment.

Twenty-two of the 22 students (100 percent) in the positive mathematics attitude category did not indicate that they tried to avoid using mathematics. Twenty-one of the 22 students (95.5 percent) reported applying mathematics in situations outside of school. When asked about taking a test, nine of the 22 students (40.9 percent) in this category indicated that they had initial feelings of anxiety, nervousness, or stress. The feelings, however, would often lessen once they received the test, looked at the first problems, and realized they were familiar with the material. Other students indicated that they worried that they had not mastered the material to the level needed or they second guessed themselves and over thought their answers. Seven of the 22 students (31.8 percent) 
indicated that they felt excited when they had to take a mathematics test. Two of the 22 students (9.1 percent) were pleased to be given the opportunity to show what they had learned. Six out of 22 students (27.3 percent) in this category were excited to be given a mathematics assignment. These students looked forward to practicing new material and improving their skills. Only two of the 22 students (9.1 percent) indicated that a mathematics assignment could be a possible waste of their time. Yet, both of these students indicated that they welcomed assignments that would benefit and challenge their learning.

\section{Career/Majors}

Several students in both the negative category and the positive category intended to pursue careers in healthcare occupations. Nineteen of the 37 students (51.4 percent) interviewed were seeking careers in the field of healthcare. Of the 15 students interviewed from the negative mathematics attitude category, 6 (40 percent) intended to pursue careers in the healthcare field. Thirteen of the 22 students (59.1 percent) in the positive mathematics attitude category indicated majors in the healthcare field. This finding is consistent with the findings of Simpkins and Davis-Kean (2005) who found that females were more likely to pursue health-related careers than mathematics or science careers.

Three of the 37 students ( 8.1 percent) were interested in community and social services occupations. Two students (13.3 percent) with negative mathematics attitudes were seeking degrees in human services. One student (4.5 percent) with positive mathematics attitudes was majoring in social work. Two of the 37 students (5.4 percent) interviewed were interested in education degrees that are not necessarily mathematics- 
related. One student (6.7 percent) with a negative attitude is pursuing a degree to teach high school English. One student (4.5 percent) with a positive attitude is pursuing a K-5 teaching degree. Three students (20 percent) with a negative mathematic attitude were pursuing degrees in criminal justice, a protective service occupation. None of the students with positive mathematics attitudes reported that they were pursuing this occupation. An occupation in the life and social sciences was the choice for one of the 37 students (2.7 percent). One student (6.7 percent) with a negative mathematics attitude is pursuing a degree in psychology.

Five of the 37 students (13.5 percent) were undecided majors or pursuing an Associate degree without a specific career goal in mind. Two students (13.3 percent) in the negative mathematics attitude category were pursuing Associate in Arts degree and were undecided about their career goals. Three students (15 percent) in the positive attitude category were undecided about their career goals. One was pursuing both an Associate in Arts and an Associate in Science degree. Another was planning to complete an Associate in Arts degree and transfer to a four-year university.

Hackett and Betz (1989) found that self-efficacy beliefs in mathematics were stronger predictors of students' choices of mathematics-related college majors than prior achievement and performance. Four out of 22 students (18.2 percent) in the positive mathematics attitude category indicated they were pursuing mathematics-related careers. Two of these students (9.1 percent) were pursuing degrees to teach mathematics: one has chosen middle school mathematics and the other has not yet decided between middle school and high school mathematics. Another student (4.5 percent) was pursuing a degree in physics. She had not decided if she would pursue teaching or research 
opportunities. Finally, one student (4.5 percent) was majoring in chemistry. No students with negative attitudes were pursuing mathematics-related degrees as defined for this study.

\section{Mathematics Opportunities in Rural Areas}

When asked about opportunities in rural areas, 21 of the 37 students (56.8 percent) interviewed were not aware of such opportunities or indicated they did not believe many opportunities were available. Ten of the 15 students (66.7 percent) in the negative attitude category felt opportunities in mathematics for people in rural areas were rare or they could not think of any opportunities. Eleven of the 22 students (50 percent) in the positive attitude also believed that there are not many mathematics-related job opportunities in rural areas.

Ten of the 37 students (27 percent) interviewed mentioned teaching as a mathematics job opportunity for people from rural areas. This choice was the most frequently mentioned mathematics-related job opportunity overall. Three of the 15 students (20 percent) in the negative attitude category identified teaching as a job opportunity in rural areas and 7 of the 22 students (31.8 percent) in the positive attitude category discussed teaching jobs. Anderson and Chang (2011) noted that teaching mathematics at the high school level is "often the only job in a rural community for someone with a post-secondary mathematics background" (p. 7). Anderson (2006) noted that it was unlikely for students in the rural community to know anyone in the community, besides their mathematics teacher, who had completed a mathematics college degree. He also noted that even in rural communities with extended business 
opportunities it would be rare to find someone who had completed a college degree in mathematics.

Healthcare occupations were mentioned second most often overall. Six of the 37 students (16.2 percent) talked about jobs in the healthcare fields. Three of the 15 students (20 percent) in the negative mathematics attitude category and three of the 22 students (13.6 percent) in the positive mathematics attitude category talked about occupations available in healthcare.

Accounting ranked as the third most frequently mentioned occupation. Five of the 37 students (13.5 percent) mentioned accounting as an option for rural communities. Two of the 15 students (13.3 percent) in the negative mathematics attitude category identified accounting-related occupations. Three of the 22 students (13.6 percent) in the positive mathematics attitude group mentioned accounting occupations as being available in rural areas.

\section{Limitations}

The sample for this study is best described as a purposive sample. The educational institutions were chosen with the purpose of identifying students from rural Central Appalachian areas. Survey data were collected on both male and female students and later narrowed to the desired category. Only students enrolled in classes in one state that had instructors willing to allow time for the survey to be given were invited to participate in the study. The distribution of the survey was dependent on the willingness of instructors to allot class time. Thirty-two BSCTC general education instructors were asked to allow time in their classes for the survey to be administered. Because I am a faculty member at BSCTC, 12 of the instructors allotted time in their classes for the 
survey. The number of instructors at BSCTC to allot time for the survey was more than the other three institutions combined (five from HCTC, two from SKCTC, and three from MSU). This resulted in a larger number of surveys completed by students at BSCTC which may be a limitation.

Only rural Central Appalachian female students already enrolled in college classes were considered for this study. Students that graduated from high schools in nonrural areas of Central Appalachia were not considered for interviews. This decision limits the generalization of the results to only rural Central Appalachian females enrolled in college. The population of females from rural areas of Central Appalachia that have chosen not to attend college was not considered for this research.

Another limitation to the study was that the telephone interviews were completed at the time of contact with students. The students were not asked to review the completed interview transcripts and this decision may have provoked other memories of mathematics experiences. Also, as in the case of self-reported data, students might have marked the selections that they believed were socially acceptable or desirable rather than their true beliefs.

Another possible limitation was that the original survey instrument used in this research was created more than 30 years ago. Although measures were taken to adjust the language used in the survey, the language in the survey statements and instructions may have seemed old fashioned to some of the participants. This language issue may have caused them to select choices that were not aligned with their true attitude about mathematics. 


\section{Future Research}

Future research based on this work could focus further on the mathematics selfefficacy of rural Central Appalachian females. Longitudinal studies could be conducted with elementary, middle school and high school females from rural Central Appalachia. This research would provide more detailed information concerning the development of mathematics efficacy beliefs. This long-term analysis of self-efficacy would also help identify when some students begin to express a negative orientation toward mathematics or when students decide to pursue or reject a career in mathematics. Interview data would not be as dependent on students' memories from past experiences but instead on current experiences. Some students in the current study were recent high school graduates while others had returned to school after beginning or raising families. A future study might compare these groups.

Another limitation was the format of the interview process. Ideally, it would be beneficial and provide richer data to conduct interviews in a face-to-face setting rather than over the phone. Interviews conducted in person allow the interviewer to observe body language and facial expressions of the interviewee and provide a more personal experience. These relational connections are not possible when interviews are conducted over the phone. An additional restriction to interviews conducted over the phone is that the interviewer is not aware of the environment of the interviewee. Distractions such as the television playing in the background or family members being present can restrict the interviewee's responses to the prompts. The interviewer can be more aware of the environmental distractions during a face-to-face interview or attempt to reduce the distractions by providing a quiet and private area for the conversation. 
An additional limitation is that these students were all in college and many decisions about majors and careers were already set in place. Therefore, it might be informative to interview females during different stages of mathematics development to see where these decisions emerge. Also, observational data focused on how they perform in mathematics classes prior to college could be collected. This information might identify strategies for teachers and other key people to help students develop an interest or stronger self-efficacy in mathematics. Data could also be collected on rural Central Appalachian males as well as non-Appalachian students and results compared.

Connections between careers and the mathematics used in careers could be investigated. Research focused on actual careers of rural Central Appalachian females might also be a valuable direction for investigation. Interviews could be conducted with rural Central Appalachian females to identify what mathematics they view as being useful in their careers. This information would be valuable to mathematics teachers and others interested in helping focus students on the need to learn mathematics. Additionally, a follow-up on the postsecondary major that students select and the eventual career they pursue would add important information. College students often change their majors multiple times (Ronan, 2005) and, because many of the students in this study were early on in their college programs, their final majors and occupations would contribute to this work.

\section{Lessons Learned}

The information gathered in this study provides valuable lessons to K-12 teachers and guidance counselors as well as college professors and advisors. The students interviewed seemed to be lacking a connection between the mathematics learned in 
school and the mathematics used in real-world situations and occupations. Some students even pointed out that they believed that mathematics was not being emphasized in school they way they believed it should. Mathematics teachers and guidance counselors need to help students make the explicit connection between mathematics and careers that use mathematics. Additionally, connections need to be made with jobs available in the local area. Unless a member of the student's family works in a mathematics-related career, the student is not being exposed to the career or to the connection that mathematics is used in the career. In some cases, even if the student's family member is employed in a mathematics-related job, the student is not hearing the mathematics discussed at home to make the connection.

The best way to expose students to real-life connections with mathematics is in the public schools. Students need to be made aware and actually practice using mathematics in every day real-life situations. Having students apply the mathematics they are learning in school to daily situations they may encounter will help them appreciate the usefulness of mathematics and learn the value of mathematics. It is important that the connections between school mathematics and the real world not stop there. Students need to learn about mathematics required for careers that they may want to pursue in their adult lives.

Being exposed to the mathematics in the real world is only one step in the right direction. Students also need to be able to connect the use of mathematics with the careers that use mathematics. They need information provided to them about careers that they could realistically pursue and become employed in their local area. Students in rural 
areas tend to wish to stay close to their family so the connection to jobs in their local area is extremely important.

Additionally, students need to be connected with mentors that currently work or have worked in the career that the student is interested in pursuing. This would be a valuable connection to the real-world use of mathematics. A mentor could not only make the student aware of the mathematics used in the job of interest, but assist the students in finding the appropriate pathway to lead them to the desired career. This mentor and pathway connection could be made in the $8^{\text {th }}$ grade with the career connections program that is currently being used in Kentucky public schools. In addition to emphasizing the characteristics that makes one employable this program could provide students with the pathway to a mathematics-related career. It is just not enough to tell students that mathematics is used in many careers and have students attempt to research the careers. Students need to know the mathematics connection to careers, which careers are available to them in their locale area, and the pathway to achieve the training required for the career.

Also, schools need to provide information to parents about the importance for students to be exposed to mathematics in the home environment. Using mathematics at home needs to go beyond the "school math" concept of completing homework assignments. Some school resource centers host parent activity days. The resource centers could assist by making parents aware of mathematics-related activities they can do with their families. Schools could host a family math night to help parents learn more ways to increase mathematics awareness in their homes. Schools could also offer programs that allow older students to work with younger students on mathematics. This 
would give younger students assistance learning mathematics and build the confidence of the older students.

\section{Summary of Study}

This study focused on the factors contributing to the self-efficacy of

undergraduate female students from rural areas of Central Appalachia. A survey and demographic questionnaire were administered to 648 students attending classes at four postsecondary educational institutions: Big Sandy Community and Technical College, Hazard Community and Technical College, Southeast Kentucky Community and Technical College, and Morehead State University. The purpose of the survey and demographic questionnaire was to identify potential interview subjects. A total of 37 students were interviewed. The interviews were transcribed and coded according to the four main contributors to self-efficacy which are enactive mastery experience; vicarious experiences; verbal/social persuasions; and physiological and affective states.

Overall, students in the negative mathematics attitude category did not receive consistent positive feedback for their efforts to learn mathematics. They did not have strong mathematics role models. They also identified with peers who struggled with learning mathematics. These students did not experience productive learning environments and did not receive a great deal of mathematics support at home. In addition, these students experienced feelings of anxiety when it came to having to show what they had learned.

Students in the positive mathematics attitude category received encouraging feedback in terms of grades and self-satisfaction for their efforts to learn mathematics. They also had role models, such as parents and other relatives, which used mathematics. 
They identified with peers that were successful with learning mathematics. They experienced productive classroom learning environments. Although some students in this category experienced feelings of anxious when it came to having to show on a test what they had learned, they overcame these feelings. Additionally, the students in this category wanted to learn. Interestingly, students in this category wanted to help others learn mathematics. Not only did students in this group talk about teaching their children mathematics, they also taught other students or relatives.

The most popular career choice for both the negative mathematics attitude and positive mathematics attitude students interviewed was in healthcare related fields. All four students interviewed who chose mathematics-related careers were from the positive mathematics attitude category. Two students from the negative mathematics attitude group and one student from the positive mathematics attitude group chose community and social service occupations. One student in each group chose a career in education that is not mathematics-related. One student in the negative attitude group chose to pursue a degree in the category of life and social sciences and three chose protective services. Two students from the negative mathematics attitude category and three from the positive mathematics attitude category were undecided about their career goals.

Students from both the negative mathematics attitude group and the positive mathematics attitude group had difficulty identifying mathematics opportunities for people in rural areas. Teaching jobs were mentioned more often than any other career. Healthcare occupations were mentioned second most often and jobs in accounting ranked third. 
The information gathered in this study provides valuable insight for rural mathematics educators at all levels. Connections need to be made between the mathematics that is learned in schools and the careers that use mathematics. Educators at all levels can play a key role in making this connection. Public schools and colleges could implement programs to increase the awareness of the connections to the use of mathematics in real-life. 


\section{REFERENCES}

Ali, S. R., \& Saunders, J. L. (2006). College expectations of rural Appalachian youth: An exploration of social cognitive career theory factors. The Career Development Quarterly, 55, 38-51. doi:10.1002/j.2161-0045.2006.tb00003.x

Anderson, R. (2006). Factors contributing to rural high school students' participation in advanced mathematics courses. (Working Paper No. 34). Athens, OH: Appalachian Collaborative Center for Learning, Assessment, and Instruction in Mathematics. Retrieved from http://www.eric.ed.gov/PDFS/ED494990.pdf

Anderson, R., \& Chang, B. (2011). Mathematics course-taking in rural high schools. Journal of Research in Rural Education, 26(1), 1-10. Retrieved from http://jrre.psu.edu/articles/26-1.pdf

Appalachian Regional Commission (2012). Appalachian Region. Retrieved from http://www.arc.gov/

Bandura, A. (1977a). Self-efficacy: Toward a unifying theory of behavioral change. Psychological Review, 84(2), 191-215. doi:10.1037/0033-295X.84.2.191

Bandura, A. (1977b). Social learning theory. Englewood Cliffs, NJ: Prentice Hall.

Bandura, A. (1989). Social cognitive theory. In R. Vasta (Ed.), Annuals of Child Development, Vol. 6. Six Theories of Child Development, 1-60, Greenwich, CT: JAI Press.

Bandura, A. (1997). Self-efficacy the exercise of control. New York, NY: W.H. Freeman and Company. 
Beede, D., Julian, T., Langdon, D., McKittrick, G., Khan, B., \& Doms, M. (2011). Women in STEM: A gender gap to innovation (ESA Issue Brief \#04-11). Washington, DC: U.S. Department of Commerce, Economics, and Statistics Administration.

Beilock, S. L., Gunderson, E. A., Ramirez, G., \& Levine, S. C. (2010). Female teachers' math anxiety affects girls' math achievement. Proceedings of the National Academy of Sciences, 107, 1860-1863. doi:10.1073/pnas.0910967107

Betz, N. E., \& Hackett, G., (1981). The relationship of career-related self-efficacy expectations to perceived career options in college women and men. Journal of Counseling Psychology, 28, 399-410. doi:10.1037/0022-0167.28.5.399

Big Sandy Community and Technical College (2012) About us: BSCTC college at a glance. Retrieved from http://www.bigsandy.kctcs.edu/

Bureau of Labor Statistics, U.S. Department of Labor (2011). Occupational outlook handbook, 2010-11 edition. Retrieved from http://www.bls.gov/oco/

Bureau of Labor Statistics, U.S. Department of Labor (2013). Occupational outlook handbook, 2012-13 edition. Retrieved from http://www.bls.gov/ooh/

Bureau of the Census, Department of Commerce (2011). Urban area criteria for the 2010 census. Federal Register, 76(164), 53029-53043. Retrieved from http://www.census.gov/geo/www/ua/2010urbanruralclass.html

Burnell, B. (2003). The "Real World" aspirations of work-bound rural students. Journal of Research in Rural Education, 18, 104-113. Retrieved from http://jrre.psu.edu/articles/v18,n2,p104-113,Burnell.pdf 
Bush, W. S. (2005). Improving research on mathematics learning and teaching in rural context. Journal of Research in Rural Education, 20(8), 1-11. Retrieved from http://www.jrre.psu.edu/articles/20-8.pdf

Camp, A. G., Gilleland, D. S., Pearson, C., \& Putten, J. V. (2009). Differentiating between women in hard and soft science and engineering disciplines. Journal of College Student Retention: Research, Theory and Practice, 11, 363-384. doi:10.2190/CS.11.3.d

Carmichael, C., \& Taylor, J.A. (2005). Analysis of student beliefs in a tertiary preparatory mathematics course. International Journal of Mathematics Education in Science and Technology, 36, 713-719. doi:10.1080/00207390500271065

Cavallo, A. M., Potter, W. H., \& Rozman, M. (2004). Gender differences in learning constructs, shifts in learning constructs, and their relationship to course achievement in a structured inquiry, yearlong college physics course for life science majors. School Science and Mathematics, 104, 288-300. doi:10.1111/j.1949-8594.2004.tb18000.x

Ceci, S. J., Williams, W. M., \& Barnett, S. M. (2009). Women's underrepresentation in science: Sociocultural and biological considerations. Psychological Bulletin, 135, 218-261. doi:10.1037/a0014412

Chen, X. (2009). Students who study science, technology, engineering, and mathematics (STEM) in postsecondary education (NCES 2009-161). Washington, DC: National Center for Education Statistics, Institute of Education Sciences, U.S. Department of Education. 
Cheryan, S. (2012). Understanding the paradox in math-related fields: Why do some gender gaps remain while others do not? Sex Roles, 66, 184-190. doi:10.1007/s11199-011-0060-z

Cogan, L. S., Schmidt, W. H., \& Wiley, D. E. (2001). Who takes what math and in which track? Using TIMSS to characterize US students' eighth-grade mathematics learning opportunities. Educational Evaluation and Policy Analysis, 23, 323-341.

Corbett, M. (2007). Learning to Leave: The irony of schooling in a coastal community. Nova Scotia, Canada: Fernwood Publishing.

Cordero, E. D., Porter, S. H., Israel, T., \& Brown, M. T. (2010). Math and science pursuits: A self-efficacy intervention comparison study. Journal of Career Assessment, 18, 362-375. doi:10.1177/1069072710374572

Correll, S. J. (2001). Gender and the career choice process: The role of biased selfassessments. American Journal of Sociology, 106, 1691-1730. doi:10.1086/321299

Dweck, C. S. (2006). Is math a gift? Beliefs that put females at risk. In S.J. Ceci and W.M. Williams (Eds.) Why aren't more women in science? Top researchers debate the evidence. Washington, DC: American Psychological Association.

Else-Quest, N. M., Hyde, J. S., \& Linn, M. C. (2010). Cross-national patterns of gender differences in mathematics: A meta-analysis. Psychological Bulletin, 136, 103127. doi: $10.1037 / \mathrm{a} 0018053$

Enochs, L. G., \& Riggs, I. M. (1990). Further development of an elementary science teaching efficacy belief instrument: A preservice elementary scale. School Science and Mathematics, 90, 694-706. doi:10.1111/j.1949-8594.1990.tb12048.x 
Fennema, E., \& Sherman, J. A., (1976a). Fennema-Sherman mathematics attitudes scales: Instruments designed to measure attitudes toward the learning of mathematics by females and males. Journal for Research in Mathematics Education, 7, 324-326. Retrieved from http://www.jstor.org/stable/748467

Fennema, E., \& Sherman, J. A. (1976b). Fennema-Sherman mathematics attitude scales: Instruments designed to measure attitudes towards the learning of mathematics by males and females. JSAS Catalog of Selected Documents in Psychology, 6(1).

Finley, G. (2002, August 29). Noteworthy news: Early success, encouragement add up to math Ph.D.s. Black Issues in Higher Education, 19(4), 8-10. Retrieved from http://findarticles.com/p/articles/mi_m0DXK/is_14_19/ai_91465235/?tag=content ; col1

Geist, E. (2010). The anti-anxiety curriculum: Combating math anxiety in the classroom. Journal of Instructional Psychology, 37, 24-31. Retrieved from http://www.highbeam.com/doc/1G1-224405375.html

Gierl, M. J., \& Bisanz, J. (1995). Anxieties and attitudes related to mathematics in grades 3 and 6. Journal of Experimental Education, 63, 139-158. doi:10.1080/00220973.1995.9943818

Goldin, C., Katz, L. F., \& Kuziemko, I. (2006). The homecoming of American college women: The reversal of the college gender gap. Journal of Economic Perspectives, 20(4), 133-156. Retrieved from http://www.aeaweb.org/jep/index.php

Guiso, L., Monte, F., Sapienza, P., \& Zingales, L. (2008). Culture, gender, and math. Science, 320, 1164-1165. doi:10.1126/science.1154094 
Gunderson, E. A., Ramirez, G., Levine, S. C., \& Beilock, S. L. (2012). The role of parents and teachers in the development of gender-related math attitudes. Sex Roles, 66, 153-166. doi:10.1007/s11199-011-9996-2

Hackett, G., \& Betz, N. E. (1989). An exploration of the mathematics selfefficacy/mathematics performance correspondence. Journal for Research in Mathematics Education, 20, 261-273. Retrieved from http://www.jstor.org/stable/749515

Handelsman, J., Cantor, N., Carnes, M., Denton, D., Fine, E., Grosz, B., ... Sheridan, J. (2005). More women in science. Science, 309, 1190-1191. doi: $10.1126 /$ science. 1113252

Hardre, P. L., Sullivan, D. W., \& Crowson, M. (2009). Student characteristics and motivation in rural high schools. Journal of Research in Rural Education, 24(16), 1-19. Retrieved from http://jrre.psu.edu/articles/24-16.pdf

Hazard Community and Technical College (2012). Admissions: What do we offer? Retrieved from http://hazard.kctcs.edu/

Herbert, J., \& Stipek, D. (2005). The emergence of gender differences in children's perceptions of their academic competence. Applied Developmental Psychology, 26, 276-295. doi: 10.1016/j.appdev.2005.02.007

Herzig, A. H. (2004). 'Slaughtering this beautiful math': graduate women choosing and leaving mathematics. Gender and Education, 16, 379-395. doi:10.1080/09540250042000251506 
Hill, C., Corbett, C., \& St. Rose, A. (2010). Why so few? Women in science, technology, engineering, and mathematics. Washington, DC: American Association of University Women.

Hong, E., \& Aqui, Y. (2004). Cognitive and motivational characteristics of adolescents gifted in mathematics: Comparisons among students with different types of giftedness. The Gifted Child Quarterly, 48, 191-201. doi:10.1177/001698620404800304

Howley, A., Gholson, M., \& Pendarvis, E. (2006). How talented rural students experienced school mathematics. (Working Paper No. 29). Athens, OH: Appalachian Collaborative Center for Learning, Assessment, and Instruction in Mathematics. Retrieved from http://www.eric.ed.gov/PDFS/ED494992.pdf

Howley, C. B., \& Gunn, E. (2003). Research about mathematics achievement in the rural circumstance. Journal of Research in Rural Education, 18, 86-95. Retrieved from http://jrre.psu.edu/articles/v18,n2,p86-95,Howley,Gunn.pdf

Huang, P., \& Brainard, S. (2001). Identifying determinants of academic self-confidence among science, math, engineering, and technology students. Journal of Women and Minorities in Science and Engineering, 7(4), 315-337. Retrieved from http://www.begellhouse.com/journals/00551c876cc2f027,2615af3e3226be3e,1f5b 6a852db48146.html

Huebner, T. A. (2009). Encouraging females to pursue math and science. Educational Leadership, 67(1), 90-91. Retrieved from http://www.ascd.org/publications/educational- 
leadership/sept09/vol67/num01/Encouraging-Girls-to-Pursue-Math-andScience.aspx

Hutchison, M. A., Follman, D. K., Sumpter, M., \& Bodner, G. M. (2006). Factors influencing the self-efficacy beliefs of first-year engineering students. Journal of Engineering Education, 95, 39-47. Retrieved from http://www.jee.org/2006/january/6.pdf

Hyde, J. S., Lindberg, S. M., Linn, M. C., Ellis, A. B., \& Williams, C. C. (2008). Gender similarities characterize math performance. Science, 321, 494-495. doi:10.1126/science. 1160364

Hyde, J., \& Mertz, J. (2009). Gender, culture, and mathematics performance. Proceedings of the National Academy of Sciences, 106, 8801-8807. doi:10.1073/pnas.0901265106

Jackson, D. L. (2010). Transfer students in STEM majors: Gender differences in the socialization factors that influence academic and social adjustment. (Doctoral dissertation). Retrieved from ProQuest Dissertation and Theses database. (AAT 3418232)

Karp, K. S. (1988). The teaching of elementary school mathematics: The relationship between how mathematics is taught and teacher's attitudes (Doctoral dissertation). Retrieved from ProQuest Dissertations and Theses database. (AAT 8816727)

Karp, K., \& Shakeshaft, C. (1997). Restructuring schools to be math friendly to females. National Association of Secondary School Principals. NASSP Bulletin, 81 (586), 84-93. doi:10.1177/019263659708158610 
Kentucky Community \& Technical College System (2006). If you conduct research You are responsible: KCTCS human subjects research policy 1.8.2.3.2.1. Retrieved from http://legacy.kctcs.edu/employee/hsrb/

Leaper, C., Farkas, T., \& Brown, C. S. (2012). Adolescent girls' experiences and genderrelated beliefs in relation to their motivation in math/science and English. Journal of Youth and Adolescence, 41, 268-282. doi:10.1007/s10964-011-9693-z

Lloyd, J. E., Walsh, J., \& Yailagh, M. S. (2005). Sex differences in performance attributions, self-efficacy, and achievement in mathematics: If I'm so smart, why don't I know it? Canadian Journal of Education, 28, 384-408. Retrieved from http://www.csse-scee.ca/CJE/Articles/FullText/CJE28-3/CJE28-3-1loyd.pdf

Lockwood, P. (2006). "Someone like me can be successful": Do college students need same-gender role models? Psychology of Women Quarterly, 30, 36-46. doi: $10.1111 / j .1471-6402.2006 .00260 . x$

Lucas, D. M. (2005). A rural community's perceptions of the importance of math and math education in Appalachia. (Monograph No. 1). Athens, Oh: Appalachian Collaboration Center for Learning, Assessment, and Instruction in Mathematics.

McCarthy, R. (2009). Beyond smash and crash: Gender-friendly tech ed. The Technology Teacher, 69(2), 16-21. Retrieved from http://www.highbeam.com/doc/1G1209800609.html

Melancon, J. G., Thompson, B., \& Becnel, S. (1994). Measurement integrity of scores from the Fennema-Sherman Mathematics Attitude Scales: The attitudes of public school teachers. Educational and Psychological Measurement, 54, 187-192. doi: $10.1177 / 0013164494054001024$ 
Miles, M. B., \& Huberman, A. M. (1984). Qualitative data analysis: A sourcebook of new methods. Beverly Hills, CA: Sage Publications, Inc.

Mireles-Rios, R., \& Romo, L. F. (2010). Maternal and teacher interaction and student engagement in math and reading among Mexican American girls from a rural community. Hispanic Journal of Behavioral Sciences, 32, 456-469.

doi:10.1177/0739986310374020

Morehead State University (2012a). Index of standard operating procedures. Retrieved March 5, 2012 from http://www2.moreheadstate.edu/irb/

Morehead State University (2012b). MSU's 22-county service region (Kentucky). Retrieved from www.moreheadstate.edu/WorkArea/DownloadAsset.aspx?id=1216

Mulhern, F., \& Rae, G. (1998). Development of a shortened form of the FennemaSherman mathematics attitudes scales. Educational and Psychological Measurement, 58, 295-306. doi:10.1177/0013164498058002012

National Science Board (2008). Science and engineering indicators 2008: Volume 1 (NSB 08-01). Arlington, VA: National Science Foundation.

O’Shea, M., Heilbronner, N. N., \& Reis, S. M. (2010). Characteristics of academically talented women who achieve at high levels on the scholastic achievement testmathematics. Journal of Advanced Academics, 21, 234-271.

doi:10.1177/1932202X1002100204

Pajares, F. (1996a). Self-efficacy beliefs and mathematical problem-solving of gifted students. Contemporary Educational Psychology, 21, 325-344. doi:10.1006/ceps.1996.0025 
Pajares, F. (1996b). Self-efficacy beliefs in academic settings. Review of Educational Research, 66, 543-578. doi:10.3102/00346543066004543

Pajares, F., \& Miller, M. D. (1994). Role of self-efficacy and self-concept beliefs in mathematical problem solving: A path analysis. Journal of Educational Psychology, 86, 193-203. doi:10.1037/0022-0663.86.2.193

Pallier, G. (2003). Gender differences in the self-assessment of accuracy on cognitive tasks. Sex Roles, 48, 265-276. doi:10.1023/A:1022877405718

Patton, M. Q. (2002). Qualitative research \& evaluation methods. Thousand Oaks, CA: Sage Publications

Pietsch, J., Walker, R., \& Chapman, E. (2003). The relationship among self-concept, and performance in mathematics during secondary school. Journal of Educational Psychology, 95, 589-603. doi:10.1037/0022-0663.95.3.589

Plant, E. A., Baylor, A. L., Doerr, C. E., \& Rosenberg-Kima, R. B. (2009). Changing middle-school students' attitudes and performance regarding engineering with computer-based social models. Computers \& Education, 53, 209-215. Retrieved from http://www.sciencedirect.com/science/journal/03601315

Ramsey, L. R., \& Sekaquaptewa, D., (2011). Changing stereotyping, changing grades: A longitudinal study of stereotyping during a college math course. Social Psychology of Education, 14, 377-387. doi:10.1007/s11218-010-9150-y

Riggs, I. M., \& Enochs, L. G. (1990). Toward the development of an elementary teacher's science teaching efficacy belief instrument. Science Education, 74, 625637. doi 10.1002/sce.3730740605 
Ronan, G. B. (2005). College freshman face major dilemma. Retrieved from http://www.nbcnews.com/id/10154383/ns/business-personal_finance/t/collegefreshmen-face-major-dilemma/

Rotter, J.B. (1966). Generalized expectancies for internal versus external control of reinforcement. Psychological Monographs, 80, 1-28.

Rotter, J.B., \& Mulry, R.C. (1965). Internal versus external control of reinforcement and decision time. Journal of Personality and Social Psychology, 2, 598-604.

Rudasill, K. M., \& Callahan, C. M. (2010). Academic self-perceptions of ability and course planning among academically advanced students. Journal of Advanced Academics, 21, 300-329. doi:10.1177/1932202X1002100206

Sandman, R. S. (1980). The mathematics attitude inventory: Instrument and user's manual. Journal for Research in Mathematics Education, 11(2), 148-149. Retrieved from http://www.jstor.org/stable/748906

Seaton, E. E. (2007). "If teachers are good to you": Caring for rural females in the classroom. Journal of Research in Rural Education, 22(6), 1-16. Retrieved from http://jrre.psu.edu/articles/22-6.pdf

Shapiro, J. R., \& Williams A. M. (2012). The role of stereotype threats in undermining girls' and women's performance and interest in STEM fields. Sex Roles, 66, 175183. doi:10.1007/s11199-011-0051-0

Simpkins, S.D., \& Davis-Kean, P.E. (2005). The intersection between self-concept and values: Links between beliefs and choices in high school. New Directions for Child and Adolescent Development, 2005(110), 31-47. doi:10.1002/cd.148 
Snyder, T. D., \& Dillow, S. A. (2011). Digest of Education Statistics 2010 (NCES 2011015). Washington, DC: National Center for Education Statistics, Institute of Education Sciences, U.S. Department of Education.

Snyder, T.D., Dillow, S.A., \& Hoffman, C.M. (2009). Digest of Education Statistics 2008 (NCES 2009-020). Washington, DC: National Center for Education Statistics, Institute of Education Sciences, U.S. Department of Education.

Southeast Kentucky Community and Technical College (2012). About us: SKCTC facts and statistics. Retrieved from http://southeast.kctcs.edu/

Steele, C. M. (1997). A threat in the air: How stereotypes shape intellectual identity and performance. American Psychologist, 52, 613-629. doi:10.1037/0003066X.52.6.613

Steele, D. F., Levin, A., K., Blecksmith, R., \& Shahverdian, J.(2008). Women in calculus: The effects of a supportive setting. Journal of College Reading and Learning, 39(1), 7-34. Retrieved from http://findarticles.com/p/articles/mi_hb3247/is_1_39/ai_n30954863/

Stevens, T., Olivarez, Jr., A., Lan, W. L., \& Tallent-Runnels, M. K. (2004). Role of mathematics self-efficacy and motivation in mathematics performance across ethnicity. The Journal of Educational Research, 97(4), 208-221. Retrieved from http://www.jstor.org/stable/27548031

Thompson, T., \& Dinnel, D. L. (2007). Poor performance in mathematics: Is there a basis for a self-worth explanation for women? Educational Psychology, 27, 377-399. doi:10.1080/01443410601104197 
Torpey, E., (2012). Math at work: Using numbers on the job. Occupational Outlook Quarterly, 56(3), 2-13. Retrieved from http://www.bls.gov/opub/ooq/

Turner, S. L., Steward, J. C., \& Lapan, R. T. (2004). Family factors associated with sixthgrade adolescents' math and science career interests. The Career Development Quarterly, 53, 41-52. doi:10.1002/j.2161-0045.2004.tb00654.x

United States Department of Agriculture Economic Research Service (2010). Briefing rooms: Measuring rurality. Retrieved from http://www.ers.usda.gov/Briefing/Rurality/

University of Louisville (2012). Human subjects' protection program. Retrieved from http://louisville.edu/research/humansubjects

Usher, E. L. (2009). Sources of middle school students' self-efficacy in mathematics: A qualitative investigation. American Educational Research Journal, 46, 275-314. Retrieved from http://www.jstor.org/stable/27667179

Vogt, C. M., Hocevar, D., \& Hagedorn, L. S., (2007). A social cognitive construct validation: Determining women's and men's success in engineering programs. The Journal of Higher Education, 78, 337-364. Retrieved from http://www.jstor.org/stable/4501213

York, E. A. (2008). Gender differences in the college and career aspirations of high school valedictorians. Journal of Advanced Academics, 19, 578-600. doi:10.4219/jaa-2008-830

Zeldin, A. L., Britner, S. L., \& Pajares, F. (2008). A comparative study of the selfefficacy beliefs of successful men and women in mathematics, science, and 
technology careers. Journal of Research in Science Teaching, 45, 1036-1058. doi:10.1002/tea.20195

Zeldin, A. L., \& Pajares, F. (2000). Against the odds: Self-efficacy beliefs of women in mathematical, scientific, and technological careers. American Educational Research Journal, 37, 215-246. Retrieved from http://www.jstor.org/stable/1163477

Zimmerman, B. J., \& Martinez-Pons, M. (1990). Student differences in self-regulated learning: Relating grade, sex, and giftedness to self-efficacy and strategy use. Journal of Educational Psychology, 82, 51-59. doi:10.1037/0022-0663.82.1.51 
Appendix A

Rural Appalachia by State and County

\section{Alabama}

Chambers, Cherokee, Clay, Cleburne, Coosa, Cullman, De Kalb, Fayette, Franklin, Jackson, Lamar, Macon, Marion, Pickens, Randolph, Tallapoosa, Winston

\section{Georgia}

Banks, Chattooga, Elbert, Fannin, Franklin, Gilmer, Gordon, Habersham, Hart, Jackson, Lumpkin, Polk, Rabun, Stephens, Towns, Union, White

\section{Kentucky}

Adair, Bath, Bell, Boyd, Breathitt, Carter, Casey, Clay, Clinton, Cumberland, Elliott, Estill, Fleming, Floyd, Garrard, Green, Harlan, Hart, Jackson, Johnson, Knott, Knox, Laurel, Lawrence, Lee, Leslie, Letcher, Lewis, Lincoln, McCreary, Magoffin, Martin, Menifee, Metcalfe, Monroe, Montgomery, Morgan, Nicholas, Owsley, Perry, Pike, Powell, Robertson, Rockcastle, Rowan, Russell, Wayne, Whitley, and Wolfe Maryland

Garrett

$\underline{\text { Mississippi }}$

Alcorn, Benton, Calhoun, Chickasaw, Choctaw, Clay, Itawamba, Kemper, Monroe, Montgomery, Noxubee, Panola, Pontotoc, Prentiss, Tippah, Tishomingo, Union, Webster, Winston, Yalobusha

$\underline{\text { New York }}$

Allegany, Chenango, Delaware, Otsego, Schuyler

North Carolina 
Alleghany, Ashe, Avery, Cherokee, Clay, Graham, Jackson, McDowell, Macon, Mitchell, Polk, Swain, Transylvania, Watauga, Wilkes, Yancey

Ohio

Adams, Coshocton, Gallia, Guernsey, Harrison, Highland, Hocking, Holmes, Jackson, Meigs, Monroe, Morgan, Noble, Perry, Pike, Vinton

$\underline{\text { Pennsylvania }}$

Bedford, Bradford, Cameron, Clarion, Clinton, Elk, Forest, Fulton, Greene, Huntingdon, Jefferson, Juniata, McKean, Montour, Potter, Snyder, Sullivan, Susquehanna, Tioga, Warren, Wayne

\section{South Carolina}

Oconee

\section{$\underline{\text { Tennessee }}$}

Bledsoe, Campbell, Claiborne, Clay, Cocke, Cumberland, DeKalb, Fentress, Franklin, Greene, Grundy, Hancock, Jackson, Johnson, Lawrence, Lewis, Meigs, Monroe, Morgan, Overton, Pickett, Rhea, Scott, Van Buren, Warren, White

\section{Virginia}

Alleghany, Bath, Bland, Buchanan, Carroll, Dickenson, Floyd, Grayson, Highland, Lee, Patrick, Rockbridge, Russell, Smyth, Tazewell, Wise, and Wythe

\section{$\underline{\text { West Virginia }}$}

Barbour, Braxton, Calhoun, Doddridge, Fayette, Gilmer, Grant, Greenbrier, Hardy, Jackson, Lewis, Logan, Mason, McDowell, Mercer, Mingo, Monroe, Nicholas, Pendleton, Pocahontas, Randolph, Ritchie, Roane, Summers, Taylor, Tucker, Tyler, Upshur, Webster, Wetzel, Wyoming 


\section{Appendix B}

Rural Central Appalachian Counties Served by BSCTC, HCTC, SKCTC, and MSU

Big Sandy Community and Technical College serves five rural Central Appalachian counties in Kentucky including Floyd, Johnson, Magoffin, Martin, and Pike.

Hazard Community and Technical College has campus locations in rural Central Appalachian counties in Kentucky including Breathitt, Knott, Leslie, and Perry.

Southeast Kentucky Community and Technical College serves students from four rural Central Appalachian counties in Kentucky including Harlan, Bell, Letcher, and Knox; the rural Central Appalachian county of Claiborne, Tennessee; and the rural Central Appalachian county of Lee, Virginia.

Morehead State University serves 19 rural Central Appalachian counties in Kentucky including Bath, Breathitt, Carter, Elliot, Fleming, Floyd, Johnson, Knott, Lawrence, Letcher, Lewis, Magoffin, Martin, Menifee, Montgomery, Morgan, Pike, Rowan, and Wolfe. 


\section{Appendix C}

Modified Fennema-Sherman Mathematics Attitude Scales and Weight

\begin{tabular}{|l|c|}
\hline \multicolumn{2}{|c|}{ Confidence in Learning Mathematics Scale } \\
\hline \multicolumn{1}{|c|}{ Item } & Weight \\
\hline $\begin{array}{l}\text { Generally I have felt secure about attempting } \\
\text { mathematics. }\end{array}$ & + \\
\hline $\begin{array}{l}\text { I am sure I could do advanced work in } \\
\text { mathematics. }\end{array}$ & + \\
\hline I am sure that I can learn mathematics. & + \\
\hline $\begin{array}{l}\text { I think I could handle more difficult } \\
\text { mathematics. }\end{array}$ & + \\
\hline I can get good grades in mathematics. & + \\
\hline $\begin{array}{l}\text { I have a lot of self-confidence when it comes } \\
\text { to math. }\end{array}$ & + \\
\hline I'm not good in math. & - \\
\hline $\begin{array}{l}\text { I don't think I could do advanced } \\
\text { mathematics. }\end{array}$ & - \\
\hline I'm not the type to do well in math. & - \\
\hline $\begin{array}{l}\text { For some reason, even though I study, math } \\
\text { seems unusually hard for me. }\end{array}$ & - \\
\hline $\begin{array}{l}\text { Most subjects I can handle O.K., but I tend to } \\
\text { mess up in math. }\end{array}$ & - \\
\hline Math has been my worst subject. & - \\
\hline
\end{tabular}

\begin{tabular}{|l|c|}
\hline \multicolumn{2}{|c|}{ Effectance Motivation in Mathematics Scale } \\
\hline \multicolumn{1}{|c|}{ Item } & Weight \\
\hline I like math puzzles. & + \\
\hline $\begin{array}{l}\text { Mathematics is enjoyable and stimulating to } \\
\text { me. }\end{array}$ & + \\
\hline $\begin{array}{l}\text { When a math problem arises that I can't } \\
\text { immediately solve, I stick with it until I have } \\
\text { the solution. }\end{array}$ & + \\
\hline $\begin{array}{l}\text { Once I start trying to work on a math puzzle, I } \\
\text { find it hard to stop. }\end{array}$ & + \\
\hline $\begin{array}{l}\text { When a math question is left unanswered in a } \\
\text { math class, I continue to think about it } \\
\text { afterward. }\end{array}$ & + \\
\hline
\end{tabular}




\begin{tabular}{|l|c|}
\hline $\begin{array}{l}\text { I am challenged by math problems I can't } \\
\text { understand immediately. }\end{array}$ & + \\
\hline $\begin{array}{l}\text { Figuring out mathematical problems does not } \\
\text { appeal to me. }\end{array}$ & - \\
\hline $\begin{array}{l}\text { The challenge of math problems does not } \\
\text { appeal to me. }\end{array}$ & - \\
\hline Math puzzles are boring. & - \\
\hline $\begin{array}{l}\text { I don't understand how some people can } \\
\text { spend so much time on math and seem to } \\
\text { enjoy it. }\end{array}$ & - \\
\hline $\begin{array}{l}\text { I would rather have someone give me the } \\
\text { solution to a difficult math problem than to } \\
\text { have to work it out for myself. }\end{array}$ & - \\
\hline I do as little work in math as possible. & - \\
\hline
\end{tabular}




\section{Appendix D}

\section{Demographic Questionnaire and Survey}

\section{The Mathematics Self-Efficacy of Rural Appalachian Women}

\section{August 2012}

\section{Dear Student,}

You are being invited to participate in a research study by answering the attached survey about your attitude toward mathematics. There are no known risks for your participation in this research study. The information collected may not benefit you directly. The information learned in this study may be helpful to others. The information you provide will assist the researcher in determining potential candidates for further study. Individuals may be asked to participate in an interview lasting approximately 30 minutes. Your completed survey will be stored at the researcher's home. The survey will take approximately 8 to 10 minutes to complete.

Individuals from the Department of Education, the Institutional Review Board (IRB), the Human Subjects Protection Program Office (HSPPO), and other regulatory agencies may inspect these records. In all other respects, however, the data will be held in confidence to the extent permitted by law. Should the data be published, your identity will not be disclosed.

Taking part in this study is voluntary. By completing this survey you agree to take part in this research study. You do not have to answer any questions that make you uncomfortable. You may choose not to take part at all. If you decide to be in this study you may stop taking part at any time. If you decide not to be in this study or if you stop taking part at any time, you will not lose any benefits for which you may qualify.

If you have any questions, concerns, or complaints about the research study, please contact: Lisa Music at (606) 889-4760 
If you have any questions about your rights as a research subject, you may call the Human Subjects Protection Program Office at (502) 852-5188. You can discuss any questions about your rights as a research subject, in private, with a member of the Institutional Review Board (IRB). You may also call this number if you have other questions about the research, and you cannot reach the research staff, or want to talk to someone else. The IRB is an independent committee made up of people from the University community, staff of the institutions, as well as people from the community not connected with these institutions. The IRB has reviewed this research study.

If you have concerns or complaints about the research or research staff and you do not wish to give your name, you may call 1-877-852-1167. This is a 24 hour hot line answered by people who do not work at the University of Louisville.

Sincerely,

Lisa J. Music 
Background

Name

Home address

Home Phone

Cell Phone

Year in college (please circle)

Freshman Sophomore Junior

Senior

Age

Gender (please circle)

Male

Female

High school attended

Location of high school

County State




\section{Survey}

For each of the following statements please circle strongly agree, agree, undecided, disagree, or strongly disagree as it applies to you. There are no correct or incorrect answers.

On the following pages there is a series of statements. There are no correct answers for these statements. They have been set up in a way which permits you to indicate the extent to which you agree or disagree with the ideas expresses. Suppose the statement is:

\begin{tabular}{|l|c|c|c|c|c|}
\hline Example 1. I like mathematics. & $\begin{array}{c}\text { Strongly } \\
\text { Agree }\end{array}$ & Agree & Undecided & Disagree & $\begin{array}{c}\text { Strongly } \\
\text { Disagree }\end{array}$ \\
\hline
\end{tabular}

As you read the statement, you will know whether you agree or disagree. If you strongly agree you will circle Strongly Agree opposite that statement. If you agree but with reservations, that is, you do not fully agree, circle Agree. If you disagree with the idea, indicate the extent to which you disagree by circling Disagree or Strongly Disagree. But if you neither agree nor disagree, that is you are not certain, mark undecided. Also, if you cannot answer a question, circle undecided.

Do not spend much time with any statement, but be sure to answer every statement. Work fast but carefully.

There are no "right" or "wrong" answers. The only correct responses are those that are true for you. Whenever possible, let the things that have happened to you help you make a choice.

\begin{tabular}{|l|c|c|c|c|c|}
\hline $\begin{array}{l}\text { Once I start trying to work on a } \\
\text { math puzzle, I find it hard to stop. }\end{array}$ & $\begin{array}{c}\text { Strongly } \\
\text { Agree }\end{array}$ & Agree & Undecided & Disagree & $\begin{array}{c}\text { Strongly } \\
\text { Disagree }\end{array}$ \\
\hline $\begin{array}{l}\text { I am challenged by math problems } \\
\text { I can't understand immediately. }\end{array}$ & $\begin{array}{c}\text { Strongly } \\
\text { Agree }\end{array}$ & Agree & Undecided & Disagree & $\begin{array}{c}\text { Strongly } \\
\text { Disagree }\end{array}$ \\
\hline
\end{tabular}




\begin{tabular}{|c|c|c|c|c|c|}
\hline $\begin{array}{l}\text { I can get good grades in } \\
\text { mathematics. }\end{array}$ & $\begin{array}{l}\text { Strongly } \\
\text { Agree }\end{array}$ & Agree & Undecided & Disagree & $\begin{array}{l}\text { Strongly } \\
\text { Disagree }\end{array}$ \\
\hline $\begin{array}{l}\text { When a math problem arises that I } \\
\text { can't immediately solve, I stick } \\
\text { with it until I have the solution. }\end{array}$ & $\begin{array}{l}\text { Strongly } \\
\text { Agree }\end{array}$ & Agree & Undecided & Disagree & $\begin{array}{l}\text { Strongly } \\
\text { Disagree }\end{array}$ \\
\hline Math has been my worst subject. & $\begin{array}{l}\text { Strongly } \\
\text { Agree }\end{array}$ & Agree & Undecided & Disagree & $\begin{array}{l}\text { Strongly } \\
\text { Disagree }\end{array}$ \\
\hline $\begin{array}{l}\text { Figuring out mathematical } \\
\text { problems does not appeal to me. }\end{array}$ & $\begin{array}{l}\text { Strongly } \\
\text { Agree }\end{array}$ & Agree & Undecided & Disagree & $\begin{array}{l}\text { Strongly } \\
\text { Disagree }\end{array}$ \\
\hline $\begin{array}{l}\text { When a math question is left } \\
\text { unanswered in a math class, I } \\
\text { continue to think about it } \\
\text { afterward. }\end{array}$ & $\begin{array}{l}\text { Strongly } \\
\text { Agree }\end{array}$ & Agree & Undecided & Disagree & $\begin{array}{l}\text { Strongly } \\
\text { Disagree }\end{array}$ \\
\hline $\begin{array}{l}\text { I think I could handle more } \\
\text { difficult mathematics. }\end{array}$ & $\begin{array}{l}\text { Strongly } \\
\text { Agree }\end{array}$ & Agree & Undecided & Disagree & $\begin{array}{l}\text { Strongly } \\
\text { Disagree }\end{array}$ \\
\hline $\begin{array}{l}\text { I don't think I could do advanced } \\
\text { mathematics. }\end{array}$ & $\begin{array}{l}\text { Strongly } \\
\text { Agree }\end{array}$ & Agree & Undecided & Disagree & $\begin{array}{l}\text { Strongly } \\
\text { Disagree }\end{array}$ \\
\hline $\begin{array}{l}\text { I am sure that I can learn } \\
\text { mathematics. }\end{array}$ & $\begin{array}{l}\text { Strongly } \\
\text { Agree }\end{array}$ & Agree & Undecided & Disagree & $\begin{array}{l}\text { Strongly } \\
\text { Disagree }\end{array}$ \\
\hline $\begin{array}{l}\text { I would rather have someone give } \\
\text { me the solution to a difficult math } \\
\text { problem than to have to work it } \\
\text { out for myself. }\end{array}$ & $\begin{array}{l}\text { Strongly } \\
\text { Agree }\end{array}$ & Agree & Undecided & Disagree & $\begin{array}{l}\text { Strongly } \\
\text { Disagree }\end{array}$ \\
\hline $\begin{array}{l}\text { I don't understand how some } \\
\text { people can spend so much time on } \\
\text { math and seem to enjoy it. }\end{array}$ & $\begin{array}{l}\text { Strongly } \\
\text { Agree }\end{array}$ & Agree & Undecided & Disagree & $\begin{array}{l}\text { Strongly } \\
\text { Disagree }\end{array}$ \\
\hline Math puzzles are boring. & $\begin{array}{l}\text { Strongly } \\
\text { Agree }\end{array}$ & Agree & Undecided & Disagree & $\begin{array}{l}\text { Strongly } \\
\text { Disagree }\end{array}$ \\
\hline $\begin{array}{l}\text { I am sure I could do advanced } \\
\text { work in mathematics. }\end{array}$ & $\begin{array}{l}\text { Strongly } \\
\text { Agree }\end{array}$ & Agree & Undecided & Disagree & $\begin{array}{l}\text { Strongly } \\
\text { Disagree }\end{array}$ \\
\hline $\begin{array}{l}\text { I do as little work in math as } \\
\text { possible. }\end{array}$ & $\begin{array}{l}\text { Strongly } \\
\text { Agree }\end{array}$ & Agree & Undecided & Disagree & $\begin{array}{l}\text { Strongly } \\
\text { Disagree }\end{array}$ \\
\hline $\begin{array}{l}\text { The challenge of math problems } \\
\text { does not appeal to me. }\end{array}$ & $\begin{array}{l}\text { Strongly } \\
\text { Agree }\end{array}$ & Agree & Undecided & Disagree & $\begin{array}{l}\text { Strongly } \\
\text { Disagree }\end{array}$ \\
\hline $\begin{array}{l}\text { For some reason, even though I } \\
\text { study, math seems unusually hard } \\
\text { for me. }\end{array}$ & $\begin{array}{l}\text { Strongly } \\
\text { Agree }\end{array}$ & Agree & Undecided & Disagree & $\begin{array}{l}\text { Strongly } \\
\text { Disagree }\end{array}$ \\
\hline $\begin{array}{l}\text { I'm not the type to do well in } \\
\text { math. }\end{array}$ & $\begin{array}{l}\text { Strongly } \\
\text { Agree }\end{array}$ & Agree & Undecided & Disagree & $\begin{array}{l}\text { Strongly } \\
\text { Disagree }\end{array}$ \\
\hline I like math puzzles. & $\begin{array}{l}\text { Strongly } \\
\text { Agree }\end{array}$ & Agree & Undecided & Disagree & $\begin{array}{l}\text { Strongly } \\
\text { Disagree }\end{array}$ \\
\hline I'm not good in math. & $\begin{array}{l}\text { Strongly } \\
\text { Agree }\end{array}$ & Agree & Undecided & Disagree & $\begin{array}{l}\text { Strongly } \\
\text { Disagree }\end{array}$ \\
\hline $\begin{array}{l}\text { Mathematics is enjoyable and } \\
\text { stimulating to me. }\end{array}$ & $\begin{array}{l}\text { Strongly } \\
\text { Agree }\end{array}$ & Agree & Undecided & Disagree & $\begin{array}{l}\text { Strongly } \\
\text { Disagree }\end{array}$ \\
\hline
\end{tabular}




\begin{tabular}{|l|c|c|c|c|c|}
\hline $\begin{array}{l}\text { I have a lot of self-confidence } \\
\text { when it comes to math. }\end{array}$ & $\begin{array}{c}\text { Strongly } \\
\text { Agree }\end{array}$ & Agree & Undecided & Disagree & $\begin{array}{l}\text { Strongly } \\
\text { Disagree }\end{array}$ \\
\hline $\begin{array}{l}\text { Most subjects I can handle O.K., } \\
\text { but I tend to mess up in math. }\end{array}$ & $\begin{array}{c}\text { Strongly } \\
\text { Agree }\end{array}$ & Agree & Undecided & Disagree & $\begin{array}{l}\text { Strongly } \\
\text { Disagree }\end{array}$ \\
\hline $\begin{array}{l}\text { Generally I have felt secure about } \\
\text { attempting mathematics. }\end{array}$ & $\begin{array}{c}\text { Strongly } \\
\text { Agree }\end{array}$ & Agree & Undecided & Disagree & $\begin{array}{l}\text { Strongly } \\
\text { Disagree }\end{array}$ \\
\hline
\end{tabular}


Appendix E

Interview Protocol

The following interview protocol has been revised from Usher (2009).

\section{Experiences}

First, I would like for you to tell me about yourself as a math student.

What grades do you receive in math?

What sort of work habits do you have in math?

What has been your favorite math class?

What do you remember about it?

\section{Learning Environment and Others}

What do you remember about your math teachers?

What do you remember about your classmates?

Under what conditions do you perform well in math?

Under what conditions do you perform less well?

What do you like to do related to math outside of school?

What do members of your family do that involve math?

Tell me what you think about people from rural areas opportunities in math.

\section{Physiological and Affective States}

When you are given a math test, how does that make you feel?

How do you feel when you are given a math assignment?

What is your major and what career are you thinking of pursuing? 


\section{Appendix F}

Interview Analysis Codes

\begin{tabular}{|c|c|}
\hline Master Code & Subcodes \\
\hline \multirow[t]{9}{*}{ Enactive Mastery Experience (ME) } & Effort (ME-Eff) \\
\hline & Management (ME-Man) \\
\hline & Struggles (ME-Strug) \\
\hline & Successful activities (ME-Act+) \\
\hline & Failed activities (ME-Act-) \\
\hline & High grades (ME-Grad+) \\
\hline & Low grades (ME-Grad-) \\
\hline & High test scores (ME-test+) \\
\hline & Low test scores (ME-test-) \\
\hline \multirow[t]{7}{*}{ Vicarious Experience (VE) } & Male role models (VE-MRM) \\
\hline & Female role models (VE-FRM) \\
\hline & Male peers (VE-MP) \\
\hline & Female peers (VE-FP) \\
\hline & Peer success (VE-P+) \\
\hline & Peer failure (VE-P-) \\
\hline & $\begin{array}{l}\text { Male relative (VE-MR) } \\
\text { Father (VE-MR-F) } \\
\text { Brother (VE-MR-B) } \\
\text { Uncle (VE-MR-U) } \\
\text { Grandfather (VE-MR-GF) }\end{array}$ \\
\hline
\end{tabular}




\begin{tabular}{|c|c|}
\hline & $\begin{array}{l}\text { Female relative (VE-FR) } \\
\text { Mother (VE-FR-M) } \\
\text { Sister (VE-FR-S) } \\
\text { Aunt (VE-FR-A) } \\
\text { Grandmother (VE-FR-GM) }\end{array}$ \\
\hline Social/Verbal Persuasions (VP) & $\begin{array}{l}\text { Male relative support (VP-MR) } \\
\begin{array}{l}\text { Father (VP-MR-F) } \\
\text { Brother (VP-MR-B) } \\
\text { Uncle (VP-MR-U) } \\
\text { Grandfather (VP-MR-GF) }\end{array}\end{array}$ \\
\hline & $\begin{array}{l}\text { Female relative support (VP-FR) } \\
\text { Mother (VP-FR-M) } \\
\text { Sister (VP-FR-S) } \\
\text { Aunt (VP-FR-A) } \\
\text { Grandmother (VP-FR-GM) }\end{array}$ \\
\hline & Male teacher support (VP-MT) \\
\hline & Female teacher support (VP-FT) \\
\hline & $\begin{array}{l}\text { Ability beliefs (VP-AB) } \\
\text { Positive mathematics childhood experiences } \\
\text { (VP-Exp+) }\end{array}$ \\
\hline & $\begin{array}{l}\text { Negative mathematics childhood experiences } \\
\text { (VP-Exp-) }\end{array}$ \\
\hline & Positive mathematics home environment (VP- \\
\hline
\end{tabular}




\begin{tabular}{|l|l|}
\hline & Home+) \\
\hline & $\begin{array}{l}\text { Negative mathematics home environment (VP- } \\
\text { Home-) }\end{array}$ \\
\hline & $\begin{array}{l}\text { Positive mathematics classroom environment } \\
\text { (VP-Class+) }\end{array}$ \\
\hline & $\begin{array}{l}\text { Negative mathematics classroom environment } \\
\text { (VP-Class-) }\end{array}$ \\
\hline Physiological and affective states (PS) & Avoidance (PS-Avoid) \\
\hline & Self-worth protection (PS-SW) \\
\hline & Anxiety (PS-Anx) \\
\hline & Stress (PS-Stre) \\
\hline & Nervous (PS-Ner) \\
\hline & Distress (PS-Dis) \\
\hline
\end{tabular}




\section{CURRICULUM VITAE}

NAME:

ADDRESS:

EDUCATION: University of Louisville

Louisville, Kentucky

Summer 2005 - Current

Doctoral Candidate (September 2007) - Curriculum \& Instruction 12 credit hours coursework

12 doctoral research hours

Ohio University

Athens, Ohio

Summer 2004 - Spring 2007

17 credit hours

The University of Tennessee

Knoxville, Tennessee

Summer 2004 - Spring 2007

9 credit hours

3 internship hours

West Virginia University

Morgantown, West Virginia

Summer 2004 - Summer 2006

12 credit hours

University of Kentucky

Lexington, Kentucky

Summer 2004 - Spring 2006

12 credit hours

Morehead State University

Morehead, Kentucky

Spring 1998 - Spring 2003

Master of Arts Degree, May 2003

Major: Secondary Guidance Counseling 
Morehead State University

Morehead, Kentucky

Fall 1989 - Fall 1994

Bachelor of Science Degree, December 1994

Major: Mathematics

CERTIFICATIONS: Provisional Certificate for Teaching Mathematics in the Secondary Grades 9-12, 1997-2017

Endorsement for Teaching Computer Science

Grades 5-12, 1997-2017

PROFESSIONAL

EXPERIENCE: $\quad$ Associate Professor - Mathematics

1997 - Present

Big Sandy Community and Technical College

Prestonsburg, Kentucky

Substitute Teacher

1995 - 1997

Floyd County Board of Education

Prestonsburg, Kentucky 